\title{
Developing nanotechnology for biofuel and plant science applications
}

by

\section{Justin Scott Valenstein}

A dissertation submitted to the graduate faculty in partial fulfillment of the requirements for the degree of

\section{DOCTOR OF PHILOSOPHY}

\author{
Major: Chemistry \\ Program of Study Committee: \\ Brian Trewyn, Major Professor \\ Kan Wang, Co-major Professor \\ Young-Jin Lee \\ Marek Pruski \\ Emily Smith
}

Iowa State University

Ames, Iowa

2012

Copyright (C) Justin Scott Valenstein, 2012. All rights reserved. 


\section{TABLE OF CONTENTS}

\section{ACKNOWLEDGEMENTS}

\section{ABSTRACT}

CHAPTER 1. GENERAL INTRODUCTION

Dissertation Organization

Introduction

References

CHAPTER 2. FUNCTIONAL MESOPOROUS SILICA NANOPARTICLES FOR THE SELECTIVE SEQUESTRATION OF FREE FATTY ACIDS FROM

Abstract

Introduction

Experimental Section

Results and Discussion

Conclusions

References

CHAPTER 3. MESOPOROUS SILICA NANOPARTICLES FOR THE PURIFICATION

Abstract

Introduction

Results and Discussion

Experimental

Conclusions

References

CHAPTER 4. PARAMETERS AFFECTING THE EFFICIENT DELIVERY OF MESOPOROUS SILICA NANOPARTICLE MATERIALS AND GOLD NANORODS INTO PLANT TISSUES BY THE BIOLISTIC METHOD

Abstract

Results and Discussion

Conclusions

Experimental Section

70

References 
CHAPTER 5. GOLD FUNCTIONALIZED MESOPOROUS SILICA NANOPARTICLE MEDIATED PROTEIN AND DNA CODELIVERY TO PLANT CELLS VIA BIOLISTIC METHOD

Abstract

Introduction

Results and Discussion

Conclusions

94

Experimental

94

References

99

Supporting Information

102

CHAPTER 6. GENERAL CONCLUSIONS

105 


\section{ACKNOWLEDGMENTS}

First, I would like to thank Prof. Victor Shang-Yi Lin for accepting me into his research group back in 2007 . His creative imagination and enthusiasm for what we are capable of as chemists is an inspiration and will not be forgotten.

I would like to thank my major professor Dr. Brian Trewyn for his guidance from the start of my graduate career. I would not be where I am today and I can not thank you enough for everything you have done for me.

To my co-major professor and collaborator Dr. Kan Wand and my POS Committee members, Dr. Marek Prusk, Dr. Emily Smith, and Dr. Young-Jin Lee, thank you for your valuable time and support.

I would also like to thank past and current group members, especially Dr. Igor Slowing, Kapil Kandel, and Forrest Melcher. It was a pleasure working with you and our countless discussions are deeply appreciated.

Last, but not least, I am deeply grateful for the support from my family, especially my wife Michele. Our time in Ames has been full of experiences and I can't wait to move on to the next chapter in our lives. 


\begin{abstract}
This dissertation presents the research on the development of mesoporous silica based nanotechnology for applications in biofuels and plant science.

Mesoporous silica nanoparticles (MSNs) have been the subject of great interest in the last two decades due to their unique properties of high surface area, tunable pore size and particle morphology. The robust nature of the silica framework is easily functionalized to make the MSNs a promising option for selective separations. Also, the independent channels that form the pores of MSN have been exploited in the use of particles as platforms for molecular delivery.
\end{abstract}

Pore size and organic functionality are varied to identify the ideal adsorbent material for free fatty acids (FFAs). The resulting material is able to sequester FFAs with a high degree of selectivity from a simulated solution and microalgal oil. The recyclability and industrial implications are also explored.

A continuation of the previous material, further tuning of MSN pore size was investigated. Particles with a smaller diameter selectively sequester polyunsaturated free fatty acids (PUFAs) over monounsaturated FFAs and saturated FFAs. The experimental results were verified with molecular modeling.

Mesoporous silica nanoparticle materials with a pore diameter of $10 \mathrm{~nm}$ (MSN-10) were decorated with small gold nanoparticles. The resulting materials were shown to deliver proteins and DNA into plant cells using the biolistic method. 


\section{CHAPTER 1. GENERAL INTRODUCTION}

\section{Dissertation Organization}

This dissertation begins with a general introduction to fundamentals of mesoporous silica materials as Chapter 1. The introduction will cover the synthesis, selective functionalization and modification of mesoporous silica nanoparticles (MSN), and a brief description of characterization methods. In Chapter 2, the use of functionalized MSN for the selective adsorption of free fatty acids from algal oil will be described. Chapter 3 will describe the use of MSNs with different pore size as a platform for polyunsaturated free fatty acid (PUFA) purification. Chapter 4 will discuss the use of nanoparticles as delivery vessels into plant cells via the biolistic method. In Chapter 5, the co-delivery of protein and DNA into plant cells using gold modified MSN and the biolistic method will be covered. Finally, Chapter 6 will be a general conclusion.

\section{Introduction}

Following the discovery of periodic mesoporous silica materials using an organic surfactant templating method in 1992 by Mobil Corporation, a wide variety of siliceous materials, such as $\mathrm{MCM}-41 / 48^{1,2}, \mathrm{FSM}_{-}{ }^{3,4}, \mathrm{KIT}_{-}{ }^{7}, \mathrm{MSU}_{-}{ }^{8}$, and $\mathrm{SBA}_{-}{ }^{9}$, have been prepared. Porous materials are divided into three categories with nomenclature that describes average pore size. The three classes of porous materials are microporous (less than $2 \mathrm{~nm}$ ), mesoporous $(2-50 \mathrm{~nm})$, and macroporous (greater than $50 \mathrm{~nm}$ ).

Typically, the previously mentioned materials are formed by the condensation of an inorganic precursor (usually tetramethylorthosilicate (TMOS) or tetraethylorthosilicate 
(TEOS)) around surfactants acting as structure directing agents (SDAs). The SDAs can later be removed by calcination, heating the samples above $773 \mathrm{~K}$ in air, $\mathrm{N}_{2}$, or $\mathrm{O}_{2}$, or by acid extraction, typically in acidic methanol or ethanol. Two different mechanisms have been suggested for the formation of the material (Figure 1); a liquid-crystal templating pathway ${ }^{5}$ and a cooperative self-assembly pathway ${ }^{10}$. The liquid-crystal templating pathway employs a high concentration of SDAs under certain temperature and $\mathrm{pH}$ conditions in which a liquid-crystal phase is formed. The condensation of the inorganic precursors provides the structural integrity of the nanoparticles. The other mechanism, cooperative self-assembly, involve the Coulombic interaction between silicate anions and the cationic surfactants. The polymerization and cross-linking of the silicate species change the charge density at the interface influencing the arrangement of the SDAs. The SDAs can later be removed either by heating the composite material in air at high temperatures $\left(>500{ }^{\circ} \mathrm{C}\right)$ or by an extraction method, which refluxes the material in anorganic solvent, typically methanol or ethanol.

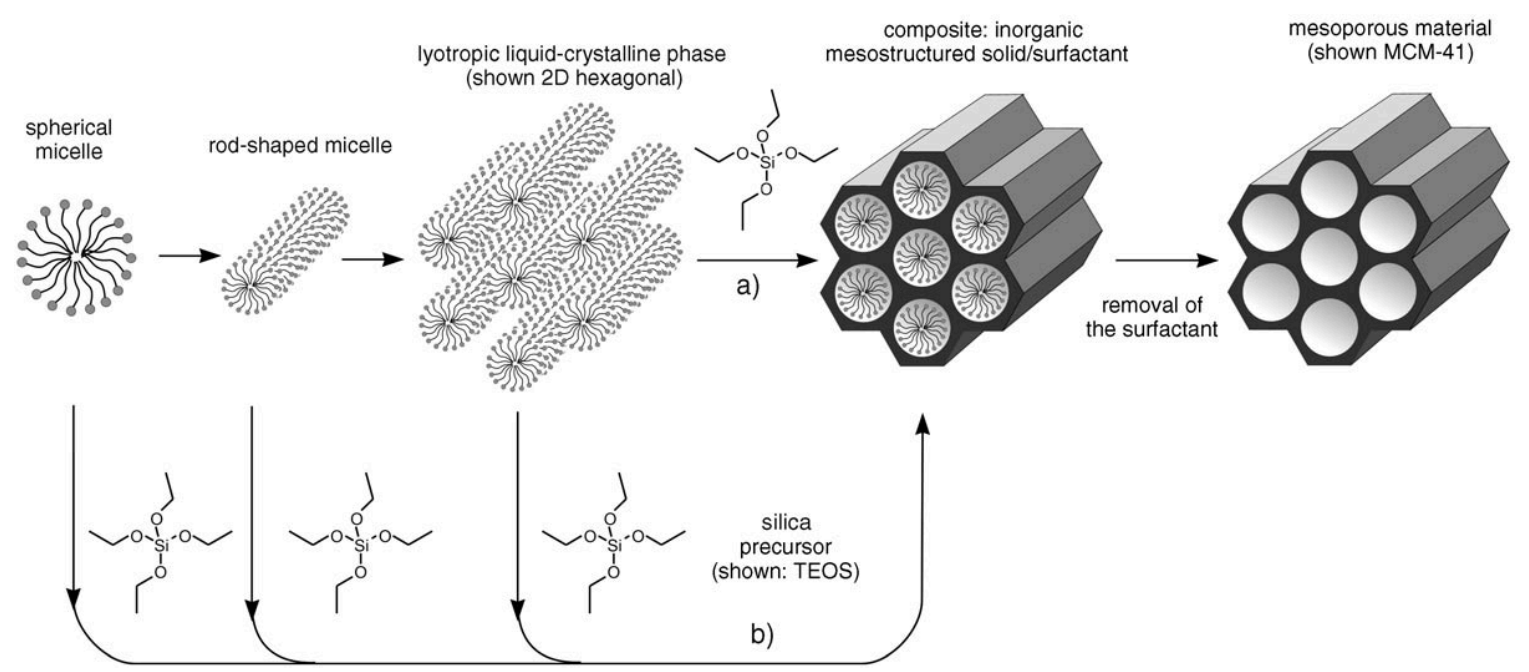

Figure 1. Formation of mesoporous materials by structure-directing liquid crystal templating mechanism (a) and cooperative mechanism (b). ${ }^{5}$ 
Organic modification of the silica materials allows for precise control and fine-tuning of the surface properties for specific applications such as selective adsorption and separations and delivery. ${ }^{11}$ There are two common routes for organic modification of MSNs; post-synthetic modification (grafting) and direct incorporation (co-condensation). As seen in Figure 2, grafting utilizes the abundant silanol groups ( $\equiv \mathrm{Si}-\mathrm{OH})$ for the immobilization of organosilanes of the type ( $\left.\mathrm{R}^{\prime} \mathrm{O}\right)_{3} \mathrm{SiR}$, chlorosilanes $\mathrm{ClSiR}_{3}$, or silazanes $\mathrm{HN}\left(\mathrm{SiR}_{3}\right)_{2}$. The advantage of the grafting is that the mesostructure of silica material is typically retained; however, the pore size and volume might be diminished depending on the size of the R group and degree of functionalization.

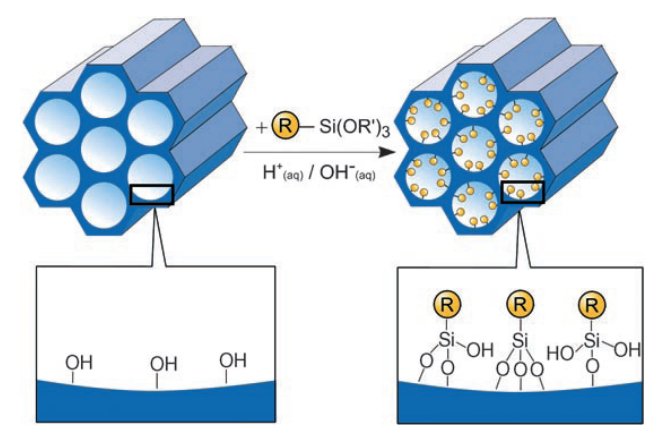

Figure 2. Grafting of silica materials with terminal organosilanes of the type $\left(\mathrm{R}^{\prime} \mathrm{O}\right)_{3} \mathrm{SiR}$ for organic modification. ${ }^{5}$

Co-condensation is an alternative method to synthesize organically functionalized silica materials. Typically, the desired organic moiety of type ( $\left.\mathrm{R}^{\prime} \mathrm{O}\right)_{3} \mathrm{SiR}$ is simultaneously added to the SDA solution with the silica precursor of (RO) $)_{4} \mathrm{Si}$ (TEOS or TMOS) as seen in Figure 3. This method incorporates the organic functionality into the framework of the material and the typical hydrophobic nature of the organic functionalities tends to intercalate into the tail region of the surfactant micelles, resulting in the projection of the functionalities into the pores. ${ }^{12}$ Because the groups are directly 
incorporated into the framework matrix, the blockage of the pores is not generally an issue with this method. Also, it is believed that this route of functionalization leads to a more homogeneous distribution of the organic groups compared to post-synthetic grafting. ${ }^{5,13}$ Co-condensation also has its drawbacks. First, the addition of organosilanes can alter the order and morphology of the resulting product. ${ }^{12}$ Second, the stability of the organic groups in acidic or basic aqueous media needs to be carefully considered. Last, consieration must be taken during the removal of the surfactant, usually leaving extraction as the only option. The acid extraction method can leave surfactant inside the pores, which can be cytotoxic to cells. ${ }^{14}$ This is particularly beneficial for cellular applications, given the reported cytotoxicity of cetyltrimethylammonium bromide.

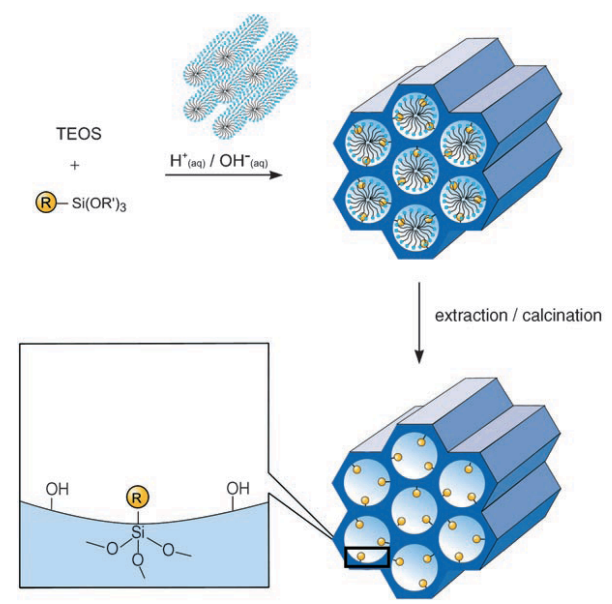

Figure 3. Co-condensation method for the organic modification of mesoporous silica materials. ${ }^{5}$

One of the most elegant uses of organic functionalization of silica was the work done by Mal et al., who anchored coumarin moieties to the external surface. ${ }^{15}$ Since the surfactant was still present in the silica particles, and only removed after successful modification, the coumarin groups reacted only with silanol groups at the pore openings 
and on the external surface. Irradiation of the samples with UV light $(\lambda>310 \mathrm{~nm})$ led to the dimerization of the coumarin, resulting in sealed pore openings that could be opened by subsequent irradiation of with UV light around $250 \mathrm{~nm}$ as shown in Figure 4.

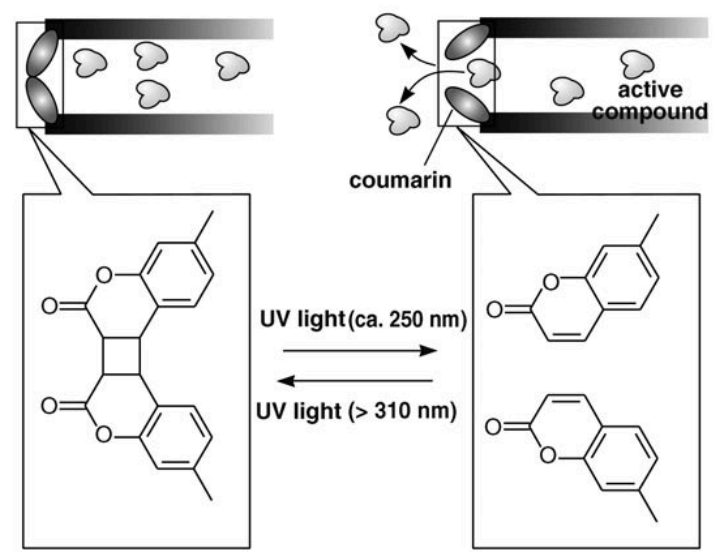

Figure 4. A coumarin based controlled release of active compounds using UV light to open and close the pores of the silica material. ${ }^{5}$

Once the synthesis is complete, the material is fully characterized to determine pore size, surface area, pore structure, particle morphology, and organic/metal content. Several characterization techniques are used to obtain the information mentioned above: transmission electron microscopy (TEM) and low angle x-ray diffraction (XRD) will provide insight into the pore structure. Pore size, pore volume, and surface area information can be obtained from nitrogen adsorption/desorption isotherms. Particle morphology can be determined by scanning electron microscopy (SEM). Solid-state nuclear magnetic resonance (ssNMR), and inductively coupled plasma optical emission spectroscopy (ICP-OES) can quantify the organic and metal contents, respectively. Energy dispersive $\mathrm{x}$-ray spectroscopy (EDX) is also a useful tool for determining the presence of additional elements present in the silica materials. Also, zeta potential and 
dynamic light scattering measurements provide insight regarding the surface charge and hydrodynamic radius of the material is aqueous media, respectively.

The high surface area, defined pore structure, high pore volume, tunable pore size and high stability make these materials attractive for a variety of applications. Some of the applications include selective separation and adsorption, heterogeneous catalysis and supports, cargo delivery and controlled release, and sensors. ${ }^{16-25}$

One of the emerging areas of application for mesoporous silica materials is in the area of separations and their role as adsorbents. Gas separations are required in a wide range of industrial processes such as the hydrogen/nitrogen separation in ammonia plants and hydrogen/hydrocarbon separation in petrochemical operations, and $\mathrm{CO}_{2}$ and water removal from natural gas. ${ }^{26}$ Conventional technologies like cryogenic air separation, condensation of organic vapors from gas mixtures and amine adsorption to remove acid gases from natural gas involved a gas-to-liquid phase change, adding increased energy costs. Using mesoporous silicas as the separation media does not require a phase change. There have also been several reports of using mesoporous silica materials for gas separations. $^{27-30}$

Mesoporous silica materials can also be used for the removal of environmental pollutants and heavy metals. Investigation into the removal of $\mathrm{CO}_{2}$ in the presence of water has been an area of active research in recent years. ${ }^{31-34}$ Hicks et al. discovered that an interaction between basic surface-bound groups and acidic $\mathrm{CO}_{2}$ groups resulted in the formation of ammonium bicarbonate and carbonate species. Also being studied was the removal of $\mathrm{H}_{2} \mathrm{~S},{ }^{35} \mathrm{Cu}^{2+},{ }^{36} \mathrm{Hg}^{2+}, 37,38$ and $\mathrm{Pb}^{2+}, \mathrm{Mn}^{2+}, \mathrm{Zn}^{2+}, \mathrm{Fe}^{2+}, \mathrm{Cd}^{2+}$, and $\mathrm{Ni}^{2+}$. 6,39 Recently, Perez-Quintanilla et al. reported the use of a mercaptopyrimidine 
functionalized material for the adsorption of $\mathrm{Cd}^{2+}$ from aqueous media via soft Lewis acid-soft Lewis base interactions. ${ }^{39}$ Under optimum conditions their material was able to adsorb $0.99 \mathrm{mmol} \mathrm{Cd}^{2+} \mathrm{g}^{-1}$. Similar work by Burke et al. was reported shortly after using diethylenetriamine, thiol, and bi-functionalized materials (Figure 5) for the removal of heavy metals from aqueous media. ${ }^{6}$ The researchers achieved their best adsorption capacities of $0.35 \mathrm{mmol} \mathrm{g}^{-1}$ for $\mathrm{Ni}, \mathrm{Cr}, \mathrm{Fe}$, and $\mathrm{Mn}$ using their thiol functionalized material.
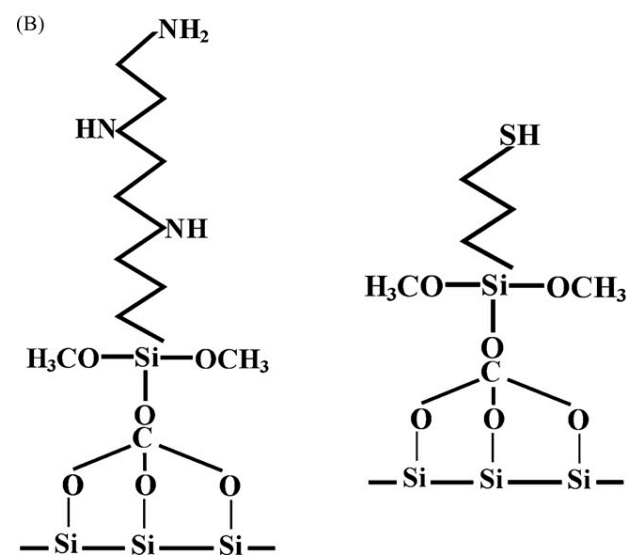

Figure 5. Schematic representation of the organic functionalization using diethylenetriamine (left) and thiol (right) groups. ${ }^{6}$

Along with the separation of gases and metal ions, the recovery of valuable organic products from organic/water mixtures has been an active area of research for the advancement of biofuels. Is it important to be mindful of the entire mixture of components in biofuel feedstocks. Each class of molecules will have its own use and market such as free fatty acids for energy production and the pharmaceutical industries. Many times, the neutraceutical compounds carry more value than the fuel-based molecules. Distillation may be used to remove organic compounds from water, it is not ideal to use when the compounds are in low concentrations or the desired compounds are 
thermally sensitive. In 2001, Park reported the silylation of MCM-48 with trimethyl and triethylsilane to increase the hydrophobicity of the silica material for the selective separation of a water/ethanol mixture. ${ }^{40}$ In a similar study, Park reported the separation of ethanol (EtOH), methylethyl ketone (MEK), and ethyl acetate (EA) by increasing hydrophobicity. ${ }^{41}$ Chowdhury reported that the permeability of water and alcohols through silica materials was affected by the affinity of the solvents for the pore surface. ${ }^{42}$ Modifying the silica surfaces with organic groups make the materials highly hydrophobic and an attractive option for the separation of organic compounds.

The mesoporous silica materials can also play an important role as a delivery system using the pores as storage space. The cargo of the nanoparticles can range from small molecules to suprabiomolecules like proteins and enzymes. Two different mechanisms that have been demonstrated for the delivery of cargo by MSNs are: an endocytosismediated pathway in animal cells and a biolistic method in plant tissues. Another very unique feature of the mesoporous silica materials is the clever use of stimuli-responsive capping systems as a way to control the release of the material's cargo. ${ }^{17,20,43-52}$

One example of small molecule delivery into animal cells was demonstrated in 2003, Lai et al. utilized CdS caps for the controlled release of vancomycin and ATP as shown in Figure $6{ }^{53}$ The release of vancomycin and ATP were triggered by the addition of dithiotreitol (DTT) that reduces the disulfide bond that anchored the CdS caps to the pore openings. 

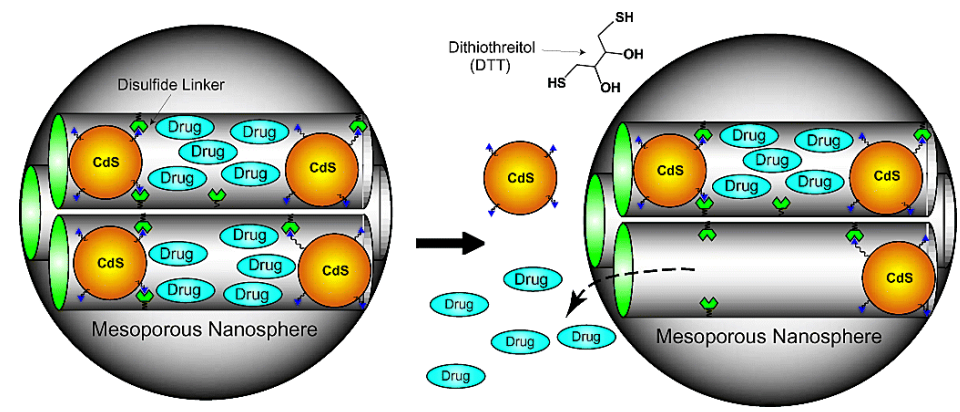

Figure 6. Schematic representation of the $\mathrm{CdS}$ capped MSN loaded with drugs/neurotransmitters. ${ }^{53}$

Shortly after, Radu et al. used a PAMAM-capped MSN to deliver plasmid DNA into several cell lines. ${ }^{17}$ The covalently attached G2-PAMAM forms a complex with the plasmid DNA and protects the DNA from enzymatic cleavage. Once inside the cells, the DNA is release and the coded eGFP protein is expressed as seen in Figure 7.

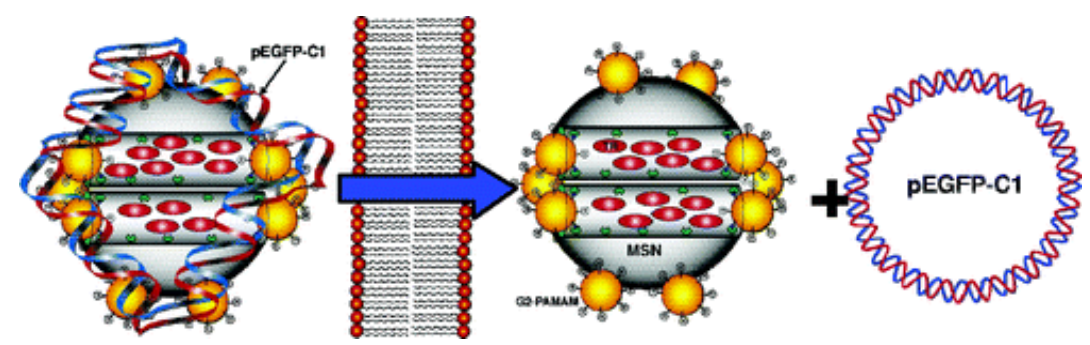

Figure 7. Schematic representation of the Au capped MSN complexed with DNA as a gene transfection agent. ${ }^{17}$

The research group of Vallet-Regi have also demonstrated the release of erythromycin ${ }^{49}$ and ibuprofen by the use of alkyl groups to control the rate of cargo release. $^{54}$ In 2007, Slowing et al. demonstrated the delivery of a membrane impermeable protein , cytochrome $c$, in to HeLa cells by using an MSN based system (Figure 8). ${ }^{18}$ By controlling the surface charge of the MSN during a change in $\mathrm{pH}$, the initial rate of 
protein release could be increased. Also, the released protein was determined to maintain full activity when tested for the oxidation of 2,2'-azino-bis(3-ethylbenzthiazoline-6sulfonate) when compared to a solution of native protein.

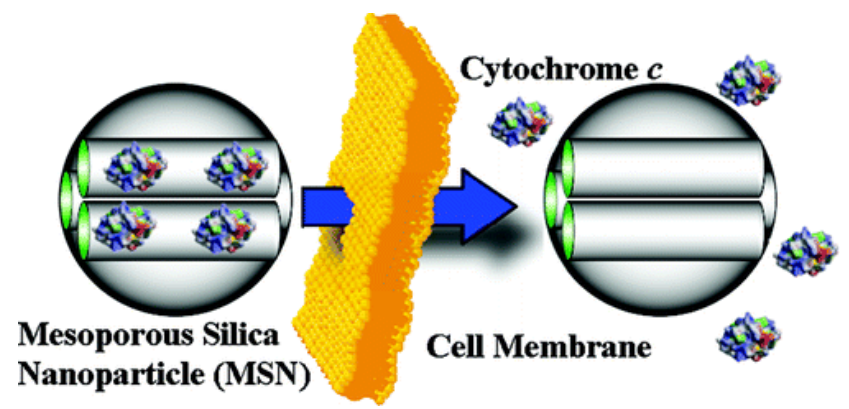

Figure 8. Schematic representation of the MSN loaded with the membrane impermeable cytochrome $c^{18}$

In the case of plant cells, common methods of particle introduction involve leaf uptake ${ }^{55,56}$ protoplast or tissue incubation and root uptake. ${ }^{57-61}$ It is difficult to control the delivery of nanoparticles using these methods because the processes can vary depending on size and surface properties of the particles. A possible solution is to use the biolistic method of delivery. The widely used biolistic method, 'gene gun,' utilizes dense microparticles coated with DNA that are accelerated during theusing a shot of pressurized helium to penetrate the cell wall of the organisms, a schematic representation is shown in Figure 9. The gene gun was developed by John Sanford in 1987 as a faster way to genetically alter plants compared to plant breeding. ${ }^{62-64}$ The delivery agents are typically non-porous dense particles and cargo is generally limited to nucleic acids adsorbed to the external surface of the vessels. The delivery vessels were originally made of tungsten, but are now more commonly comprised of gold. The switch from gold to tungsten occurred due to the toxicity of tungsten and the increased uniformity of gold microcarriers; however, the use of gold may be limited by its availability and cost. 


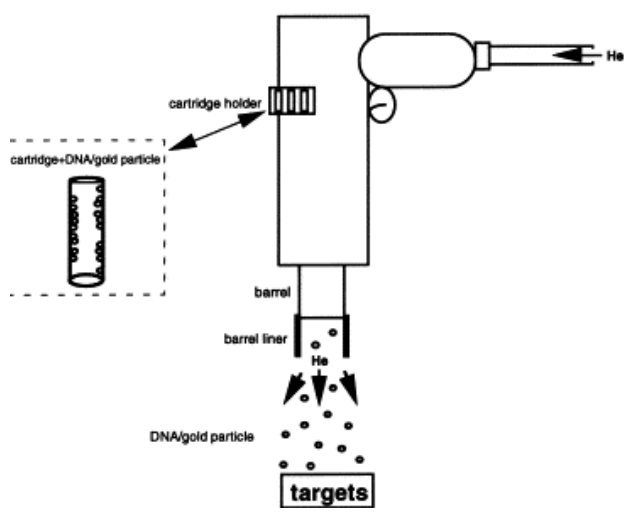

Figure 9. Schematic representation of the biolistic delivery method for delivery of transfection agents into plant cells.

In 2007, Torney et al. demonstrated the delivery of DNA-coated, gold-capped MSNs carrying $\beta$-oestradiol into tobacco protoplasts via biolistic methods as seen in Figure $10 .^{65}$ First, DNA coated MSN with gold caps were bombarded into tobacco cells to demonstrate the ability of MSN to deliver DNA into plant cells. Next, to test wether controlled release, previously demonstrated in animal cells, could be applied to plant cells, $\beta$-oestradiol was loaded inside the pores of the MSN. The addition of dithiothreitol (DTT) to the growth media triggered the uncapping of the gold particles from the pore openings and the release of $\beta$-oestradiol inside the cells. Expression of GFP coded for by the plasmid coated on the outer surface is only observed when the loaded chemical inducer $\beta$-oestradiol is released. 


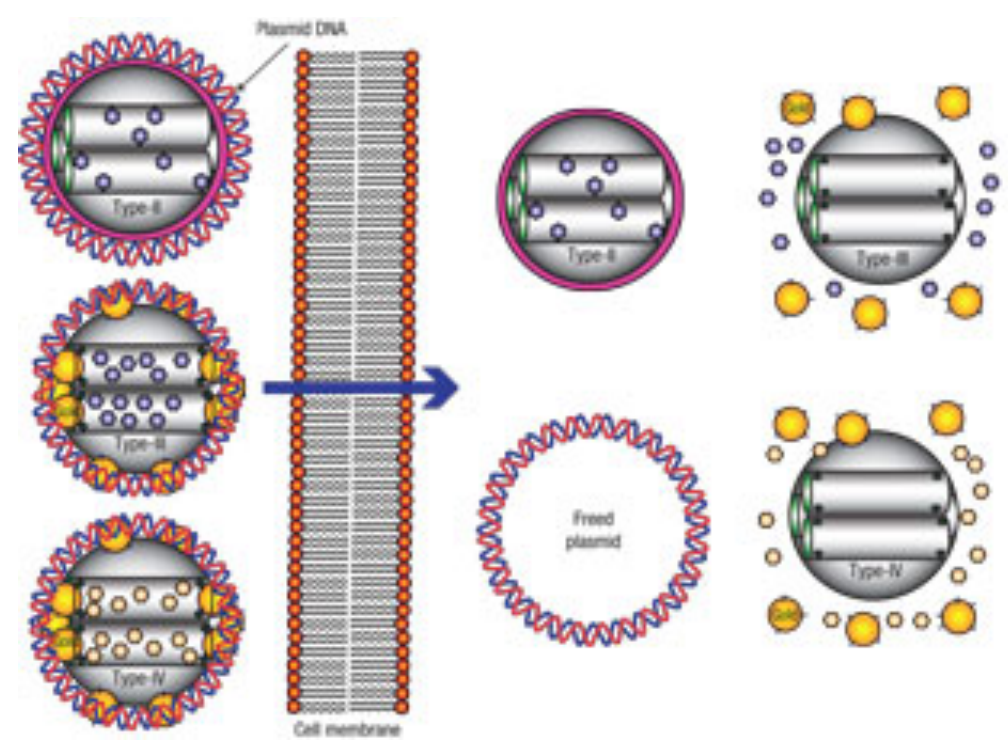

Figure 10. Schematic representation of the biolistic delivery method for delivery of transfection agents into plant cells. ${ }^{65}$

The contents of this thesis are focused on the topics covered more thoroughly in Chapter 1: using MSNs as a tool for the separation of high-value chemicals and as delivery vessels into plant cells.

\section{References}

(1) Beck, J. S.; Vartuli, J. C.; Roth, W. J.; Leonowicz, M. E.; Kresge, C. T.; Schmitt, K. D.; Chu, C. T. W.; Olson, D. H.; Sheppard, E. W.; et al. J. Am. Chem. Soc. 1992, 114, 10834.

(2) Kresge, C. T.; Leonowicz, M. E.; Roth, W. J.; Vartuli, J. C.; Beck, J. S. Nature (London) 1992, 359, 710.

(3) Inagaki, S.; Fukushima, Y.; Kuroda, K. J. Chem. Soc., Chem. Commun. 1993, 680 . 
(4) Inagaki, S.; Koiwai, A.; Suzuki, N.; Fukushima, Y.; Kuroda, K. Bull. Chem. Soc. Jpn. 1996, 69, 1449.

(5) Hoffmann, F.; Cornelius, M.; Morell, J.; Froeba, M. Angew. Chem., Int. Ed. 2006, 45, 3216.

(6) Burke, A. M.; Hanrahan, J. P.; Healy, D. A.; Sodeau, J. R.; Holmes, J. D.; Morris, M. A. J. Hazard. Mater. 2009, 164, 229.

(7) Ryoo, R.; Kim, J. M.; Ko, C. H.; Shin, C. H. J. Phys. Chem. 1996, 100, 17718.

(8) Bagshaw, S. A.; Prouzet, E.; Pinnavaia, T. J. Science (Washington, D. C.) 1995, 269, 1242.

(9) Zhao, D.; Feng, J.; Huo, Q.; Melosh, N.; Frederickson, G. H.; Chmelka, B. F.; Stucky, G. D. Science (Washington, D. C.) 1998, 279, 548.

(10) Wan, Y.; Zhao, D. Chem. Rev. (Washington, DC, U. S.) 2007, 107, 2821.

(11) Stein, A.; Melde, B. J.; Schroden, R. C. Adv. Mater. (Weinheim, Ger.) 2000, 12, 1403.

(12) Huh, S.; Wiench, J. W.; Yoo, J.-C.; Pruski, M.; Lin, V. S. Y. Chem. Mater. 2003, 15, 4247.

(13) Sayari, A.; Hamoudi, S. Chem. Mater. 2001, 13, 3151.

(14) Trewyn, B. G.; Whitman, C. M.; Lin, V. S. Y. Nano Lett. 2004, 4, 2139.

(15) Mal, N. K.; Fujiwara, M.; Tanaka, Y. Nature (London) 2003, 421, 350.

(16) Huh, S.; Chen, H.-T.; Wiench, J. W.; Pruski, M.; Lin, V. S. Y. J. Am. Chem. Soc. 2004, 126, 1010. 
(17) Radu, D. R.; Lai, C.-Y.; Jeftinija, K.; Rowe, E. W.; Jeftinija, S.; Lin, V. S. Y. J. Am. Chem. Soc. 2004, 126, 13216.

(18) Slowing, I. I.; Trewyn, B. G.; Lin, V. S. Y. J. Am. Chem. Soc. 2007, 129, 8845.

(19) Valenstein, J. S.; Kandel, K.; Melcher, F.; Slowing, I. I.; Lin, V. S. Y.; Trewyn, B. G. ACS Appl. Mater. Interfaces, Ahead of Print.

(20) Vivero-Escoto, J. L.; Slowing, I. I.; Wu, C.-W.; Lin, V. S. Y. J. Am. Chem. Soc. 2009, 131, 3462.

(21) Zhao, Y.; Trewyn, B. G.; Slowing, I. I.; Lin, V. S. Y. J. Am. Chem. Soc. 2009, 131,8398 .

(22) Ciesla, U.; Schuth, F. Microporous Mesoporous Mater. 1999, 27, 131.

(23) Schuth, F.; Schmidt, W. Adv. Mater. (Weinheim, Ger.) 2002, 14, 629.

(24) Scott, B. J.; Wirnsberger, G.; Stucky, G. D. Chem. Mater. 2001, 13, 3140.

(25) Ying, J. Y.; Mehnert, C. P.; Wong, M. S. Angew. Chem., Int. Ed. 1999, 38, 56.

(26) Kumar, P.; Guliants, V. V. Microporous Mesoporous Mater. 2010, 132, 1.

(27) Ghosal, K.; Chern, R. T.; Freeman, B. D.; Daly, W. H.; Negulescu, I. I. Macromolecules 1996, 29, 4360.

(28) McCool, B. A.; DeSisto, W. J. Adv. Funct. Mater. 2005, 15, 1635.

(29) Ruthven, D. M.; DeSisto, W. J.; Higgins, S. Chem. Eng. Sci. 2009, 64, 3201.

(30) Vercauteren, S.; Keizer, K.; Vansant, E. F.; Luyten, J.; Leysen, R. J. Porous Mater. 1998, 5, 241. 
(31) Hicks, J. C.; Drese, J. H.; Fauth, D. J.; Gray, M. L.; Qi, G.; Jones, C. W. J. Am. Chem. Soc. 2008, 130, 2902.

(32) Knofel, C.; Martin, C.; Hornebecq, V.; Llewellyn, P. L. J. Phys. Chem. C 2009, 113, 21726.

(33) Knowles, G. P.; Delaney, S. W.; Chaffee, A. L. Ind. Eng. Chem. Res. 2006, 45, 2626.

(34) Chang, A. C. C.; Chuang, S. S. C.; Gray, M.; Soong, Y. Energy Fuels 2003, 17,468 .

(35) Wang, X.; Ma, X.; Sun, L.; Song, C. Green Chem. 2007, 9, 695.

(36) Oh, S.; Kang, T.; Kim, H.; Moon, J.; Hong, S.; Yi, J. J. Membr. Sci. 2007, 301, 118.

(37) Antochshuk, V.; Jaroniec, M. Chem. Commun. (Cambridge, U. K.) 2002, 258.

(38) Liu, J.; Feng, X. D.; Fryxell, G. E.; Wang, L. Q.; Kim, A. Y.; Gong, M. L. Adv. Mater. (Weinheim, Ger.) 1998, 10, 161.

(39) Perez-Quintanilla, D.; Del Hierro, I.; Fajardo, M.; Sierra, I. J. Mater. Chem. 2006, 16, 1757.

(40) Park, D.-H.; Nishiyama, N.; Egashira, Y.; Ueyama, K. Ind. Eng. Chem. Res. 2001, 40, 6105.

(41) Park, D.-H.; Nishiyama, N.; Egashira, Y.; Ueyama, K. Microporous Mesoporous Mater. 2003, 66, 69.

(42) Chowdhury, S. R.; Schmuhl, R.; Keizer, K.; ten Elshof, J. E.; Blank, D. H. A. J. Membr. Sci. 2003, 225, 177. 
(43) Giri, S.; Trewyn, B. G.; Stellmaker, M. P.; Lin, V. S. Y. Angew. Chem., Int. Ed. 2005, 44, 5038.

(44) Sun, X.; Zhao, Y.; Lin, V. S. Y.; Slowing, I. I.; Trewyn, B. G. J. Am. Chem. Soc. 2011, 133, 18554.

(45) Meng, H.; Xue, M.; Xia, T.; Zhao, Y.-L.; Tamanoi, F.; Stoddart, J. F.; Zink, J. I.; Nel, A. E. J. Am. Chem. Soc. 2010, 132, 12690.

(46) Leung, K. C. F.; Nguyen, T. D.; Stoddart, J. F.; Zink, J. I. Chem. Mater. 2006, $18,5919$.

(47) Hernandez, R.; Tseng, H.-R.; Wong, J. W.; Stoddart, J. F.; Zink, J. I. J. Am. Chem. Soc. 2004, 126, 3370.

(48) Ferris, D. P.; Zhao, Y.-L.; Khashab, N. M.; Khatib, H. A.; Stoddart, J. F.; Zink, J. I. J. Am. Chem. Soc. 2009, 131, 1686.

(49) Doadrio, J. C.; Sousa, E. M. B.; Izquierdo-Barba, I.; Doadrio, A. L.; Perez-Pariente, J.; Vallet-Regi, M. J. Mater. Chem. 2006, 16, 462.

(50) Liu, J.; Du, X.; Zhang, X. Chemistry--A European Journal 2011, 17, 810.

(51) Schlossbauer, A.; Dohmen, C.; Schaffert, D.; Wagner, E.; Bein, T. Angew. Chem., Int. Ed. 2011, 50, 6828.

(52) Schlossbauer, A.; Kecht, J.; Bein, T. Angew. Chem., Int. Ed. 2009, 48, 3092.

(53) Lai, C.-Y.; Trewyn, B. G.; Jeftinija, D. M.; Jeftinija, K.; Xu, S.; Jeftinija, S.; Lin, V. S. Y. J. Am. Chem. Soc. 2003, 125, 4451.

(54) Vallet-Regi, M. Chemistry--A European Journal 2006, 12, 5934. 
(55) Birbaum, K.; Brogioli, R.; Schellenberg, M.; Martinoia, E.; Stark, W. J.; Guenther, D.; Limbach, L. K. Environ. Sci. Technol. 2010, 44, 8718.

(56) Corredor, E.; Testillano, P. S.; Coronado, M.-J.; Gonzalez-Melendi, P.; Fernandez-Pacheco, R.; Marquina, C.; Ibarra, M. R.; de la Fuente, J. M.; Rubiales, D.; Perez-de-Luque, A.; Risueno, M.-C. BMC Plant Biology 2009, 9

(57) Hischemoeller, A.; Nordmann, J.; Ptacek, P.; Mummenhoff, K.; Haase, M. J. Biomed. Nanotechnol. 2009, 5, 278.

(58) Lin, D.; Xing, B. Environ. Sci. Technol. 2008, 42, 5580.

(59) Liu, Q.; Chen, B.; Wang, Q.; Shi, X.; Xiao, Z.; Lin, J.; Fang, X. Nano Lett. 2009, 9, 1007.

(60) Yu, G.; Liang, J.; He, Z.; Sun, M. Chem. Bio. 2006, 13, 723.

(61) Zhu, H.; Han, J.; Xiao, J. Q.; Jin, Y. J. Environ. Monit. 2008, 10, 713.

(62) Klein, T. M.; Fromm, M.; Weissinger, A.; Tomes, D.; Schaaf, S.; Sletten, M.; Sanford, J. C. Proc. Natl. Acad. Sci. U.S. A. 1988, 85, 4305.

(63) Sanford, J. C.; Klein, T. M.; Wolf, E. D.; Allen, N. Part. Sci. Technol. $1987,5,27$.

(64) Wang, Y. C.; Klein, T. M.; Fromm, M.; Cao, J.; Sanford, J. C.; Wu, R. Plant Mol. Biol. 1988, 11, 433.

(65) Torney, F.; Trewyn, B. G.; Lin, V. S. Y.; Wang, K. Nature Nanotechnol. 2007, 2, 295. 


\title{
CHAPTER 2. FUNCTIONAL MESOPOROUS SILICA NANOPARTICLES FOR THE SELECTIVE SEQUESTRATION OF FREE FATTY ACIDS FROM MICROALGAL OIL
}

Modified from a paper published in ACS Applied Materials and Interfaces 2012, 4(2), 1003 Justin S. Valenstein, Kapil Kandel, Forrest Melcher, Igor I. Slowing, Victor S.-Y. Lin ${ }^{*}$ and Brian G. Trewyn*

${ }^{\#}$ Deceased May 4, 2010

\begin{abstract}
A series of 2d-hexagonally packed mesoporous silica nanoparticle material with $10 \mathrm{~nm}$ pore diameter (MSN-10) covalently functionalized with organic surface modifiers have been synthesized via a post-synthesis grafting method. The material structure has been characterized by powder X-ray diffraction, electron microscopy, and nitrogen sorption analyses, and the free fatty acid (FFA) sequestration capacity and selectivity was investigated and quantified by thermogravimetric and GC/MS analysis. We discovered that aminopropyl functionalized $10 \mathrm{~nm}$ pore mesoporous silica nanoparticle material (AP-MSN10) sequestered all available FFAs and left nearly all other molecules in solution from a simulated microalgal extract containing FFAs, sterols, terpenes, and triacylglycerides. We also demonstrated selective FFA sequestration from commercially available microalgal oil.
\end{abstract}




\section{INTRODUCTION}

The US and the European Union produce nearly 1.5 billion liters of biodiesel annually. ${ }^{1}$ The high cost of biodiesel can be greatly attributed to the high costs of the oil feedstock and are slowing the global commercialization. One solution is to use waste oils ${ }^{2,3}$ and non-food sources $^{4}$ as feedstocks. Algae present themselves as a potential feedstock source because many species grow in oceanwater or wastewater and produce more energy than other biofuel crops. ${ }^{5}$ The large-scale production of biodiesel was recently demonstrated by Li and coworkers when they published the requirements to successfully grow algae to a density of $14.2 \mathrm{~g} \mathrm{~L}^{-1}$ in an $11,000 \mathrm{~L}$ bioreactor with a lipid content of $44.3 \%$ dry weight and converted the oil to fatty acid methyl esters (FAMEs or biodiesel) through transesterification using immobilized lipase. ${ }^{6}$

Since algae are known to produce a wide variety of high-value and value-added hydrocarbons and lipids, ${ }^{7,8}$ it is necessary to develop technology to separate the algaeproduced molecules to optimize the economics of converting algae oil to energy. An example of a high-value hydrocarbon found in algae is free fatty acids (FFAs), where some have considerable value to the pharmaceutical, neutraceutical and cosmetic industries, particularly the omega-3 and other polyunsaturated FFAs. Another reason to selectively sequester FFAs from feedstocks is the negative effects they have on the conversion of oils to biodiesel. Biodiesel is currently produced from very low FFA percentage $(<1 \%)$ crop oils by the conversion of triacylglycerides (TAGs) through a base-catalyzed transesterification. When the concentration of acid in the feedstock is too high, as they are often found in algal oil; the basic catalyst is neutralized and additional catalyst is required to maintain the reaction kinetics. 
Current separation and purification methods for organic acids are challenging and energy intensive, with extraction and distillation the most common techniques, either using organic solvents or supercritical fluids. ${ }^{9-11}$

The discovery and development of surfactant micelle-templated mesoporous silica nanoparticle (MSN) materials with high surface area and pore volume have advanced the utilization of these materials for applications in catalysis ${ }^{12,13}$, sensors ${ }^{14}$, delivery vessels ${ }^{15-20}$ and adsorbents. ${ }^{21}$ One unique property of MSN is the ease and control at which the surfaces can be functionalized with organic moieties. The performance of the MSN in these sequestration applications is strongly dependent upon the surface functionalization, the interaction between the MSN and specific molecules will vary depending on the nature of the surface chemistry.

Herein, we report the synthesis of a series of mesoporous silica nanoparticles of similar pore diameters with various surface functional groups as sequestration nanomaterials for FFAs. The structure of the resulting materials were investigated via standard material characterization methods including powder X-ray diffraction (XRD), transmission electron microscopy (TEM), scanning electron microscopy (SEM), and nitrogen sorption analysis. The sequestration capacity and FFA selectivity was demonstrated in a simulated feedstock oil with the optimized MSN material to determine the feasibility of using this material for the isolation and purification of FFA from microalgal feedstocks. We discovered that aminopropyl functionalized MSN, with $10 \mathrm{~nm}$ pore diameter (AP-MSN-10), selectively sequestered FFAs. The high affinity of amines as adsorbents for organic acids ${ }^{21}$ coupled with the high surface area and uniform pore structure of the mesoporous material ${ }^{22}$ makes the amine-functionalized mesoporous material an ideal candidate for FFA adsorption. Finally, 
we demonstrated the selective FFA sequestration ability of AP-MSN-10 from a crude, commercially produced algae oil feedstock.

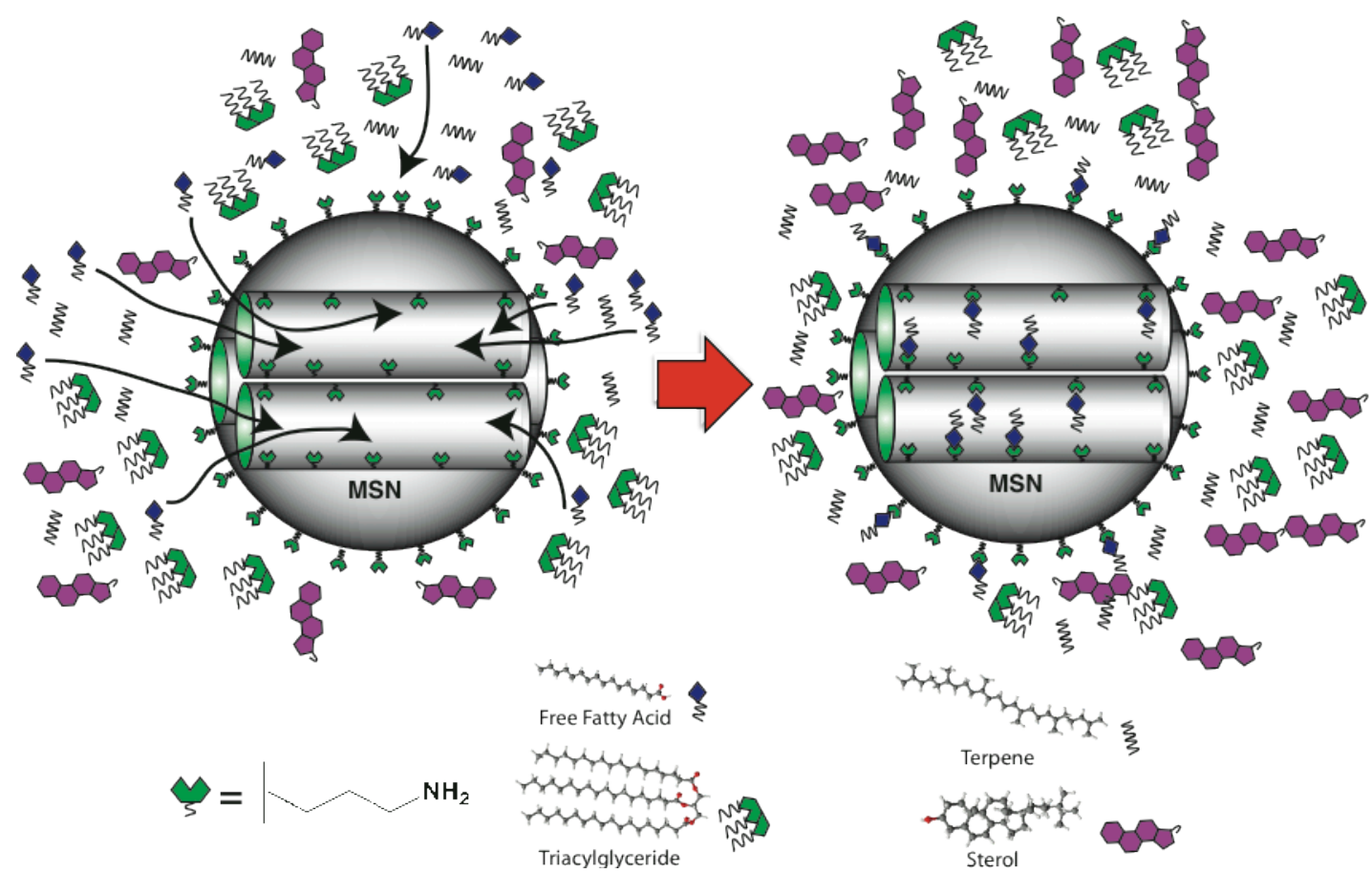

Scheme 1. Schematic illustrating the selective uptake and sequestration of the free fatty acids from a solution of lipids and hydrocarbons found in algal oil.

\section{EXPERIMENTAL SECTION}

MSN-10. ${ }^{23}$ The non-ionic surfactant Pluronic $\AA$ P104 $(7.0 \mathrm{~g})$ was added to $1.6 \mathrm{M} \mathrm{HCl}$ $(273.0 \mathrm{~g})$. After stirring for $1 \mathrm{~h}$ at $55^{\circ} \mathrm{C}$, tetramethylorthosilicate (TMOS, $\left.10.64 \mathrm{~g}\right)$ was added and stirred for an additional $24 \mathrm{~h}$. The resulting mixture was further posthydrothermally treated for $24 \mathrm{~h}$ at $150{ }^{\circ} \mathrm{C}$ in a high-pressure reactor. Upon cooling to room temperature, the white solid was collected by filtration, washed with copious amounts of methanol and dried in air. To remove the surfactant P104 by calcination, the MSN material was heated at a ramp rate of $1.5^{\circ} \mathrm{C} \mathrm{min}^{-1}$ and maintained at $550{ }^{\circ} \mathrm{C}$ for $6 \mathrm{~h}$. 
x-MSN-10. Functionalized MSN-10 will be denoted as $\mathrm{x}-\mathrm{MSN}-10$, where $\mathrm{x}$ represents the organoalkoxysilane. Organoalkoxysilane $(3 \mathrm{mmol})$ was added to a toluene suspension (100 $\mathrm{mL})$ of MSN-10 (1.0 g). The suspension was refluxed for $20 \mathrm{~h}$ under nitrogen. The resulting material was filtered, washed with toluene and methanol, and dried under vacuum overnight. The silanes used to functionalize the MSN-10 were 3-aminopropyltrimethoxysilane (AP), benzyltrimethoxysilane (Bz), hexadecyltrimethoxysilane (Hex), 1-propyl-3-methyl imidazolium bromide trimethoxysilane (PMIm), and 3-mercaptopropyltrimethoxysilane (MP).

AP-silica gel. 3-aminopropyltrimethoxysilane (3 mmol) was added to a toluene suspension $(100 \mathrm{~mL})$ of silica gel $(1.0 \mathrm{~g})$. The suspension was refluxed for $20 \mathrm{~h}$ under nitrogen. The resulting material was filtered, washed with toluene and methanol, and dried under vacuum overnight.

Material Characterization. Powder X-ray diffraction experiments were performed on a Rigaku Ultima IV diffractometer using a $\mathrm{Cu} \mathrm{K} \alpha$ radiation source. Low angle diffraction with a 2-theta range of 0.8 to $6^{\circ}$ was used to investigate the long-range order of the porous materials. TEM studies were done by placing a small aliquot of an aqueous suspension on a lacey carbon film coated 400 mesh copper grid and drying it in air. The TEM images were obtained on a Tecnai $\mathrm{F}^{2}$ microscope. Particle morphology was determined by SEM using a Hitachi S4700 FE-SEM system with $10 \mathrm{kV}$ accelerating voltage. The surface area and average pore diameter were measured using $\mathrm{N}_{2}$ adsorption/desorption measurements in a Micromeritics ASAP 2020 BET surface analyzer system. The data were evaluated using Brunauer-Emmett-Teller (BET) and Barrett-Joyner-Halenda (BJH) methods to calculate surface area and pore distributions, respectively. Samples were prepared by degassing at 100 
${ }^{\circ} \mathrm{C}$ overnight before analysis. Surface functional group loadings were determined by TGA. For TGA, $10 \mathrm{mg}$ samples were heated from 25 to $650{ }^{\circ} \mathrm{C}$ in air at a heating rate of $2{ }^{\circ} \mathrm{C} \mathrm{min}{ }^{-1}$ using a TA Instruments Model 2950 Thermogravimetric Analyzer. The subsequent data was analyzed by Universal Analysis 2000 software. Zeta-potential measurements were carried out by sonicating $5 \mathrm{mg}$ of sample in $5 \mathrm{~mL}$ PBS for $30 \mathrm{~min}$. The samples were then analyzed on a Malvern Instruments Zetasizer. All adsorption studies were done using GC-MS analysis. Samples were dissolved in hexanes and analyzed using an Agilent Technologies 7890A gas chromatograph equipped with a HP-5ms column in-line with a 5975C mass detector.

Adsorption Experiments. Adsorption experiments were conducted using 16 x $125 \mathrm{~mm}$ culture tubes. The adsorbent MSN material $(25 \mathrm{mg}$ ) was suspended in a 10-mL hexane solution containing either a single component or a mixture of components that make up the microalgal simulated solution for $6 \mathrm{~h}$ The adsorbate was separated from the solution using centrifugation and the supernatant was analyzed by GC-MS.

Microalgal Simulated Solution. A mixture of naturally occurring microalgal products ${ }^{7,8}$ was prepared to investigate the adsorption selectivity. Palmitic acid $(57 \mu \mathrm{M})$, glyceryl tristearate $(400 \mu \mathrm{M})$, squalene $(114 \mu \mathrm{M})$, and ergosterol $(57 \mu \mathrm{M})$ were all dissolved in a single solution of hexanes.

Microalgal Oil Adsorption. Crude microalgal oil obtained from Solix Biofuels, Inc, was used for testing the sequestration abilities of amine functionalized MSN-10 and amine functionalized silica gel. Silica material (100 or $300 \mathrm{mg}$ ) was added to $200 \mathrm{mg}$ of microalgal oil in $10 \mathrm{~mL}$ hexanes and mixed for $6 \mathrm{~h}$.

Methyl esterification of Free Fatty Acids. Esterification of the MSN adsorbed FFAs was necessary for quantitative analysis via GC/MS. The hexanes were removed under reduced 
pressure. To the resulting residue, $0.01 \mathrm{M} \mathrm{HCl}$ in methanol $(4 \mathrm{~mL})$ and nonadecanoic acid, as an internal standard, was added and stirred for $1 \mathrm{~h}$ at $80{ }^{\circ} \mathrm{C}$. After cooling to room temperature, $1 \% \mathrm{NaCl}(1 \mathrm{~mL})$ was added to the reaction mixture to increase the recovery of fatty acid methyl esters (FAMEs) from the reaction mixture by solvent extraction. The FAMEs were extracted with subsequent portions of hexane $(3 \times 3 \mathrm{~mL})$. The combined portions were diluted to a final volume of $10 \mathrm{~mL}$ with hexane and transferred to a $\mathrm{GC}$ vial for analysis by GC/MS.

Silylation of Sterols ${ }^{24}$. Derivatization of sterols is necessary for quantification via GC/MS. The hexanes were removed under reduced pressure. Hexanes $(2 \mathrm{~mL})$ and $1 \mathrm{~mL}$ Sylon (BSTFA (N,O-bis(trimethylsilyl)trifluoroacetamide) and TMCS (trimethylchlorosilane), 99:1) were added to the residue and heated to $70{ }^{\circ} \mathrm{C}$ for $1 \mathrm{~h}$ while stirring. The products were diluted to a final volume of $10 \mathrm{~mL}$ with hexane and transferred to $\mathrm{GC}$ vials for analysis by GC/MS.

Transesterification of Triacylglycerides. Transesterification of triacylglycerides are necessary for quantification via GC/MS. The hexanes were removed under reduced pressure and the resulting residue was dissolved in $4 \mathrm{~mL}$ of $0.04 \mathrm{M}$ methanolic $\mathrm{NaOH}$. The mixture was heated to $75{ }^{\circ} \mathrm{C}$ for $1 \mathrm{~h}$ while stirring. After cooling to room temperature, $1 \% \mathrm{NaCl}(1$ $\mathrm{mL}$ ) was added to the reaction mixture. The FAMEs were extracted with subsequent portions of hexane $(3 \times 3 \mathrm{~mL})$. The combined portions were diluted to a final volume of $10 \mathrm{~mL}$ with hexane and transferred to a GC vial for analysis by GC/MS.

Titration of Free Fatty Acids. The free fatty acids remaining in solution from the algal oil are quantified by titration with $\mathrm{KOH}$. The hexanes were removed under reduced pressure and resulting residue was dissolved in $125 \mathrm{~mL}$ isopropyl alcohol that was previously 
neutralized with $\mathrm{KOH}$. A few drops of phenolphthalein solution were added to the alcholol mixture and titrated with $0.05 \mathrm{M} \mathrm{KOH}$ until a color change was observed. The titration of FFAs was repeated to produce a triplicate of experiments.

\section{RESULTS AND DISCUSSION}

\section{Screening of MSN Pore Size Dependence on FFA Sequestration. Initially, two} mesoporous silica nanoparticle (MSN) materials with different pore sizes were synthesized and tested to determine the FFA sequestration dependence on pore diameter. Mesoporous silica nanoparticle material with a pore diameter of 2.5-nm (MSN-2.5) were synthesized following a previously reported method ${ }^{25}$ and MSN with 10-nm pores (MSN-10) were synthesized by modifying Linton's procedure. ${ }^{26}$ The two MSN materials were individually mixed with a hexane solution of FFAs for $6 \mathrm{~h}$ and the FFAs remaining in the supernatant were analyzed by GC-MS. The FFA sequestration capacity of MSN-2.5 and MSN-10 were 0.40 and $0.65 \mathrm{mmol} \mathrm{FFA} \mathrm{g}^{-1}$, respectively. Since MSN-10 was shown to sequester $63 \%$ more FFAs, it was chosen as the base material for continued studies.

Characterization of the $\mathbf{x}-\mathrm{MSN}-10 \mathrm{~s}$. The organoalkoxysilanes that were utilized to functionalize the MSN by post-synthetic grafting were 3-aminopropyltrimethoxysilane (AP), benzyltrimethoxysilane (Bz), hexadecyltrimethoxysilane (Hex), 1-propyl-3-methyl imidazolium bromide trimethoxysilane (PMIm), and 3-mercaptopropyltrimethoxysilane (MP). To functionalize the MSN-10, $3 \mathrm{mmol} \mathrm{g}^{-1}$ of each organoalkoxysilane was added to a refluxing toluene suspension of the mesoporous material. The amount of each functional group loaded on the surface of MSN-10 can be found in Table 1 as determined by TGA analysis. The X-ray diffraction patterns of $\mathrm{x}-\mathrm{MSN}-10$ are shown in Figure 1c. The observed 
diffraction patterns with intense $\left(d_{100}\right)$ peaks are characteristic of highly ordered twodimensional (2-D) hexagonal mesostructures with uniform channels. ${ }^{27}$ To directly visualize the pore structure, the $\mathrm{x}-\mathrm{MSN}-10$ materials were analyzed by transmission electron microscopy (TEM). As shown in Figure $1 \mathrm{~b}$, the parallel stripes indicate that the postsynthetic grafting did not destroy the cylindrical mesoporous channels ${ }^{17}$, which is consistent with the XRD measurements. The scanning electron micrograph (SEM) in Figure 1a shows the particles have a spherical structure and not a flat, disk-like shape. ${ }^{26}$
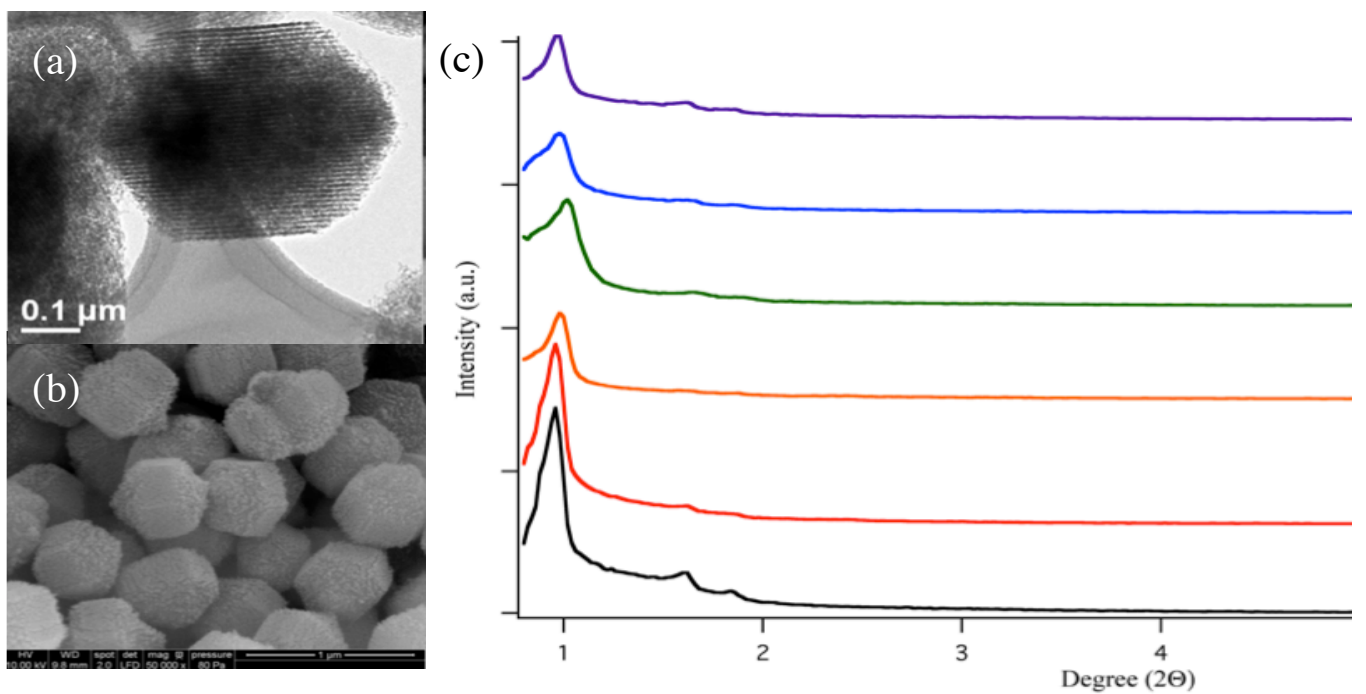

Figure 1. Transmission electron micrograph (a), scanning electron micrograph (b), and XRD spectra of the surfactant removed unfunctionalized MSN-10 (black), AP-MSN-10 (red), Bz-MSN-10 (orange), Hex-MSN-10 (green), PMIM-MSN-10 (blue), and MP-MSN-10 (purple).

The maintenance of the pore structure is also confirmed by nitrogen sorption analysis using BET and BJH calculations, see Figure 2 for isotherms. A small decrease in the pore diameter of appoximately $0.5 \mathrm{~nm}$ is observed after functionalization, along with a drop in surface area $\left(375 \mathrm{~m}^{2} \mathrm{~g}^{-1}\right.$ to $\left.290 \mathrm{~m}^{2} \mathrm{~g}^{-1}\right)$. 

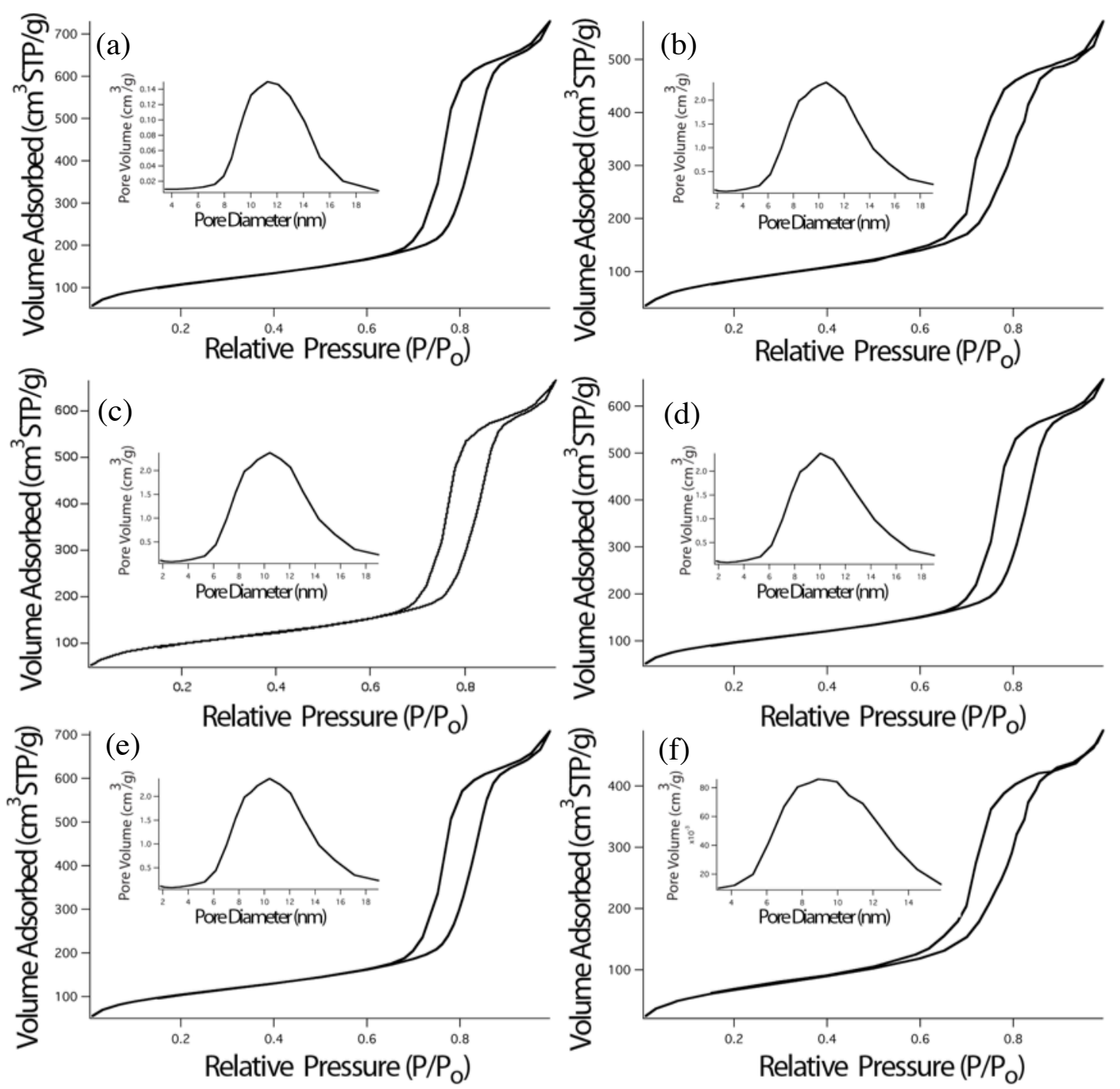

Figure 2. BET isotherms and BJH pore size distributions (insets) of MSN-10 (a), APMSN-10 (b), Bz-MSN-10 (c), Hex-MSN-10 (d), PMIM-MSN-10 (e), and MP-MSN10 (f).

Thermogravimetric analysis (TGA) of $\mathrm{x}-\mathrm{MSN}-10 \mathrm{~s}$ was utilized to determine the loading amounts of each organoalkoxysilane. A summary of all of the characterization measurements can be found in Table 1. 
Table 1. Structure Properties of MSN-10 and x-MSN-10

\begin{tabular}{|c|c|c|c|c|c|c|c|}
\hline Sample & $\begin{array}{l}\mathbf{d}_{100} \\
{[\AA]}\end{array}$ & $\begin{array}{c}\mathbf{a}_{\mathbf{0}} \\
{[\AA]}\end{array}$ & $\begin{array}{c}\mathbf{W}_{\text {BJH }}{ }^{[\mathrm{a}]} \\
{[\AA]}\end{array}$ & $\begin{array}{c}\mathrm{S}_{\mathrm{BET}}{ }^{[\mathrm{a}]} \\
{\left[\mathrm{m}^{2} \mathrm{~g}^{-1}\right]}\end{array}$ & $\begin{array}{c}\mathbf{P V}^{[\mathrm{a}]} \\
{\left[\mathrm{cm}^{3} \mathrm{~g}^{-1}\right]}\end{array}$ & $\begin{array}{l}\text { Loading }^{[\mathrm{b}]} \\
{\left[\mathrm{mmol} \mathrm{g}^{-1}\right]}\end{array}$ & $\begin{array}{c}\text { Zeta- } \\
\text { Potential } \\
{[\mathrm{mV}]}\end{array}$ \\
\hline MSN-10 & 100.38 & 115.91 & 104.7 & 375 & 1.02 & - & -28.1 \\
\hline AP-MSN-10 & 92.02 & 106.25 & 100.7 & 290 & 0.78 & 1.54 & +19.3 \\
\hline Bz-MSN-10 & 90.09 & 104.03 & 101.0 & 266 & 0.72 & 1.25 & -19.8 \\
\hline Hex-MSN-10 & 86.63 & 100.03 & 98.3 & 265 & 0.94 & .682 & -21.7 \\
\hline PMIM-MSN-10 & 90.14 & 104.08 & 101.2 & 281 & 0.76 & 1.34 & +28.7 \\
\hline MP-MSN-10 & 91.85 & 106.06 & 100.3 & 233 & 0.86 & 1.20 & -22.4 \\
\hline
\end{tabular}

${ }^{[a]} \mathrm{W}_{\mathrm{BJH}}$ represents the pore diameter; $\mathrm{S}_{\mathrm{BET}}$ represents the surface area; PV represents the pore volume

${ }^{[b]}$ Loading represents the amount of functional group grafted on to the material

Selection of the Optimal Functional Group for FFA Sequestration. To determine the organic functional group that optimized the effectiveness of our adsorbent material, the resulting $\mathrm{x}-\mathrm{MSN}-10$ materials were mixed with a hexane solution of FFAs and the FFAs remaining in solution were analyzed. The results varied but AP-MSN-10 sequestered $98 \%$ of available FFA (0.98 mmol FFA g $\mathrm{MSN}^{-1}$ from a $1.0 \mathrm{mM}$ FFA solution), followed by BzMSN-10, which sequestered $0.50 \mathrm{mmol} \mathrm{FFA} \mathrm{g} \mathrm{MSN}^{-1}$, see Table 2 for a complete list of the sequestration results. The high sequestration capacity of the AP-MSN-10 lends itself to be used as an adsorbent for FFAs. 
Table 2. Adsorption Dependence of FFAs on MSN Surface Grafted Functional Group

\begin{tabular}{|c|c|c|}
\hline $\begin{array}{c}\text { Functional Group } \\
\text { (x-trialkoxysilane) }\end{array}$ & $\begin{array}{c}\text { Amount Adsorbed } \\
\left(\text { mmol FFA g MSN }^{-1}\right)\end{array}$ & $\begin{array}{c}\text { Amount Adsorbed } \\
\left(\mathrm{mmol} \mathrm{FFA} \mathrm{m}^{-2}\right)\end{array}$ \\
\hline 3-Aminopropyl & 0.98 & 0.00173 \\
\hline Benzyl & 0.50 & 0.00338 \\
\hline Hexadecyl & 0.30 & 0.00188 \\
\hline $\begin{array}{c}\text { 1-Propyl-3-methyl } \\
\text { Imidazolium Chloride }\end{array}$ & 0.40 & 0.00113 \\
\hline 3-Mercaptopropyl & 0.25 & 0.00108 \\
\hline None & 0.65 & \\
\hline
\end{tabular}

Adsorption Isotherms. The kinetics of palmitic acid adsorption on AP-MSN-10 was measured (Figure 3) to determine the time required for equilibrium to be reached between the adsorbent and adsorbate. The amount of acid adsorbed on the AP-MSN-10 reached 100\% at $120 \mathrm{~min}$. The adsorbent capacities of the sequestration materials were determined by treating unfunctionalized MSN-10 and AP-MSN-10 materials with different analytes in varying concentrations that are commonly found in microalgal solutions. The components of the simulated microalgal solution were palmitic acid (FFA), glyceryl tristearate (triacylglyceride), squalene (terpene), and ergosterol (sterol). 


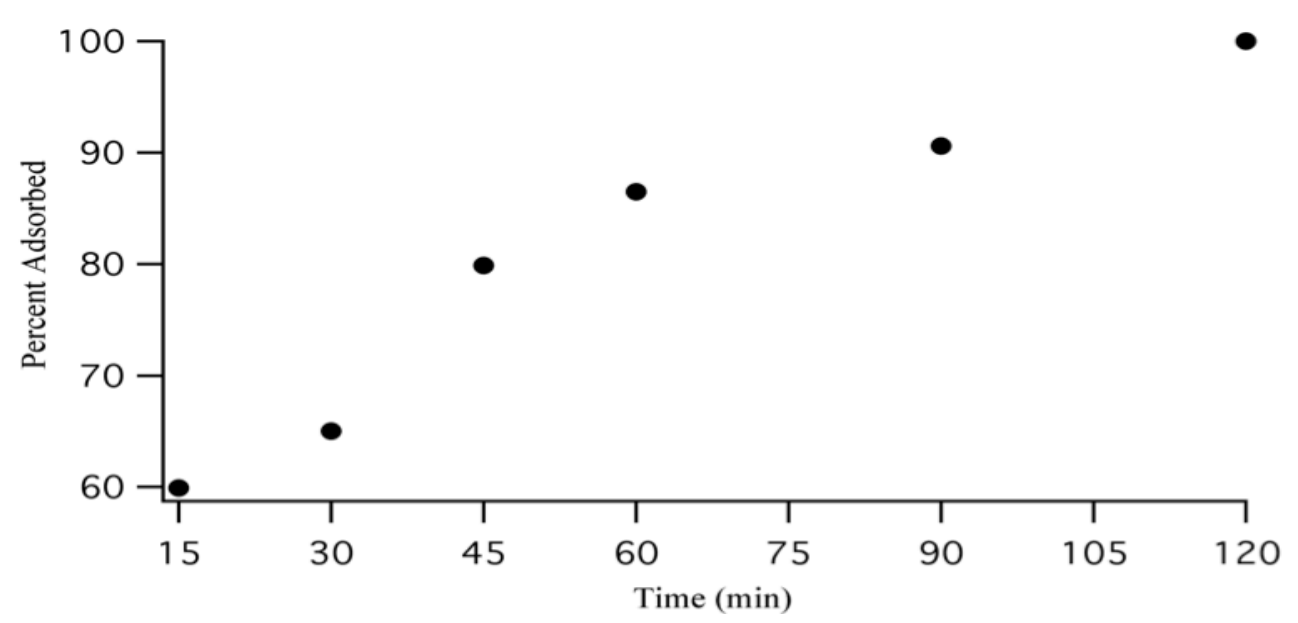

Figure 3. Amount of palmitic acid adsorbed on AP-MSN-10 as a function of contact time (initial [palmitic acid] $=2.1 \mathrm{mM}$ ).

Data found in Table 3 and the adsorption isotherms indicate AP-MSN-10 has a higher adsorption capacity for FFAs than unfunctionalized MSN-10.

Table 3. $\mathrm{Q}_{\max }$ Values (mmol $\mathrm{g}^{-1}$ ) for Adsorbates on MSN-10 and AP-MSN-10

\begin{tabular}{|c|c|c|}
\hline & MSN-10 & AP-MSN-10 \\
\hline Palmitic acid & 0.81 & 1.50 \\
\hline Glyceryl tristearate & 0.44 & 0.22 \\
\hline Ergosterol & 0.48 & 0.18 \\
\hline Squalene & 0.0089 & 0.0063
\end{tabular}

Interestingly, an adsorption capacity of $1.50 \mathrm{mmol} \mathrm{g}^{-1}$ is equal to the number of surface

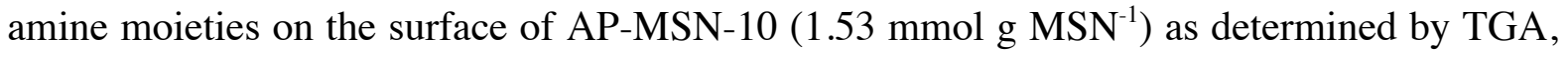
indicating a 1:1 complexation between the surface amines and free fatty acids and monolayer coverage of the surface. All of the adsorption isotherms that were measured were fitted to the Langmuir equation: 


$$
Q=\frac{\left(k_{1} \times C\right)}{\left(k_{2}+C\right)}
$$

where $\mathrm{Q}\left(\mathrm{mmol} \mathrm{g}^{-1}\right)$ is the amount of adsorbate adsorbed per gram of adsorbent, $\mathrm{C}$ is the adsorbate concentration, and $\mathrm{k}_{1}$ and $\mathrm{k}_{2}$ are Langmuir adsorption equilibrium constants. The data was fitted to the equation with the coefficient of determination values exceeding 0.95 , indicating a statistical goodness of fit. The adsorption isotherms and Langmuir adsorption model curve fits are shown in Figures 4 and 5. In addition to improved FFA adsorption over unfunctionalized MSN-10, AP-MSN-10 had a significantly higher adsorption capacity for FFAs compared to the other classes of adsorbates. The non-functionalized MSN-10 reached an adsorption capacity of $0.81 \mathrm{mmol} \mathrm{g}^{-1}$ for palmitic acid compared to the maximum adsorption capacity of $1.50 \mathrm{mmol} \mathrm{g} \mathrm{g}^{-1}$ for palmitic acid on the AP-MSN-10. In addition, the adsorption capacity of $1.50 \mathrm{mmol} \mathrm{g}^{-1}$ is much higher than previous reports for porous silica materials ranging from 0.18 to $0.6 \mathrm{mmol} \mathrm{g}^{-1} \cdot{ }^{28-30}$ 


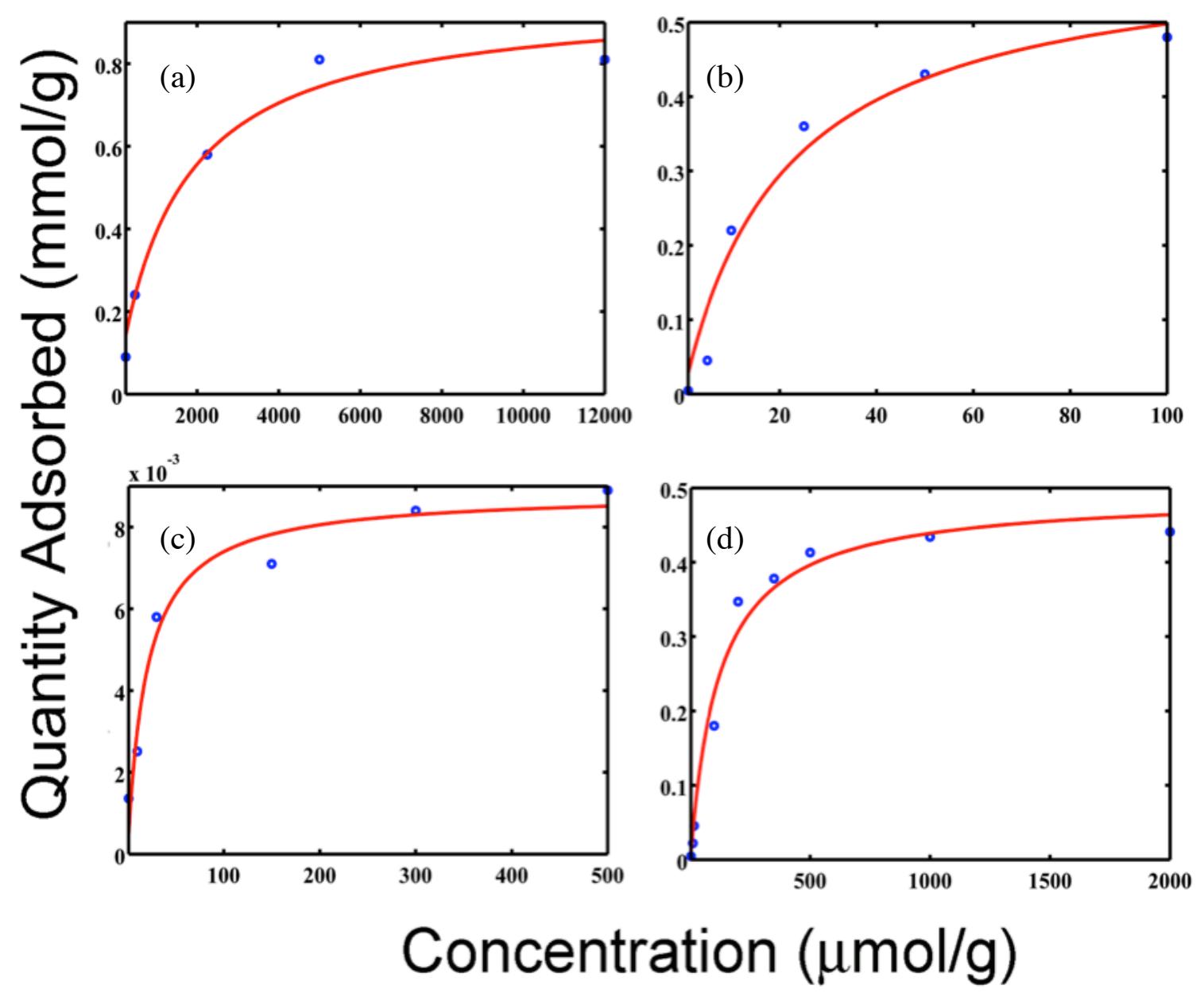

Figure 4. Adsorption isotherms of palmitic acid (a), ergosterol (b), squalene (c), and glyceryl tristearate (d) adsorbed on MSN-10. 


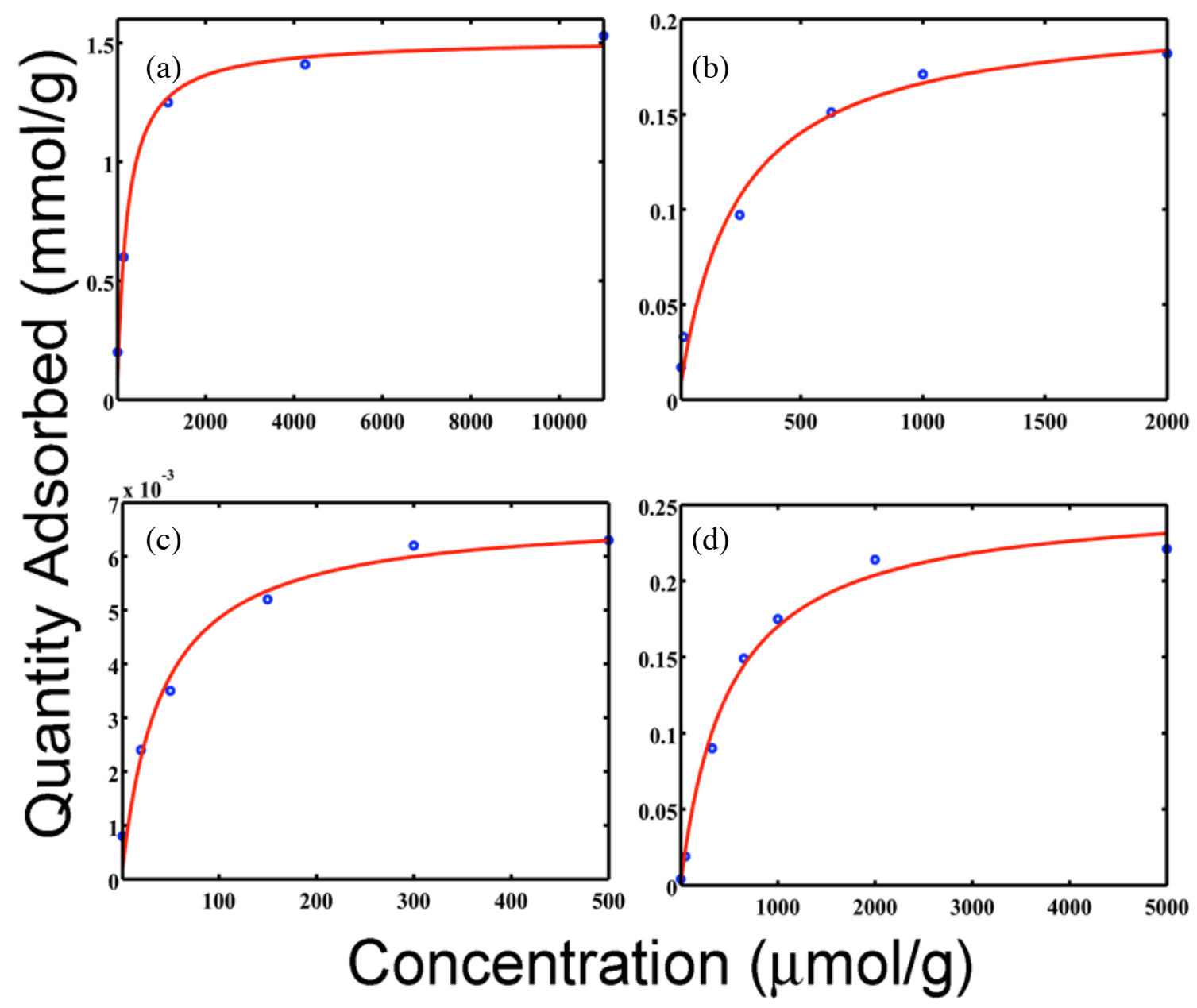

Figure 5. Adsorption isotherms of palmitic acid (a), ergosterol (b), squalene (c), and glyceryl tristearate (d) adsorbed on AP-MSN-10.

Selectivity of AP-MSN-10. To demonstrate the selectivity of AP-MSN-10 for FFAs, 25 mg of AP-MSN-10 was mixed with $10 \mathrm{~mL}$ of a simulated solution closely resembling microalgal oil containing a mixture of palmitic acid $(57 \mu \mathrm{M})$, glyceryl tristearate $(400 \mu \mathrm{M})$, squalene $(114 \mu \mathrm{M})$, and ergosterol $(57 \mu \mathrm{M})$. After removal of the AP-MSN-10 from the solution, the hydrocarbons remaining in solution were quantified. The results of the selectivity experiments are listed in Table 4. AP-MSN-10 exhibited a dramatic preference for adsorbing palmitic acid over all the other substances, while MSN-10 adsorbed all 
substances equally except for squalene. This phenomenon can be explained by the surface amines of AP-MSN-10 acting as specific binding sites for FFAs. According to Bruckenstein and Untereker, an uncharged complex will form in hexane resulting from the exchange of the acidic proton from the FFA to the primary amine. ${ }^{31}$ This phenomenon is used to explain the high selectivity of AP-MSN-10 towards FFAs. The other three classes of adsorbates do not contain an acidic proton or in the case of ergosterol, the $\mathrm{pKa}$ is too high to exchange with the surface amine. While unfunctionalized MSN-10 did not demonstrate any selectivity, the incorporation of the amine group greatly shifted the selectivity of the mesoporous material towards free fatty acids.

Table 4. Adsorption Values $\left(\mathrm{mmol} \mathrm{g}^{-1}\right)$ from Simulated Microalgal Oil for MSN-10 and AP-MSN-10.

\begin{tabular}{|c|c|c|c|c|}
\hline & MSN-10 & $\begin{array}{c}\text { MSN-10 } \\
\text { Percent } \\
\text { Sequestered }\end{array}$ & AP-MSN-10 & $\begin{array}{c}\text { AP-MSN-10 } \\
\text { Percent } \\
\text { Sequestered }\end{array}$ \\
\hline Palmitic Acid & 0.0228 & 100 & 0.0228 & 100 \\
\hline $\begin{array}{c}\text { Glyceryl } \\
\text { tristearate }\end{array}$ & 0.150 & 93.8 & 0.012 & 7.5 \\
\hline Ergosterol & 0.0228 & 100 & 0.0039 & 17.1 \\
\hline Squalene & 0.0082 & 17.9 & 0.0048 & 10.5 \\
\hline
\end{tabular}

Recyclability of AP-MSN-10. The recyclability of AP-MSN-10 was tested by repeated experiments of palmitic acid adsorption. The AP-MSN-10 with adsorbed palmitic acid was added to the esterification reaction mixture to transform the acids to the methyl esters. By reacting the acidic proton involved in the complexation responsible for the acid selectivity, we can desorb the sequestered molecules from the surface of the AP-MSN-10. After the first 
cycle of adsorption, we are able to recover $92 \%$ of the adsorbed palmitic acid; however, the adsorption efficiency of the second and third cycles dropped to $73 \%$ and $59 \%$ of the first cycle, respectively. The decrease in adsorption efficiency is likely due to the remaining acid still adsorbed to the silica surface after desorption is attempted and the harsh conditions of the acid-catalyzed esterification deteriating the silica material. Active research is currently underway to identify less harsh, more efficient methods to recycle the sequestration MSN material.

\section{Adsorption of FFAs by AP-MSN-10 from commercial microalgal oil. To demonstrate} the selective adsorption ability of the AP-MSN-10 with commercially available microalgal oil, $100 \mathrm{mg}$ AP-MSN-10 and $300 \mathrm{mg}$ AP-silica gel, as a control, were mixed with microalgal oil obtained from Solix, Inc (Fort Collins, CO). Once the materials were separated from the oil, the supernatant was analyzed for remaining FFA content. Using varying amounts of

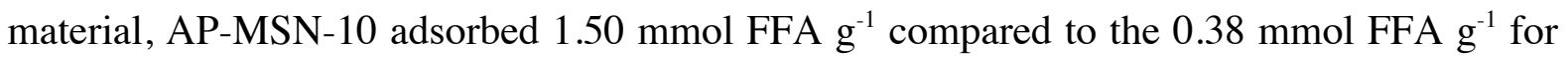
the AP-silica gel. The increase in surface area and pore volume by the incorporation of mesopores into the structure of the silica adsorbent plays a vital role in increasing the adsorption capacity. Both adsorption quantities closely match the amount of amine groups grafted on the surface of each material. The AP-MSN-10 is able to maintain the adsorption capabilities in a complex mixture applicable to current processes.

Further experiments were conducted using AP-MSN-10 for the adsorption of FFAs from commercial microalgal oil. By using the calculated value for amine moieties on the surface of AP-MSN-10, we determined the amount of material necessary to introduce a 1:1 ratio of amine groups to FFA in the microalgal oil. A $100 \mathrm{mg}$ aliquot of microalgal oil was dissolved in hexanes and mixed with $25 \mathrm{mg}$ of AP-MSN-10 for $2 \mathrm{~h}$. After separating the silica 
materials from the supernatant, the supernatant was added to a second vial for a second adsorption cycle. The remaining FFAs were analyzed by titration. The FFA content of the microalgal oil was reduced from $11.5 \%$ to $3.2 \%$ after the first cycle and $0.70 \%$ after the second cycle, calculated by $\mathrm{KOH}$ titration. Reducing the FFA content to less than $1 \%$ will increase the feasibility of using current industrial transesterification catalysts for microalgal biodiesel.

\section{CONCLUSIONS}

In summary, the successful synthesis and characterization of aminopropyl functionalized $10 \mathrm{~nm}$ pore mesoporous silica nanoparticle material has been demonstrated. We showed that functionalizing MSN-10 was necessary to optimize the sequestration capacity and selectivity for FFAs. The addition of the primary amine group to the surface of MSN-10 increased the

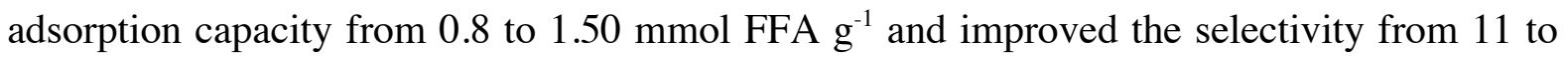
$53 \mathrm{~mol} \%$ uptake by utilizing proton exchange to create specific binding sites for FFAs. We have also demonstrated the ability to reduce the FFA content of microalgal oil to less than $1 \%$ using AP-MSN-10, which makes it more favorable to be used as a biodiesel source. We are currently establishing a series of mesoporous nanomaterials that are specific for different biomolecules produced by microorganisms.

Acknowledgement. BGT, IIS, and JSV would like to thank the U.S. Department of Energy, Office of Energy Efficiency and Renewable Energy (Grant No. DE-FG260NT08854), for financial support. BGT, KK, and FM would also like to acknowledge 
funding of this work by the US Department of Energy under contract DE-EE0003046 awarded to the National Alliance for Advanced Biofuels and Bioproducts. 


\section{References}

1. Gerpan, J. V., Fuel Process Technology 2005, 86 (10), 10.

2. Yoshimura, T., Petrotech (Tokyo) 1998, 21 (10), 967-972.

3. Zhang, Y.; Dube, M. A.; McLean, D. D.; Kates, M., Bioresour. Technol. 2003, 90 (3), 229-240.

4. Cheng, Y.; Lu, Y.; Gao, C.; Wu, Q., Energy Fuels 2009, 23 (8), 4166-4173.

5. Chisti, Y., Biotechnol. Adv. 2007, 25 (3), 294-306.

6. $\quad$ Li, X.; Xu, H.; Wu, Q., Biotechnol. Bioeng. 2007, 98 (4), 764-771.

7. Metzger, P.; Largeau, C., Appl. Microbiol. Biotechnol. 2005, 66 (5), 486-496.

8. Zhila, N. O.; Kalacheva, G. S.; Volova, T. G., Russ. J. Plant Physiol. 2005, 52 (3), 311-319.

9. Angenent, L. T.; Karim, K.; Al-Dahhan, M. H.; Wrenn, B. A.; Domiguez-Espinosa, R., Trends Biotechnol. 2004, 22 (9), 477-485.

10. Bungay, H. R., Trends Biotechnol. 2004, 22 (2), 67-71.

11. Wu, Z.; Yang, S.-T., Biotechnol. Bioeng. 2003, 82 (1), 93-102.

12. Chen, H.-T.; Huh, S.; Wiench, J. W.; Pruski, M.; Lin, V. S. Y., J. Am. Chem. Soc. 2005, $127(38), 13305-13311$.

13. Nieweg, J. A.; Lemma, K.; Trewyn, B. G.; Lin, V. S. Y.; Bakac, A., Inorg. Chem. 2005, 44 (16), 5641-5648.

14. Zhao, Y.; Trewyn, B. G.; Slowing, I. I.; Lin, V. S. Y., J. Am. Chem. Soc. 2009, 131 (24), 8398-8400. 
15. Giri, S.; Trewyn, B. G.; Stellmaker, M. P.; Lin, V. S. Y., Angew. Chem., Int. Ed. 2005, 44 (32), 5038-5044.

16. Lai, C.-Y.; Trewyn, B. G.; Jeftinija, D. M.; Jeftinija, K.; Xu, S.; Jeftinija, S.; Lin, V. S. Y., J. Am. Chem. Soc. 2003, 125 (15), 4451-4459.

17. Radu, D. R.; Lai, C.-Y.; Jeftinija, K.; Rowe, E. W.; Jeftinija, S.; Lin, V. S. Y., J. Am. Chem. Soc. 2004, 126 (41), 13216-13217.

18. Slowing, I. I.; Trewyn, B. G.; Lin, V. S. Y., J. Am. Chem. Soc. 2007, 129 (28), 88458849.

19. Torney, F.; Trewyn Brian, G.; Lin Victor, S. Y.; Wang, K., Nat Nanotechnol 2007, 2 (5), 295-300.

20. Trewyn, B. G.; Whitman, C. M.; Lin, V. S. Y., Nano Lett. 2004, 4 (11), 2139-2143.

21. Jun, Y.-S.; Huh, Y. S.; Park, H. S.; Thomas, A.; Jeon, S. J.; Lee, E. Z.; Won, H. J.; Hong, W. H.; Lee, S. Y.; Hong, Y. K., J. Phys. Chem. C 2007, 111 (35), 1307613086.

22. Lin, V. S. Y.; Lai, C.-Y.; Huang, J.; Song, S.-A.; Xu, S., J. Am. Chem. Soc. 2001, 123 (46), 11510-11511.

23. Kim, T.-W.; Slowing, I. I.; Chung, P.-W .; Lin, V. S.-Y., ACS Nano 2011, 5 (1), 360366.

24. Blau, K., Halket, J., Handbook of Derivatives for Chromatography. John Wiley \& Sons: New York, 1993; Vol. 2nd ed.

25. Huh, S.; Wiench, J. W.; Yoo, J.-C.; Pruski, M.; Lin, V. S. Y., Chem. Mater. 2003, 15 (22), 4247-4256.

26. Linton, P.; Alfredsson, V., Chem. Mater. 2008, 20 (9), 2878-2880. 
27. Zhao, D.; Huo, Q.; Feng, J.; Chmelka, B. F.; Stucky, G. D., J. Am. Chem. Soc. 1998, $120(24), 6024-6036$.

28. Gao, Q.; Xu, W.; Xu, Y.; Wu, D.; Sun, Y.; Deng, F.; Shen, W., J. Phys. Chem. B 2008, $112(7), 2261-2267$.

29. O'Connor, A. J.; Hokura, A.; Kisler, J. M.; Shimazu, S.; Stevens, G. W.; Komatsu, Y., Sep. Purif. Technol. 2006, 48 (2), 197-201.

30. Topallar, H.; Bayrak, Y., Turk. J. Chem. 1999, 23 (2), 193-198.

31. Bruckenstein, S.; Untereker, D. F., J. Am. Chem. Soc. 1969, 91 (21), 5741-5. 


\title{
CHAPTER 3. MESOPOROUS SILICA NANOPARTICLES FOR THE SELECTIVE PURIFICATION OF
} POLYUNSATURATED FREE FATTY ACIDS

\author{
Modified from a paper to be submitted to Chemical Communications \\ Forrest Melcher, Justin S. Valenstein, Kapil Kandel, Igor Slowing and Brian G. Trewyn
}

\begin{abstract}
Mesoporous materials with an ordered pore structure were examined to test their ability to selectively sequester polyunsaturated free fatty acids from a mixture also containing saturated and monounsaturated free fatty acids. The materials were modified using several organosilanes and the co-condensation method. MSNs with an average pore diameter of $3 \mathrm{~nm}$ demonstrated an increased selectivity towards polyunsaturated free fatty acids (PUFAs). Application of the selectivity was tested in a mixture of free fatty acids derived from an algae sample.
\end{abstract}

\section{Introduction}

Polyunsaturated Free Fatty Acids (PUFAs) have been known to play a crucial role in brain function as well as normal growth and development. ${ }^{1}$ PUFAs have also been shown to reduce the risk of cardiovascular disease, cancer, and arthritis. ${ }^{2}$ These fatty acids can be found in fish, algae, and other aquatic species. When starting with a pure FFA mixture the desired product PUFAs can be used for pharmaceuticals as described previously. However, 
the other FFAs can then be sent to an esterification reactor to make biodiesel. Since the degree of unsaturation of the fatty acid methyl esters (FAMEs) are not important in biodiesel, this by-product could greatly offset the cost of production and ultimately lower the price of the fuel. Current methods of extraction and purification are expensive and time consuming, commonly using supercritical fluid extraction. Other methods have been proposed using selective esterification, ${ }^{3}$ urea complexation, and supported silver salts. ${ }^{4}$ Some of these current adsorbents show little recyclability and less than desirable selectivity. A new approach will be introduced using functionalized mesoporous silica nanoparticles (MSN) to separate PUFAs from a mixture also containing saturated and monounsaturated FFAs. Ordered mesoporous materials containing various functional groups were tested for selectivity. The surface functional groups as well as the pore size of the particles were varied to achieve selectivity towards the polyunsaturated FFAs. The MSNs were functionalized in situ to incorporate the functional groups within the pores of the material while the outer surface of the material was left unfunctionalized to promote the entrance of the FFAs into the pores. One phenomenon we attempted to take advantage of to achieve selectivity was the pi-cation interaction. This interaction is often observed between the face of an electron rich pi system and an adjacent cation. Silver cations have been shown to strongly exhibit this effect. ${ }^{5}$ In addition to the pi-cation interaction, selectivity towards PUFAs was further increased by tuning the pore size. 


\section{Results and Discussion}

\subsection{Molecular Modeling}

The three FFA species were modeled using Cambridgesoft Chem3D. The structures were constructed using Chem3D software and the free energy of each molecule was minimized via the GAMESS interface using hexanes as the model solvent and by MM2 calculations, which both yielded similar results. Intermolecular measurements were taken to approximate the size of each molecule as shown in Table 1.

Table 1. Molecular Modeling Results

\begin{tabular}{|l|c|}
\hline \multicolumn{1}{|c|}{ Species } & Molecular Size ( $\AA$ ) \\
\hline Arachidic Acid & 26.50 \\
\hline Cis-11-Eicosenoic Acid & 25.49 \\
\hline Eicosapentaenoic Acid & 18.05 \\
\hline
\end{tabular}

As expected, the PUFA exhibited the smallest radius followed by the monounsaturated, and then saturated. The foundation of this size difference is due to the nature of FFAs found in biomass. In these FFAs all of the double bonds exhibit a cis stereochemical configuration, which leads to a "coiling" effect of the molecule, therefore reducing the molecular radius. Illustrations of these results can be found in Figures 1-3. 


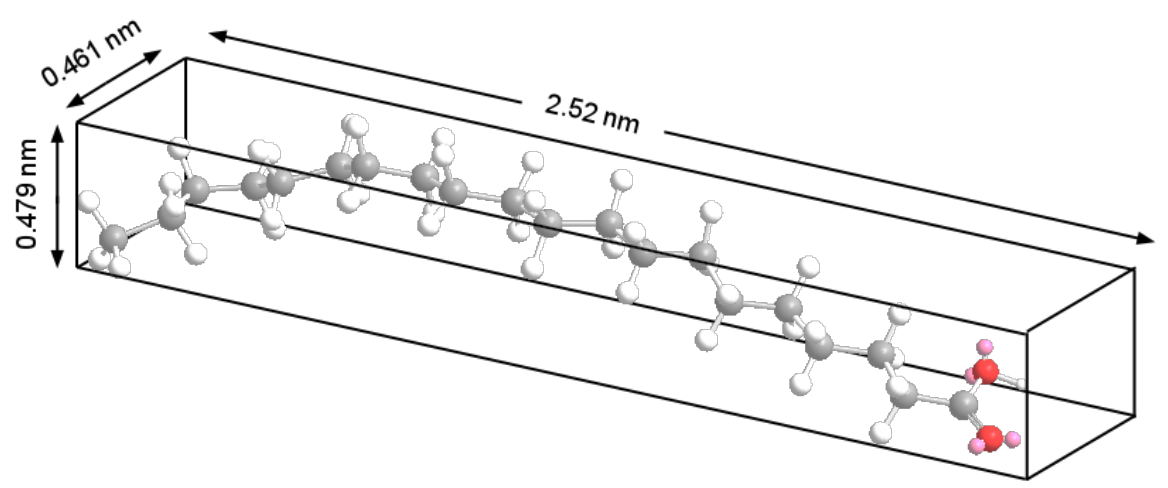

Figure 1. Minimized energy conformation of Arachidic Acid.

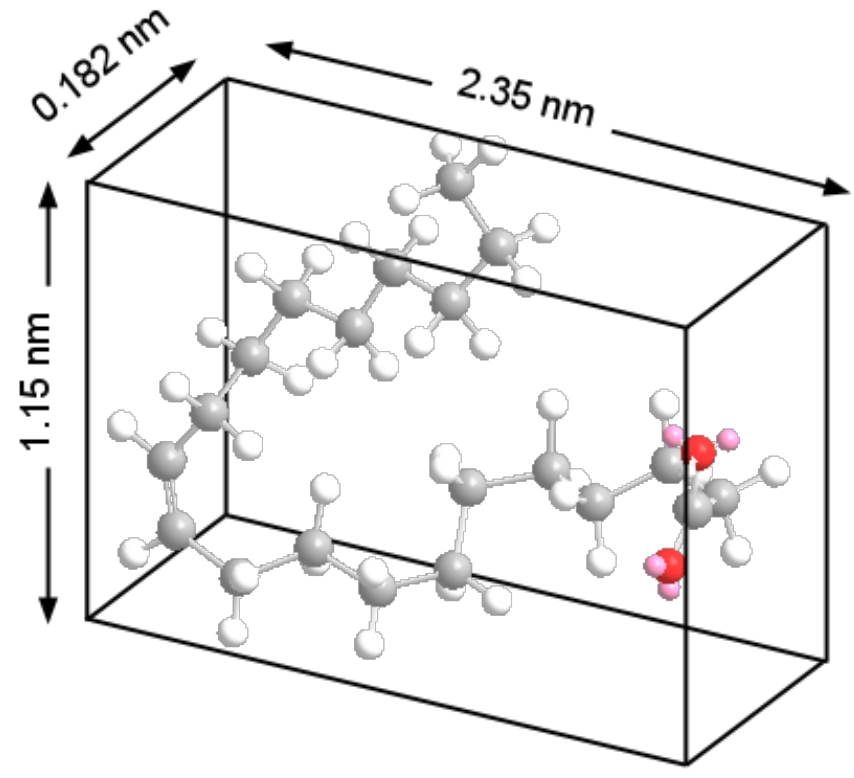

Figure 2. Minimized energy conformation of Cis-11-Eicosenoic Acid. 


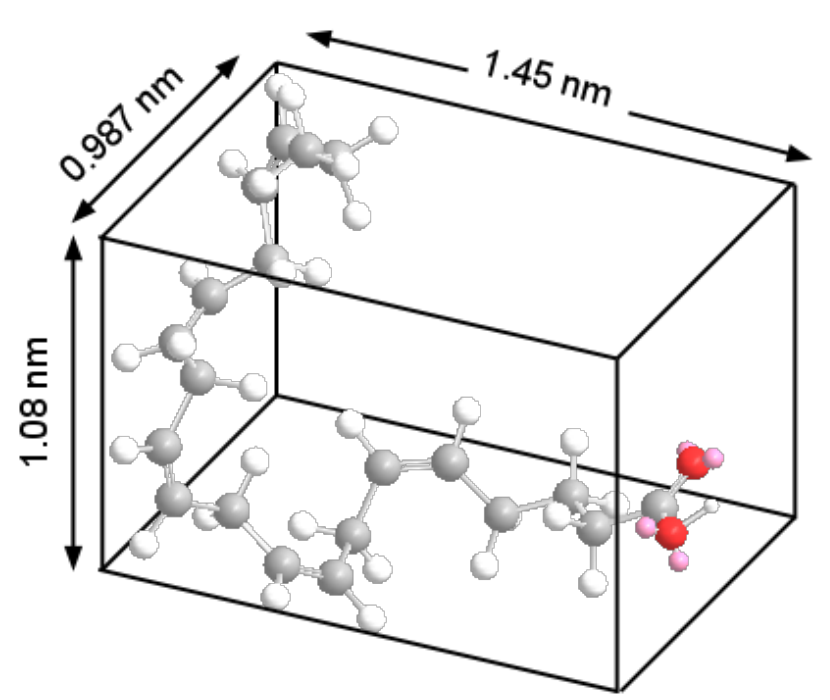

Figure 3: Minimized energy conformation of Eicosapentaenoic Acid.

\subsection{Influence of functional group interaction on selectivity}

The surfaces within the pores of the MSN were decorated with three different functional groups: a primary amine, succinic anhydride, and silver dicarboxylate to observe the effect of their interaction with the FFAs and more specifically pi bonds. The succinic anhydride ring was then opened to obtain a dicarboxylate, followed by an ion exchange with silver nitrate to obtain a silver dicarboxylate. The functionalized MSN showed little selectivity sequestering $65 \%$ of the saturated FFAs and $73 \%$ of the monounsaturated FFAs. These percentages are of the available analytes (FFAs) in simulated FFA solution. When the material was functionalized with a primary amine the selectivity increased by $43-49 \%$ in an equimolar solution of saturated, monounsaturated, and polyunsaturated FFAs. Similarly the succinic anhydride functionalized MSN showed even less selectivity than the naked MSN; however, upon conversion to silver dicarboxylate the results were similar to that of the primary amine as shown in Table 2, this is likely due to the pi-cation interaction between the unsaturation of 
the FFA and the silver cation. It is also noteworthy that both the primary amine and silver dicarboxylate are cationic head groups which explains the similar results obtained from these two materials.

Table 2. Percent Sequestered by $3 \mathrm{~nm}$ pore size MSN containing various functional groups

\begin{tabular}{|l|c|c|c|c|}
\hline \multicolumn{1}{|c|}{ Analyte } & Amine & $\begin{array}{c}\text { Silver } \\
\text { Dicarboxylate }\end{array}$ & $\begin{array}{c}\text { Succinic } \\
\text { Acid }\end{array}$ & Unfunctionalized \\
\hline Saturated FFA & $29 \%$ & $32 \%$ & $80 \%$ & $65 \%$ \\
\hline Monounsaturated FFA & $31 \%$ & $30 \%$ & $83 \%$ & $73 \%$ \\
\hline PUFA & $100 \%$ & $100 \%$ & $100 \%$ & $100 \%$ \\
\hline
\end{tabular}

\subsection{Influence of pore size on selectivity}

MSNs with pore sizes of 3, 5, and 10nm were synthesized and tested for selectivity. All materials were functionalized with a primary amine and the amount of amine was determined by TGA to confirm that the amount of functional groups on each material was similar. As the pore size was decreased the selectivity increased since the unsaturations in the PUFA cause it to have a smaller hydrodynamic radius, as shown from the molecular modeling results, than the saturated and monounsaturated versions of the acid. The material with $3 \mathrm{~nm}$ pores adsorbed all of the available PUFAs and approximately $30 \%$ of the saturated and monounsaturated FFAs compared to the materials with average pore diameters of 5 and 10 nm. The two materials possessing larger pore diameters exhibited almost no selectivity towards any type of FFA. This was not suprising since the $10 \mathrm{~nm}$ pore size MSN has been previously shown to sequester all FFAs by Valenstein. ${ }^{6}$ Further research is being done to see if this trend can be extrapolated such that an even smaller pore size would give more selectivity. 
Table 3. Percent Sequestered by MSN with different pore sizes

\begin{tabular}{|l|c|c|c|}
\hline \multicolumn{1}{|c|}{ Analyte } & $\mathbf{3} \mathbf{~ n m}$ & $\mathbf{5} \mathbf{~ n m}$ & $\mathbf{1 0} \mathbf{~ n m}$ \\
\hline Saturated FFA & $30 \%$ & $95 \%$ & $100 \%$ \\
\hline Monounsaturated FFA & $31 \%$ & $95 \%$ & $100 \%$ \\
\hline PUFA & $100 \%$ & $83 \%$ & $100 \%$ \\
\hline
\end{tabular}

\subsection{Langmuir Isotherm Adsorption Experiments}

Samples of the representative saturated, monounsaturated, and polyunsaturated free fatty acids were made at varying concentrations. The previously described method of sequestration, esterification, and GC-MS analysis was performed on each sample. Figure 1 shows the increasing capacity for the FFAs with increasing unsaturations. The data points were fitted using the Langmuir Equation:

$$
Q=\frac{k_{1} C}{k_{2}+C}
$$

Where $\mathrm{Q}$ is the quantity adsorbed per gram of MSN $\left(\mathrm{mmol} \mathrm{g}^{-1}\right), \mathrm{C}$ is the adsorbate concentration (mmol), and $\mathrm{k}_{1}$ and $\mathrm{k}_{2}$ are the corresponding Langmuir coefficients. 


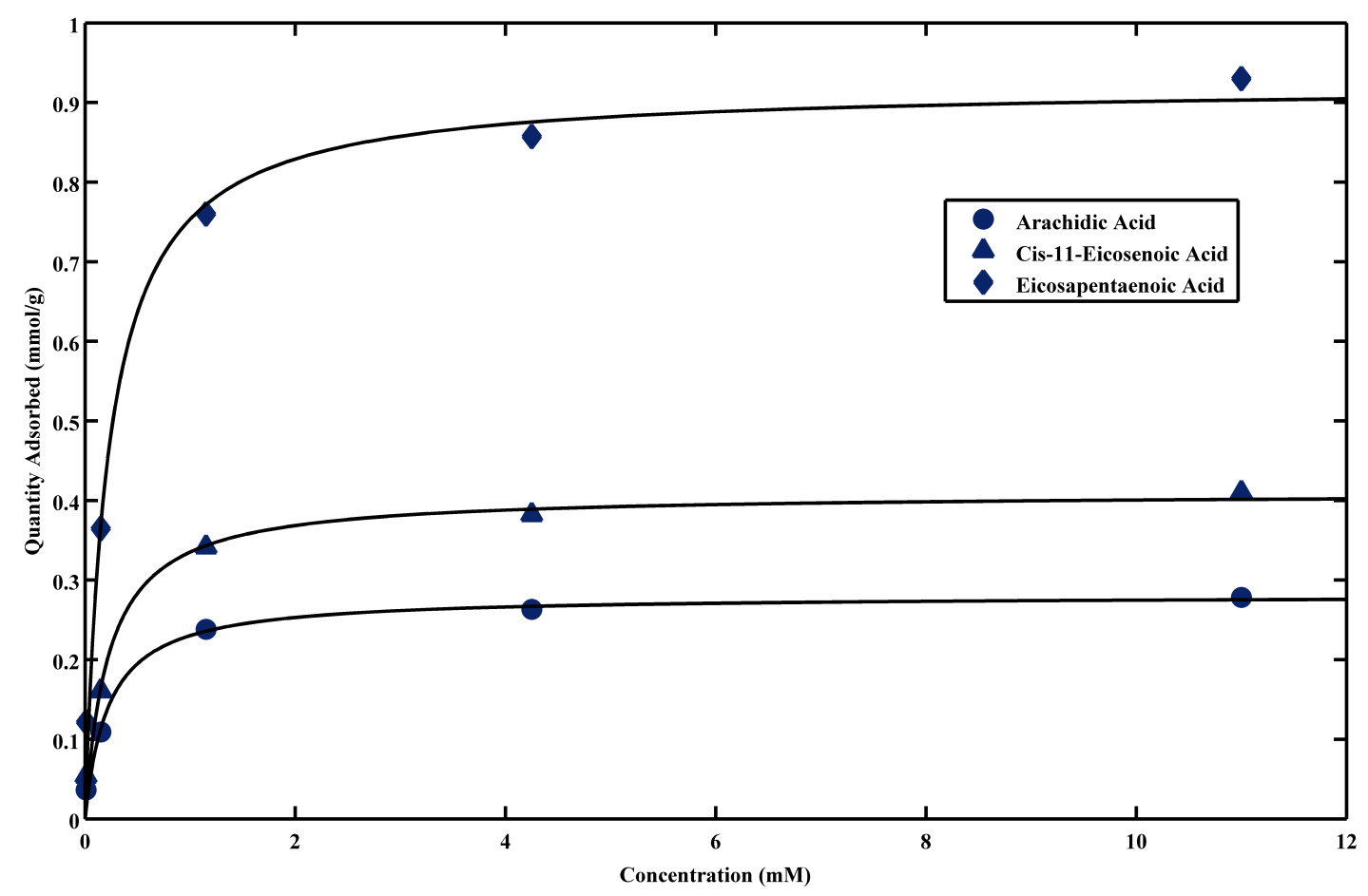

Figure 4: Langmuir Isotherms for saturated FFAs, monounsaturated FFAs , and PUFAs.

Table 4. Langmuir coefficients for the corresponding isotherms.

\begin{tabular}{|l|c|c|c|}
\hline & $\begin{array}{c}\text { Arachidic Acid } \\
\text { (saturated FFA) }\end{array}$ & $\begin{array}{c}\text { cis-Eicosenoic Acid } \\
\text { (monounsaturated FFA) }\end{array}$ & $\begin{array}{c}\text { Eicosapentaenoic Acid } \\
\text { (PUFA) }\end{array}$ \\
\hline $\mathrm{k}_{1}$ & 0.2809 & 0.4095 & 0.9215 \\
\hline $\mathrm{k}_{2}$ & 0.2196 & 0.2215 & 0.2230 \\
\hline
\end{tabular}

\subsection{Sequestration of polyunsaturated from algal biomass}

Algae was obtained from Israel and dried in an oven to remove any remaining water. The dried biomass was stirred in hexanes overnight and filtered to yield a mixture of extracted FFAs. Adsorption of the FFAs was performed using the same procedure described in the experimental section by shaking a small amount of amine functionalized MSN in the solution using hexanes as the solvent. As can be seen in Table 4, the amine functionalized material 
were able to sequester $86 \%$ of the available PUFA, compared to the $11 \%$ and $28 \%$ of the available saturated and monounsaturated FFAs, respectively. Similar selectivity was seen when compared to the previously mentioned experiments using a simulated solution. This observation is an illustration of a real world application using this technology.

Table 5. Sequestration of Polyunsaturated from algae derived FFAs

\begin{tabular}{|c|c|}
\hline Analyte Classification & Percent Sequesterd \\
\hline Saturated FFA & $11 \%$ \\
\hline Monounsaturated FFA & $28 \%$ \\
\hline PUFA & $86 \%$ \\
\hline
\end{tabular}

\section{Experimental}

\subsection{Reagents and Materials}

Pluronic ${ }^{\circledR}$ P104, tetramethylorthosilicate (TMOS), cetyltrimethylammonium bromide (CTAB), tetraethylothosilicate (TEOS), and aminopropyltrimethoxy silane were all purchased from Sigma Aldrich Chemicals. 3-(triethoxysilyl)propylsuccinic anhydride was purchased through Gelest.

\subsection{MSN-10}

Procedure from (reference) was followed for the synthesis of MSN-10. The non-ionic surfactant Pluronic ${ }^{\circledR}$ P104 (7.0 g) was added to $1.6 \mathrm{M} \mathrm{HCl}(273.0 \mathrm{~g})$. After stirring for $1 \mathrm{~h}$ at $55{ }^{\circ} \mathrm{C}$, tetramethylorthosilicate (TMOS, $10.64 \mathrm{~g}$ ) was added and stirred for an additional $24 \mathrm{~h}$. The resulting mixture was further post-hydrothermal treated for $24 \mathrm{~h}$ at $150{ }^{\circ} \mathrm{C}$ in a highpressure reactor. Upon cooling to room temperature, the white solid was collected by filtration, washed with copious amounts of methanol and dried in air. To remove the 
surfactant P104, the silica material was heated at a ramp rate of $1.5^{\circ} \mathrm{C}$ min-1 and maintained at $550{ }^{\circ} \mathrm{C}$ for $6 \mathrm{~h}$.

\subsection{MSN-3}

A $1000 \mathrm{~mL}$ round bottom flask was charged with $1.0 \mathrm{~g}$ CTAB, $480 \mathrm{~mL}$ nanopure water, $3.5 \mathrm{~mL} 2 \mathrm{M} \mathrm{NaOH}$, and a magnetic stir bar. The mixture was heated to 80 and was allowed to stir for one hour until it reached a thermal equilibrium. $5 \mathrm{~mL}$ tetraethylorthosilicate (TEOS) was added to the mixture concurrently with the desired silane functionalize in situ. The reaction mixture was allowed to stir for $2 \mathrm{hrs}$ at 80 . The solid white product was then filtered, washed with methanol, and dried overnight. The surfactant was removed by stirring in a mixture of $100 \mathrm{~mL}$ methanol and $2 \mathrm{~mL}$ of $2 \mathrm{M} \mathrm{HCl}$ per gram of material.

\subsection{Silver dicarboxylate MSN}

Silver dicarboxylate functionalized MSN was prepared by addition of 3(triethoxysilyl)propylsuccinic anhydride during the synthesis described above (cocondensation) followed by base-catalyzed ring opening and ion exchange with a silver nitrate solution. The ring opening was performed by adjusting the $\mathrm{pH}$ of an aqueous solution to 9, followed by the addition of the MSN to the solution. The mixture was stirred for four hours and filtered and washed with water and methanol.

\subsection{MSN-5}

A $1000 \mathrm{~mL}$ round bottom flask was charged with $1.0 \mathrm{~g} \mathrm{CTAB}, 480 \mathrm{~mL}$ nanopure water, $3.5 \mathrm{~mL} 2 \mathrm{M} \mathrm{NaOH}$, and a magnetic stir bar. The mixture was heated to 80 and was allowed to 
stir for one hour until it reached a thermal equilibrium. $8 \mathrm{~mL}$ mesitylene was added to the mixture and allowed to dissociate for an additional hour. $5 \mathrm{~mL}$ tetraethylorthosilicate (TEOS) was added to the mixture concurrently with the desired silane functionalize in situ. The reaction mixture was allowed to stir for $2 \mathrm{hrs}$ at 80 . The solid white product was then filtered, washed with methanol, and dried overnight. The surfactant was removed by stirring in a mixture of $100 \mathrm{~mL}$ methanol and $2 \mathrm{~mL}$ of $2 \mathrm{M} \mathrm{HCl}$ per gram of material.

\subsection{Adsorption Experiments}

Adsorption experiments were conducted using a 16 × $125 \mathrm{~mm}$ culture tube. Silica adsorption material (15 mg) was suspended in a $10-\mathrm{mL}$ hexane solution containing: hexadecanoic acid, 7-hexadecenoic acid, and eicosapentaenoic acid for $2 \mathrm{~h}$. The adsorbate was separated from the solution using centrifugation and the hexanes removed from the supernatant by a rotary evaporator. The remaining solid was suspended in a $1 \mathrm{~N}$ $\mathrm{HCl} / \mathrm{Methanol}$ solution and esterified by stirring at $80 \mathrm{C}$ for $2 \mathrm{~h}$. The FFAs were extracted with hexanes and analyzed by GC-MS.

\section{Conclusions}

It was shown that the functionality as well as the pore size of MSN can be optimized to selectively extract polyunsaturated FFAs from a mixture of FFAs commonly found in algal biomass. The best functional group was determined to be the primary amine because of the relatively simple synthesis and comparable selectivity to the silver dicarboxylate. The pore size was a large factor in the selectivity of the material with $3 \mathrm{~nm}$ pores providing the best selectivity toward polyunsaturated FFAs. This was supported by results of molecular 
modeling to approximate the size of the FFA molecules. The method presented surpasses current techniques in both selectivity and technoeconomics. Incorporating this sieve into a process would be a great deal for the pharmaceutical industry as well as the biofuel industry.

\section{References}

(1) Hong, M.-P.; Kim, H. I.; Shin, Y. K.; Lee, C. S.; Park, M.; Song, J.-H. Brain Research 2004, 1008, 81.

(2) Ward, O. P.; Singh, A. Process Biochemistry 2005, 40, 3627.

(3) Schmitt-Rozieres, M.; Deyris, V.; Comeau, L.-C. Journal of the American Oil Chemists' Society 2000, 77, 329.

(4) Li, M.; Pham, P. J.; Pittman, C. U.; Li, T. Microporous Mesoporous Mater. 2008, $117,436$.

(5) A. Srinivas Reddy, G. M. S., and G. Narahari Sastry Wiley InterScience 2007, 67, 1179.

(6) Valenstein, J. S.; Kandel, K.; Melcher, F.; Slowing, I. I.; Lin, V. S. Y.; Trewyn, B. G. ACS Appl. Mater. Interfaces, Ahead of Print. 


\title{
CHAPTER 4. PARAMETERS AFFECTING THE EFFICIENT DELIVERY OF MESOPOROUS SILICA NANOPARTICLE MATERIALS AND GOLD NANORODS INTO PLANT TISSUES BY THE BIOLISTIC METHOD
}

\author{
Modified from a paper published in Small 2012, 8(3), 413 \\ Susana Martin-Ortigosa, Justin Valenstein, Wei Sun ${ }^{1}$, Lorena Moeller ${ }^{2}$, Ning Fang, Brian G. \\ Trewyn, Victor S.-Y. Lin", and Kan Wang* \\ \# Deceased May 4, 2010 \\ In memory of Professor Victor S.-Y. Lin
}

\begin{abstract}
Application of nanotechnology to plant science requires efficient delivery systems of nanoparticles (NPs) to plant cells and tissues. The presence of a cell wall in plant cells make them challenging to extend NP delivery methods available for animal research. In this work, we present research establishing an efficient NP delivery system for plant tissues using the biolistic method. We show that biolistic delivery of the mesoporous silica nanoparticle (MSN) materials can be improved by increasing the density of MSN through gold plating. Additionally, we use a DNA coating protocol based on calcium chloride and spermidine for MSN and gold nanorods to enhance the NP-mediated DNA delivery. Furthermore, we demonstrate that NPs delivery can be drastically improved when they are combined with 0.6 $\mu \mathrm{m}$ gold particles during bombardment. The methodology described here provides an efficient NPs delivery system into plant cells using the biolistic method.
\end{abstract}




\section{Introduction}

The application of nanotechnology to biological sciences has brought a revolution in many areas because of the unique characteristics and potentials of nanoparticles (NPs). The main applications of nanobiotechnology include biological sensing, imaging, cell targeting and drug delivery among others ${ }^{[1-4]}$. Nanotechnology has been expanding into animal and human biology research mainly because cells can readily uptake NPs. However, the utility of NPs in plant science remains limited due to a characteristic architectural feature of the plant cells, the cell wall, which restricts their uptake ${ }^{[5]}$. This could be the reason why the convergence between nanotechnology and plant biology has been limited to passive uptake, monitoring and phytotoxicity of different NPs in planta $^{[6-7]}$ or the biological synthesis of NPs ${ }^{[8]}$. Even though bombardment ${ }^{[9-10]}$, injection ${ }^{[11-12]}$ and ultrasonication ${ }^{[13-14]}$ methods have been used for NP delivery into plant cells, the most common methods involve passive introduction, such as leaf uptake ${ }^{[12,15-16]}$, protoplast or tissue incubation and root uptake ${ }^{[17-30]}$. Because the passive uptake processes of NPs can vary depending on the size $\mathrm{e}^{[11-12,15-16,31]}$ and properties ${ }^{[32]}$ of NPs and the types of plant tissues or cell structures ${ }^{[33]}$, it is challenging to control the delivery and function of the NPs in the particular tissues or cells that are targeted.

One of the most powerful tools for plant biotechnologists is the biolistic system for plant genetic transformation. This method has been used for the delivery of DNA into nuclear or plastid genomes of multiple plant species ${ }^{[34-35]}$. A gene gun allows for the mechanical introduction of DNA coated microcarriers, made of solid tungsten or gold with diameters ranging between $0.4-1.5 \mu \mathrm{m}$, into plant cells. The introduction of these microcarriers inside plant cells through bombardment relies on the acceleration during the shot and therefore, is dependent on their size and density. Bombardment can be considered 
an attractive alternative to the passive NP uptake methods, and in fact, gene guns have been used already to introduce NPs into animal ${ }^{[36-38]}$ and plant ${ }^{[9-10]}$ cell systems. The NPs delivered to plant cells by the biolistic method were mesoporous silica nanoparticles (MSN) in tobacco plantlets and maize immature embryos ${ }^{[10]}$ and nanodiamonds in banana fruits ${ }^{[9]}$. In both cases the efficiency of NP delivery was not studied or optimized.

We intend to develop an efficient NP delivery system to plant cells through the biolistic method. The purpose of this work is not to simply test the nucleic acid delivery abilities of NPs, because the current biolistic method (using either gold or tungsten microparticles) can deliver DNA and RNA molecules to plant tissues rather effectively. We are interested in developing systems that would allow, for example, the NP-mediated delivery of other biomolecules (such as chemicals or proteins) that cannot be delivered by the current methods. In our previous study ${ }^{[10]}$, we were able to encapsulate $\beta$-estradiol (a chemical inducer) in the pore matrix and coat DNA carrying an $\beta$-estradiol-induced marker gene on the exterior of gold capped MSN. Both the inducer and inducible gene were delivered into plant tissues simultaneously and performed their functions.

The type of particle used in the biolistic method is one of the most important parameters that affect delivery ${ }^{[39]}$. Therefore, one of major challenges for the delivery of NPs to plant cells is their small sizes and low weights comparing to any typical microcarries used in plant transformation. For DNA delivery, small size and surface characteristics of NPs could also attribute to the inefficient delivery due, partially to poor binding/attachment of DNA and NPs. Most published protocols used simple NP and DNA incubation steps and, depending on the nature of NPs, usually a surface functionalization step was required to promote binding ${ }^{[2,38]}$. To overcome these problems, we focused our research on the 
improvement of the NP density, the NP-DNA coating protocols as well as parameters in the biolistic delivery system such as: (1) increasing the density by gold plating MSN surfaces; (2) using the $\mathrm{CaCl}_{2} /$ Spermidine DNA coating protocol for enhanced DNA-NPs attachment; (3) co-bombarding NPs with $0.6 \mu \mathrm{m}$ gold microparticles (GPs) and DNA. These improvements were tested over two distinct types of NPs used for different biological applications, MSN and gold nanorods (NRs), and can provide a promising way to expand the utility of nanobiotechnology to plant sciences.

\section{Results \& Discussion}

\subsection{Improvement of MSN delivery in plant cells by altering particle properties, DNA coating procedure and bombardment parameters}

\subsubsection{Increasing the density of MSN by gold plating}

Because one of the parameters affecting particle delivery is its density, we first explored to modify this property of MSNs. In this study, we used MSN with $10 \mathrm{~nm}$ pore size $(\mathrm{MSN}-10)^{[40]}$. These MSN were around $600 \mathrm{~nm}$ in diameter (Figure 1a) but their porous structure and the lower density of the silica material made them much lighter than a gold particle of the same size, a scanning electron micrograph (SEM) can be seen in Figure 1b.

To increase the density of MSN, two different strategies were designed: (1) capping

of the pores of the MSN with gold NPs (Figure 1a, Au ${ }^{\text {Capped }}-\mathrm{MSN}-10$ ) or (2) gold plating of the MSN surface. The first approach is analogous to the one we described previously ${ }^{[10]}$, which was proven to allow for controlled release of the encapsulated cargo and to increase the performance of the bombardment of plant tissues.

The second approach involved plating gold on the surface of the MSN including the pore walls, a procedure that was repeated multiple times to increase the surface gold loading 
and, thus, the density of the MSN. In this example, MSN-10 were gold-plated 1, 2 or 3 times resulting in the $1 \mathrm{x}, 2 \mathrm{x}$ or $3 \mathrm{xAu}{ }^{\text {Plated }}-\mathrm{MSN}-10$ (Figure 1a), respectively. Transmission electron microscopy (TEM) and scanning transmission electron microscopy (STEM) images of these MSN are presented in Figure 1c and 1d. As is observed in Fig. 1d, the gold plating steps have produced gold nanoparticles attached to the surfaces of MSN-10, which can be seen as white dots.
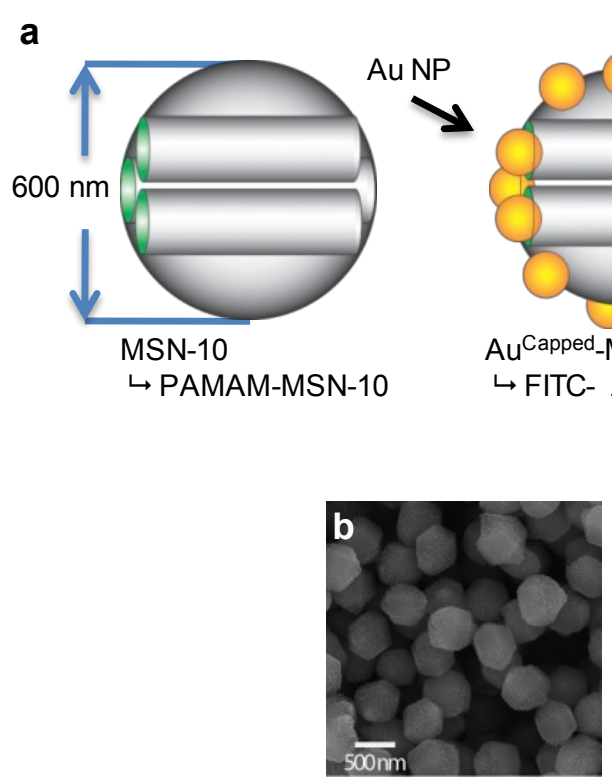

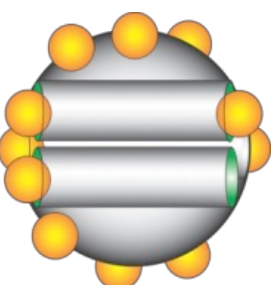

AuCapped_MSN-10

$\hookrightarrow$ FITC- AuCapped_MSN-10

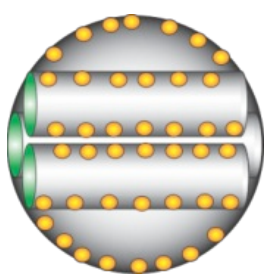

$1 \times A u$ Plated-MSN-10

$\rightarrow$ IL-1XAuPlated $-M S N-10$

2xAuPlated $-M S N-10$

$3 \times$ A Plated $_{\text {PSN-10 }}$

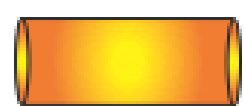

Au Nanorod $25 \times 73 \mathrm{~nm}$
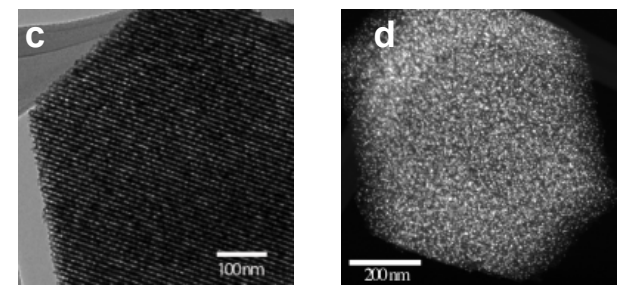

Figure 1. a) Schemes of the 3 different classes of MSN and gold NR used in this work. From left to right: MSN-10, and the

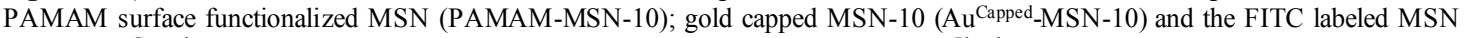

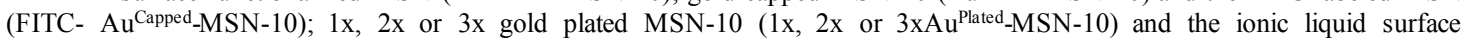

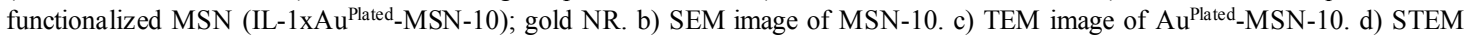
image of $\mathrm{Au}^{\text {Plated-MSN-10. }}$

The most unique feature of MSN is the high surface area and relatively large pore size. These properties allow for the incorporation of gold via our plating method. As seen in Table 1, the gold plating procedures decreased both the surface area and the pore volume of the MSN, but the final value can be considered sufficient for the encapsulation of molecules. The density of silica is $2.2 \mathrm{~g} \mathrm{~mL}^{-1}$ and the density of gold is $19.3 \mathrm{~g} \mathrm{~mL}^{-1}$. Therefore, any amount of gold coated on the surfaces should increase the density of the MSN. Increasing the 
density provides the NPs more momentum during the bombardment and is expected to improve the amount of NPs introduced into plant cells. Both the gold capping and gold plating processes involve the use of gold to increase the density, but the gold plating technique seems to allow more gold due to the amount of surface area capable of plating compared to the number of pores that can be capped per MSN. The gold plating method can be considered more straightforward technique that does not involve the synthesis of gold NPs, attachment to the pore entrances, and subsequent uncapping to release the encapsulated molecules.

Table 1. Pore volume and surface area of MSN-10

subjected to 1, 2 or 3 gold plating procedures.

\begin{tabular}{lcc}
\hline & $\begin{array}{c}\text { Surface area } \\
{\left[\mathrm{m}^{2} / \mathrm{g}\right]}\end{array}$ & $\begin{array}{c}\text { Pore volume } \\
{[\mathrm{mL} / \mathrm{g}]}\end{array}$ \\
\hline MSN-10 & 385 & 1.04 \\
1xAu ${ }^{\text {Plated }}-\mathrm{MSN}-10$ & 351 & 0.98 \\
2xAu ${ }^{\text {Plated }}-\mathrm{MSN}-10$ & 318 & 0.89 \\
$3 \times \mathrm{Au}^{\text {Plated }}-\mathrm{MSN}-10$ & 308 & 0.88 \\
\hline
\end{tabular}

\subsubsection{DNA coating procedures onto the nanoparticles}

DNA or RNA delivery to living cells is one of the most important tools in biotechnology. When this delivery is mediated through NPs it usually relies on the ability of their surface to bind electrostatically to the negatively charged nucleic acid molecules. In our previous work, the NP-DNA coating was done by simple incubation, namely, DNA and MSN were incubated in water for 2 hours before bombarded into plant cells ${ }^{[10]}$. To improve the MSN-DNA binding capability, we tested two surface functionalization methods to provide an overall positive charge on the MSN-10, which as a consequence, will be 
electrostatically attracted to negatively charged DNA. PAMAM-MSN-10 (Figure 1a) was surface functionalized with a polyamidoamine dendrimer (PAMAM) layer that improved the MSN-DNA complexation and consequently DNA transfection ${ }^{[41]}$. IL-1xAu ${ }^{\text {Plated }}$-MSN-10 (Figure 1a) was covalently surface functionalized with the ionic liquid (IL), 1-propyl-3methylimidazolium bromide, to maintain a permanent positive charge on the MSN.

The negatively charged nature of MSN-10 was reflected on its negative zeta potential $(-28.0 \mathrm{mV})$, while the surface functionalized PAMAM-MSN-10 and IL-1xAu ${ }^{\text {Plated }}$-MSN-10 had +30.0 and $+28.1 \mathrm{mV}$, respectively. This change in the MSN surface charge led to an improved DNA binding after a one-hour incubation period. The DNA-MSN complexation experiments (Figure 2a) showed how both functionalized MSN, PAMAM-MSN-10 and IL$1 \times u^{\text {Plated }}-\mathrm{MSN}-10$, had a nearly complete DNA complexation in the 1:10 (DNA:MSN) ratio, while $1 \mathrm{xAu}^{\text {Plated }}-\mathrm{MSN}-10$ did not retain any of the DNA even with 1:50 ratio. This result suggests that both functionalizations have enhanced the DNA binding capacity of the MSN-10 or $1 \times \mathrm{Au}^{\text {Plated }}-\mathrm{MSN}-10$. 
a

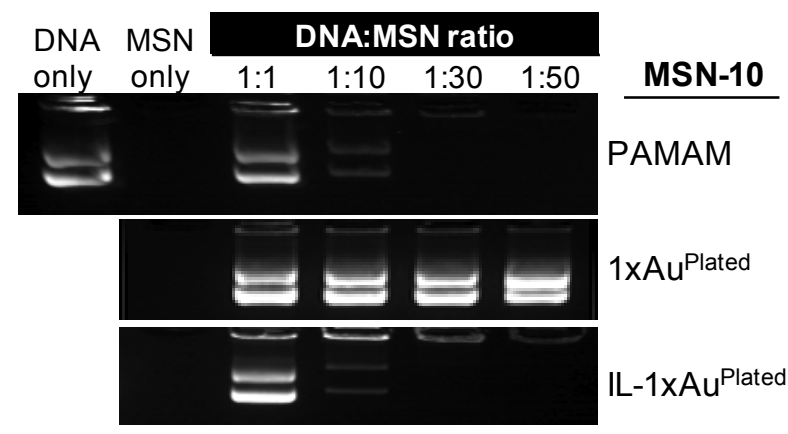

b

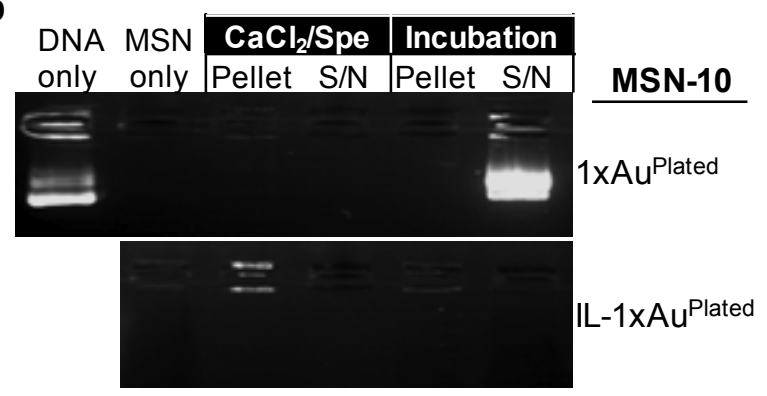

Figure 2. a) Agarose gel electrophoresis images of DNAMSN complexation experiments of PAMAM-MSN-10, $1 \mathrm{xAu}^{\text {Plated }}$-MSN-10 and IL-1xAu ${ }^{\text {Plated }}$-MSN-10 at different ratios with $1 \mu \mathrm{g}$ of DNA after 1 hour incubation at RT. b) Agarose gel electrophoresis of the comparison of the $\mathrm{CaCl}_{2} / \mathrm{Spe}$ and incubation DNA coating protocols done with 1 $\mu \mathrm{g}$ of plasmid DNA and $100 \mu \mathrm{g}$ of $1 \mathrm{xAu}^{\text {Plated }}$-MSN-10 or IL$1 \mathrm{xAu} u^{\text {Plated }}$-MSN-10. The pellet (DNA coated MSN) or the supernatant $(\mathrm{S} / \mathrm{N}$, free DNA) were loaded for each procedure.

To quantitatively test the differences of these NPs and other parameters in plant cells through biolistic transformation, we measured the number of fluorescent cells in onion epidermis tissues one day after they were bombarded with MSN coated with GFP or mCherry expressing plasmid DNA. The tissue can be cut into flat rectangles containing homogeneous shaped cells that facilitate the comparison between replicates and offered excellent fluorescent imaging properties.

As seen in Figure 3a (white bars, Incubation), under the same gene gun conditions, more cells were transiently expressing mCherry after bombardment with the surface functionalized IL-1xAu ${ }^{\text {Plated }}-\mathrm{MSN}-10 \quad(10.66 \pm 5.66)$ than with the non-functionalized $1 \times u^{\text {Plated }}-\mathrm{MSN}-10(0.33 \pm 0.33)$. This result demonstrates that the positively charged MSN provides an advantage for DNA expression in living cells than the non-functionalized one, likely due to more DNA coated MSN delivered into plant cells. 
In a typical biolistic-mediated plant transformation procedure, DNA molecules are coated onto gold or tungsten microparticles by $\mathrm{CaCl}_{2}$ and spermidine $\left(\mathrm{CaCl}_{2} / \mathrm{Spe}\right)$ prior to bombardment ${ }^{[42-43]}$. We compared the DNA-MSN incubation method with $\mathrm{CaCl}_{2} / \mathrm{Spe}$ DNA coating protocol ${ }^{[44]}$ using $1 \mathrm{xAu}^{\text {Plated }}$-MSN-10 (negatively charged surface) and IL-1xAu ${ }^{\text {Plated }}$ MSN-10 (positively charged surface). In the MSN-DNA complexation experiments (Figure $2 b$ ) we tested the amount of DNA and MSN used per shot in a bombardment procedure for both coating protocols. The incubation protocol worked only with the positively charged

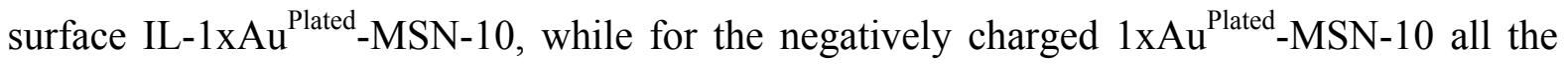
DNA was found free in the supernatant. The $\mathrm{CaCl}_{2} / \mathrm{Spe}$ protocol, on the other hand, permitted DNA complexation in both types of MSN, regardless of the charge of their surface (Figure $2 \mathrm{~b}$ ). We tested this ability on bombarded onion epidermis cells. For the same gene gun conditions, the $\mathrm{CaCl}_{2} / \mathrm{Spe}$ DNA coating protocol worked significantly better $(\mathrm{P}=$ 0.0182) than the incubation (Figure 3a). Using the $\mathrm{CaCl}_{2} / \mathrm{Spe}$ coating protocol we were able to coat DNA onto various NPs and bombard different plant tissues. Figure $3 \mathrm{~b}$ shows the delivery of either GFP or mCherry expressing plasmids coated onto various types of NPs such as NRs, $\mathrm{Au}^{\text {Capped }}-\mathrm{MSN}-10$ and FITC- $\mathrm{Au}^{\text {Capped }}-\mathrm{MSN}-10$ (Figure 1a), into onion epidermis, maize and tobacco leaves. We were also able to coat two different plasmids simultaneously onto the NPs, which resulted in the co-expression of both GFP and mCherry in same cells (data not shown).

The delivery of DNA or RNA molecules by NPs into plant cells has been reported. In all cases, the DNA-NP coating was done after $20 \mathrm{~min}$ to $12 \mathrm{~h}$ incubation ${ }^{[10,14,18,23,28,45]}$. In some cases, adding an L-lysine solution ${ }^{[14]}$, an ultrasonication step $^{[18]}$ or an amino functionalization to the $\mathrm{NP}^{[45]}$ had to be done to promote a DNA-NP complexation. We have 
shown that the $\mathrm{CaCl}_{2}$ /Spe DNA coating protocol is efficient in different types of NPs, regardless of their ionic nature. Therefore, this coating protocol is used in the rest of the experiments reported here unless otherwise indicated. This procedure may help to reduce the reliance of surface functionalization of NPs in DNA delivery, thus making it easier for the design and manufacture of the NPs.

\subsubsection{Parameters affecting nanoparticle delivery to plant cells through biolistics}

To improve the NP delivery efficiency in plant tissues or cells, we tested a number of parameters used in the biolistic system, including target distances and the type of rupture disk. In our previous work, we used 650 psi rupture disks and $10 \mathrm{~cm}$ target distance for tobacco leaves and maize immature embryos ${ }^{[10]}$. Bombardment of onion epidermis tissue with $\mathrm{Au}^{\text {Capped }}$-MSN-10 showed that the rupture disks for higher pressures (1350 or 1550 psi) and smaller target distances $(4 \mathrm{~cm}$ ) resulted in an improved transient expression (data not shown). We also confirmed that twice bombarded samples had more cells transiently expressing the fluorescent proteins than the cells bombarded only once, which is in agreement with an earlier publication ${ }^{[46]}$. Therefore, all DNA-NP delivery data presented in this report utilized the twice bombardment protocol for each sample unless otherwise indicated.

Figure 4a shows the data comparing MSN-10 and the gold plated 3xAu ${ }^{\text {Plated }}-\mathrm{MSN}-10$ (Figure 1a), using 5 different rupture disks. As can be seen, the number of fluorescent plant cells bombarded with MSN-10 and 3xAu ${ }^{\text {Plated }}-\mathrm{MSN}-10$ did not differ much when using rupture disk types 650, 900 and 1100 psi, respectively. However, the number of fluorescent cells after bombardment with $3 \times \mathrm{Au}^{\text {Plated }}$-MSN-10 increased significantly when using rupture 
disk types 1350 and $1550 \mathrm{psi}(\mathrm{P}=0.0017)$. These data demonstrated that the increase in the density acquired during the gold plating of $3 \mathrm{xAu}^{\text {Plated }}-\mathrm{MSN}-10$ improved its performance comparing to the MSN-10 when higher pressures are used.

a

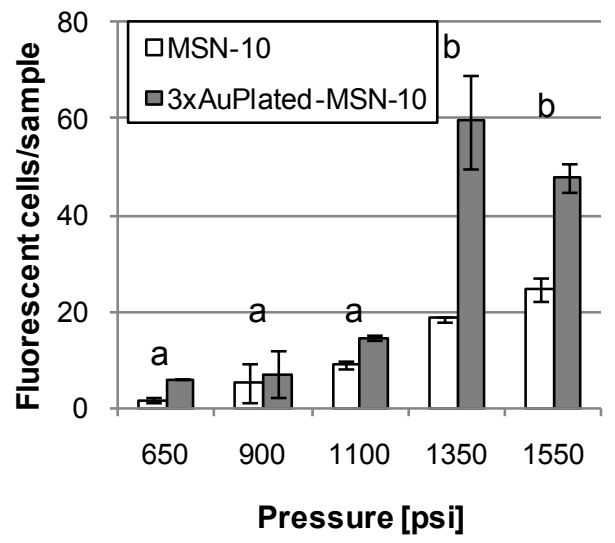

b

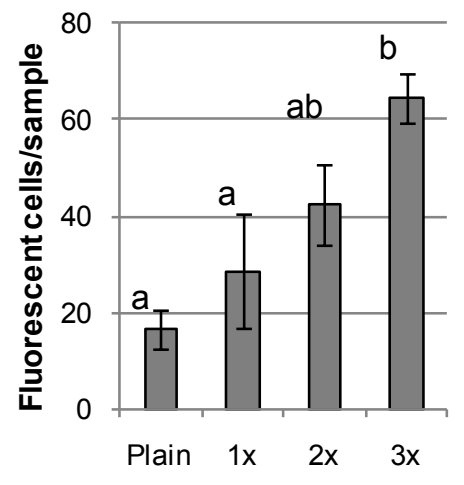

Gold plating procedures
C

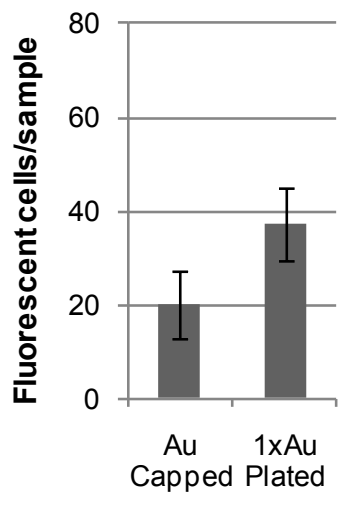

Type of MSN-10

Figure 4. a) Effects of rupture disk types on MSN-10 and 3xAu Plated-MSN-10 delivery efficiency. b) Effects of gold plating rounds $\left(\mathrm{MSN}-10,1 \mathrm{x}, 2 \mathrm{x}\right.$ and $\left.3 \mathrm{xAu}^{\text {Plated }}-\mathrm{MSN}-10\right)$ on delivery efficiency. c) Comparison of the bombardment

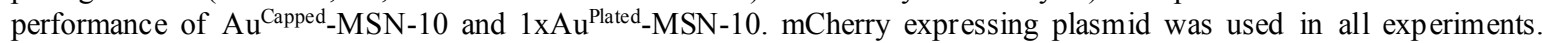
Number of red fluorescent cells per sample $(2 \mathrm{~cm}$ x $3.5 \mathrm{~cm}$ onion epidermal tissue) was scored one day after bombardment using a 10X objective of Zeiss Axiostar plus microscope. Bars in the graphs labeled with different letters indicate significantly different means according to Duncan's New Multiple Range Test $(\alpha=0.05)$.

We also compared the delivery of four different types of gold-plated MSN-10 (MSN$10,1 \mathrm{x}, 2 \mathrm{x}$ and $3 \mathrm{xAu^{ \text {Plated } }}$-MSN-10) in bombarded onion epidermis cells under the same gene gun conditions (1350 psi rupture disk and $4 \mathrm{~cm}$ target distance). As shown in Figure 4b, each time MSN-10 went through a gold plating process, the increase in density enhanced its delivery to plant cells, which can be indirectly measured by the increasing number of cells expressing mCherry. The optimal MSN for DNA delivery was $3 \mathrm{xAu}^{\text {Plated }}-\mathrm{MSN}-10$, as was determined by the significantly greater number of fluorescent cells $(\mathrm{P}=0.015)$ than MSN-10 or $1 \mathrm{x}$ or $2 \mathrm{xAu}^{\text {Plated }}$-MSN-10 (Figure $4 \mathrm{~b}$ ).

This is the first time, to the best of our knowledge, that the gold plating technique is used to treat the MSN for enhancing the performance of delivery to plant cells by the biolistic 
method. The $1 \mathrm{xAu}^{\text {Plated }}$-MSN-10 also showed better performance than the $\mathrm{Au}^{\text {Capped }}-\mathrm{MSN}-10$ (Figure 4c). Compared to the $\mathrm{Au}^{\text {Capped }}$-MSN, the $\mathrm{Au}^{\text {Plated }}$-MSN is easier to manufacture and allows for more functionalization. For example, we are limited to just gold nanoparticles as

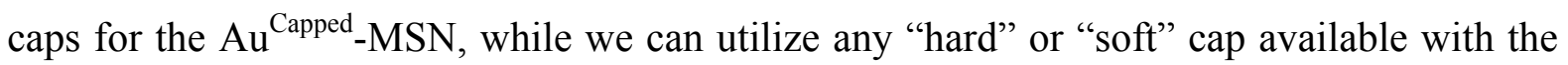
$\mathrm{Au}^{\text {Plated }}-\mathrm{MSN}^{[47]}$. This allows us more freedom to design a delivery system tailored around the cell type and cargo of interest. While each gold-plating process increases the density of MSN, it also decreases surface area and pore volume proportionally (Table 1). Therefore, a balance between those factors needs to be determined and tested for each case.

\subsection{Co-bombardment of nanoparticles with solid $0.6 \mu \mathrm{m}$ gold microparticles for efficient delivery through the biolistic method}

In an attempt to extend the biolistic delivery system for plant cells to different types of NP, we explored the possibility of utilizing the commercially available $0.6 \mu \mathrm{m}$ gold particles (GP), a standard microcarrier for delivering DNA in biolistic-mediated plant transformation, as a microcarrier for various NPs. It was hypothesized that the NPs would attach to the GP in the presence of DNA molecules and/or chemicals such as $\mathrm{CaCl}_{2}$ and spermidine. This type of NP-GP-DNA complex would more readily penetrate plant tissues through bombardment.

Using two types of NPs different in size and nature, $\mathrm{Au}^{\text {Capped }}$-MSN-10 or gold NRs (Figure 1a), we tested four different treatments involving different NP, GP, and DNA combinations and delivery strategies. Figure 5a summarizes the four treatments and results. In Treatment \#1 (Figure 5a, S1:cNP/S2:cNP), plant samples were bombarded twice with either DNA-coated NRs (mCherry NR) or MSN (mCherry MSN). This treatment yielded $4 \pm 3$ (NR) or $12 \pm 11$ (MSN) fluorescent cells per sample on average as was typically observed in 
our study. In Treatment \#2 (Figure 5a, S1:GP/S2:cNP), the samples were first bombarded with the GP followed by a second shot with the DNA coated NPs. This was to test whether the holes on the cell walls made by the GPs would ease the following NP introduction. However, this treatment did not enhance the delivery of NP-DNA into plant cells as indicated by the number of fluorescent cells $(4 \pm 1$ and $27 \pm 15$ for NR and MSN, respectively). 
a

Treatment

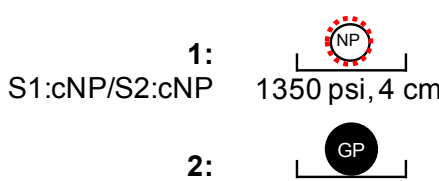

S1:GP/S2:cNP $1100 \mathrm{psi}, 6 \mathrm{~cm}$

3:

$\mathrm{S} 1: \mathrm{GP}+\mathrm{CNP}$

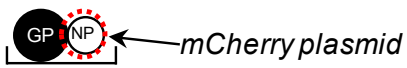

4: $1100 \mathrm{psi}, 6 \mathrm{~cm}$

$\mathrm{S} 1:(\mathrm{c}(\mathrm{cNP}) \mathrm{GP})$

\section{Shot 2}
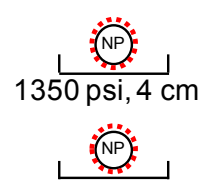

$1350 \mathrm{psi}, 4 \mathrm{~cm}$

Cherry plasmid

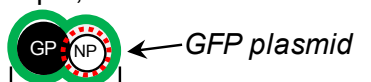

$1100 \mathrm{psi}, 6 \mathrm{~cm}$ b

Bright field
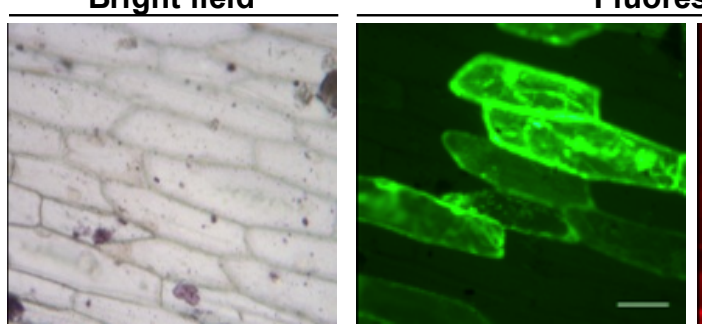

d

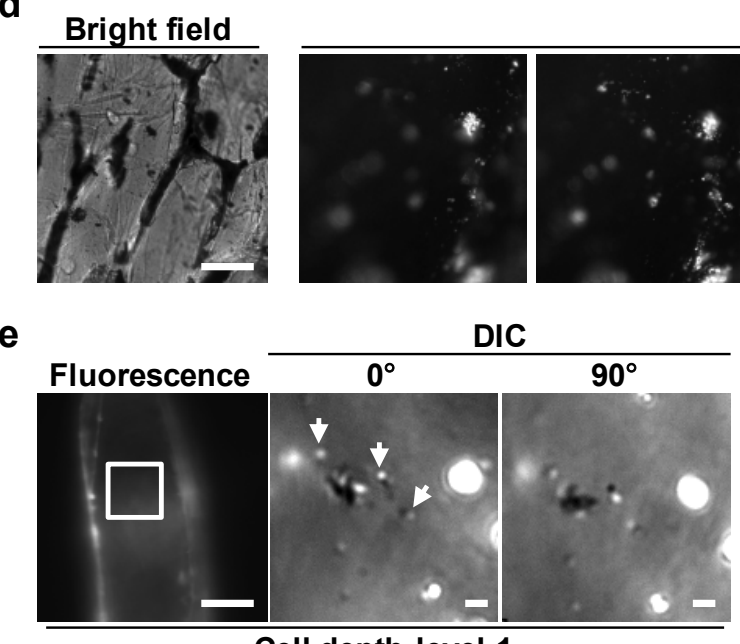

e

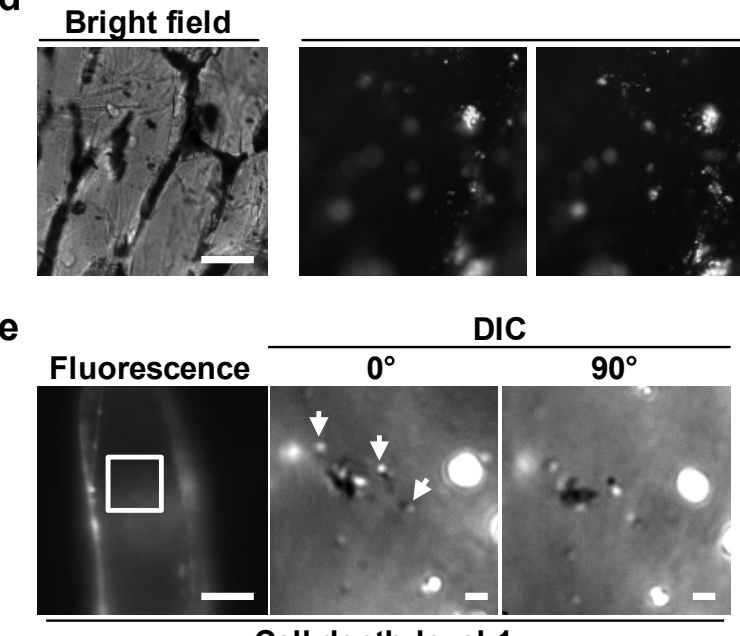

Cell depth level 1
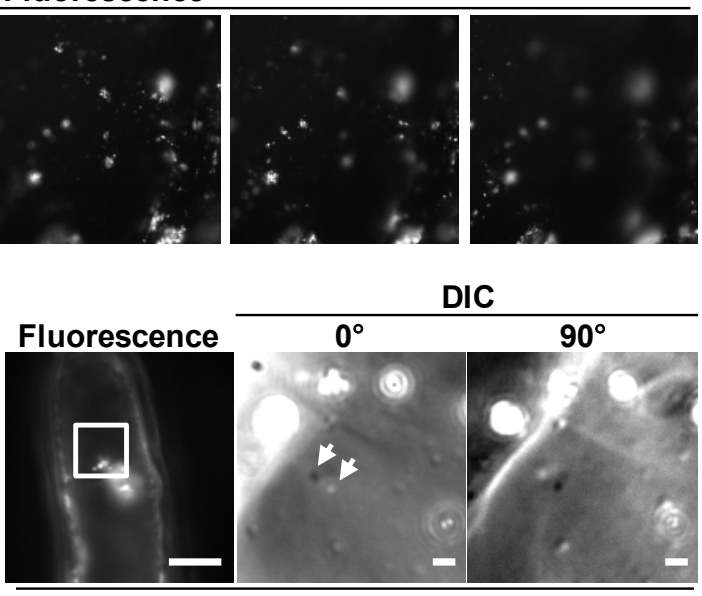

Cell depth level 2

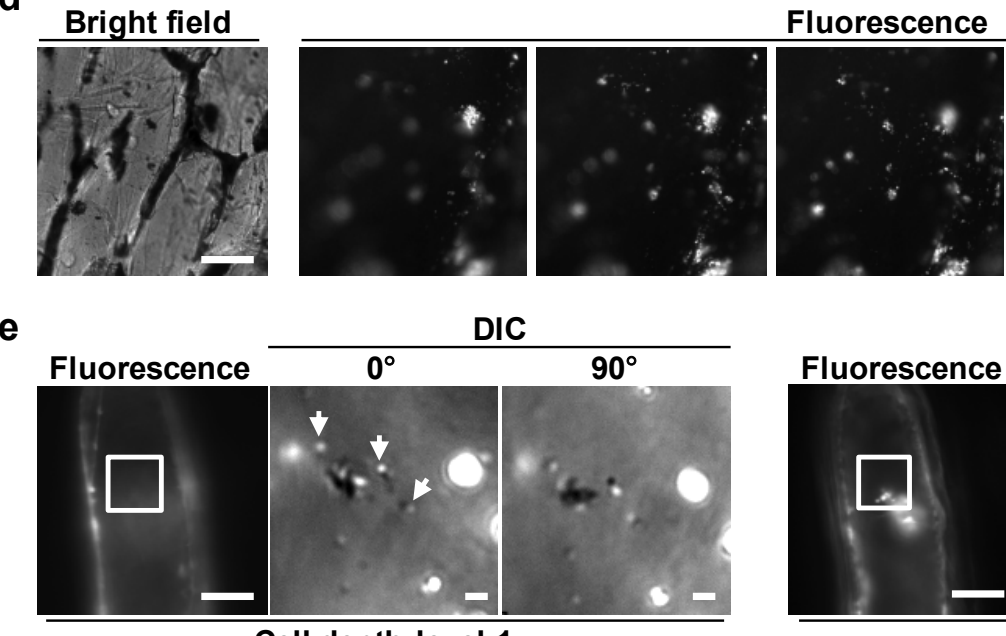

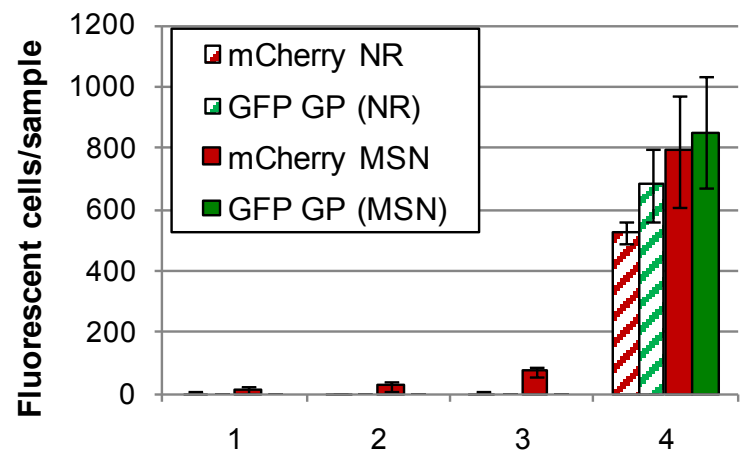

Bombardment treatment
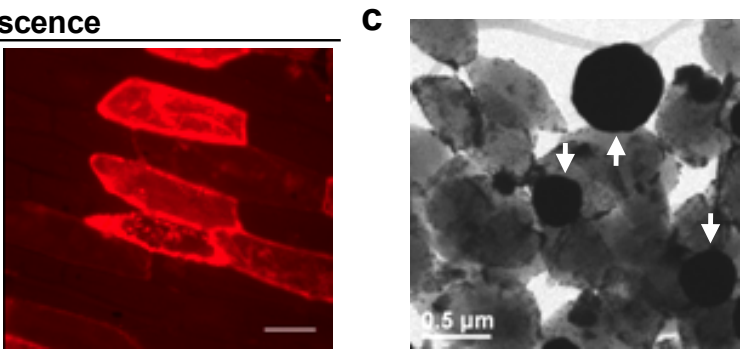

Figure 5. a) Schemes showing NP ( $\mathrm{Au}^{\text {Capped }}$-MSN-10 or gold NRs)-GP co-bombardment treatments (left) and graph showing the effects in NPs delivery to onion epidermis cells (right). Treatment \#1 (S1:cNP/S2:cNP): two shots with mCherry expressing plasmid coated NPs. Treatment \#2 (S1:GP/S2:cNP): first shot with uncoated $0.6 \mu \mathrm{m}$ gold and second shot with coated NPs. Treatment \#3 (S1:GP+cNP): the macrocarrier was loaded first with an aliquot of uncoated $0.6 \mu \mathrm{m}$ gold and after the DNA coated NPs. One shot of this mixture was bombarded to plant tissues. Treatment \#4 (S1:(c(cNP)GP)): one shot with a double DNA coating procedure, first mCherry expressing plasmid is coated onto NPs and then, a second coating procedure is made to the mixture of these particles, $0.6 \mu \mathrm{m}$ gold and GFP expressing plasmid. S1: shot 1; S2: shot 2; NP: nanoparticle; GP: $0.6 \mu \mathrm{m}$ gold; cNP, cNR and cMSN: coated NP, NR or MSN respectively. In Treatments \#2 and 3 where uncoated $0.6 \mu \mathrm{m}$ gold was used, $2 \mu 1$ aliquot of $0.6 \mu \mathrm{m}$ gold (from a $30 \mu \mathrm{g} \mu \mathrm{L}^{-1}$ in sterile $\mathrm{ddH}_{2} \mathrm{O}$ stock) was centrifuged at $5000 \mathrm{rpm}$, removed the supernatant, resuspended in $5 \mu 1$ of ethanol and loaded in the macrocarrier. b) Bright field and fluorescence images of onion epidermis cells expressing GFP and mCherry after co-bombardment with the $\mathrm{Au}^{\text {Capped }}{ }_{-M S N}-10$ and $0.6 \mu \mathrm{m}$ gold complex $\left.\mathrm{c}\left(\mathrm{c}\left(\mathrm{Au}^{\mathrm{Capped}}{ }_{-\mathrm{MSN}}-10\right) \mathrm{GP}\right) . \mathrm{Bar}=100 \mu \mathrm{m} . \mathrm{c}\right)$ TEM image of the (c(cAu $\left.\left.{ }^{\text {Capped}}-M S N-10\right) G P\right)$ complex. d) Onion epidermis tissue bombarded with S1:c(FITC- Au ${ }^{\text {Capped-MSN- }}$ $10+\mathrm{GP}$ ) complex. Bright field image on the left and then subsequent fluorescence images of a $\mathrm{Z}$ stack of the tissue in which focused MSN can be seen along the depth of the cell. Bar $=10 \mu \mathrm{m}$, distance between $\mathrm{Z}$ stack images $=1.5 \mu \mathrm{m}$. e) Two layers in different depth levels of a mCherry expressing onion epidermis cell after bombardment with $\mathrm{S} 1: \mathrm{c}(\mathrm{NR}+\mathrm{GP})$ complex. For each layer the fluorescence image (left) and an amplified image corresponding to the white square of the 2 consecutive and rotated $\left(0\right.$ and $\left.90^{\circ}\right)$ DIC images are shown. In these images several nanorods (pointed with white arrows) can be detected by the change on light emission on the rotated images. Bar in fluorescence images $=50 \mu \mathrm{m}$; in DIC images $=1 \mu \mathrm{m}$. 
In Treatment \#3 (Figure 5a, S1:GP+cNP), GP was first loaded onto the macrocarrier followed by the loading of DNA-coated NPs, and plant tissues were bombarded once. In this treatment, a slight increase of red fluorescent cells $(76 \pm 15)$ can be observed in samples bombarded with GP+MSN complex (mCherry MSN). The results of Treatment \#2 and \#3 suggested that the delivery of MSN, not nanorod, could be enhanced by the mixture of DNAcoated NPs and GP on the macrocarrier.

In Treatment \#4 (Figure 5a, S1:c(cNP)GP)), we first coated the mCherry expressing plasmid DNA onto the NPs and then, we washed the coated NPs 3 times with ethanol to get rid of any free DNA molecules. We then added the GP and a GFP expressing plasmid DNA for a second round of the $\mathrm{CaCl}_{2} / \mathrm{Spe}$ coating procedure. Plant tissues were bombarded once using this $\mathrm{c}(\mathrm{cNP}) \mathrm{GP}$ complex. As can be seen in the graph of Figure 5a, this treatment led to a drastic improvement of NP delivery, indirectly indicated by the expression of both mCherry for NP delivery (mCherry NR or MSN) and GFP for GP delivery (GFP GP (NR) or (MSN)). This treatment resulted in around 130 times better for NR delivery and over 60 times in the case of MSN. Both red and green fluorescent proteins were expressed in 77\% (NR) or 93\% (MSN) of the cells, indicating the co-delivery of both GP and NPs (Figure 5b). In both MSN and NR delivery experiments, the number of green fluorescent cells was slightly higher than the red fluorescent cells. This may suggest that more GP than NP were delivered by this procedure. We also confirmed that a single DNA coating procedure for a mixture of GP and $\mathrm{NP}, \mathrm{c}(\mathrm{GP}+\mathrm{NP})$, was also effective for co-bombardment (data not shown).

We examined the $\mathrm{c}(\mathrm{GP}+\mathrm{MSN})$ complex under TEM. Figure $5 \mathrm{c}$ shows an example of a heterogeneous population of MSNs and GPs (white arrows). While this delivery strategy 
has been efficient and reproducible in our hands with onion epidermal tissues, this type of particle agglomeration can cause excessive damage to plant tissues upon bombardment. Therefore, an adequate ratio of NPs and GP and biolistic gun parameters needs to be tested for different types of plant tissues.

Further evidence for the presence of NPs inside plant cells using GP as a carrier were collected by performing optical sectioning of the sample with either fluorescence microscopy or differential interference contrast (DIC) microscopy with the aid of a high precision motorized rotary stage. As shown in Figure 5d, after the c(GP+FITC-Au $\left.{ }^{\text {Capped }}-\mathrm{MSN}-10\right)$ complex bombardment, the FITC labeled MSNs were found to be distributed in different axial planes of the bombarded onion epidermis cells, confirming the introduction of multiple MSNs inside the tissue. For NR detection we examined, after bombardment with the $\mathrm{c}(\mathrm{GP}+\mathrm{NR})$ complex, mCherry expressing onion cells. Multiple NRs (white arrows in Figure 5e) could be identified based on the change of the DIC image patterns at $0^{\circ}$ and $90^{\circ}$ : after rotating $90^{\circ}$, the DIC images of NRs changed from dark to bright or from bright to dark; while the DIC images of other cellular organelles did not have such an effect ${ }^{[48-49]}$. In addition, NRs were detected inside a red fluorescent cell at two planes located at different depths which confirms that this method can deliver multiple NRs and DNA into the same cell. This strategy also worked in different NP delivery in other plant explants like tobacco or maize leaf tissues (data not shown).

Using this co-bombardment strategy, we were able to effectively introduce two different types of NPs, MSNs and NRs, into plant cells. This suggests that the strategy may be applicable to NPs of different sizes, shapes, and properties. In mammalian cell systems, the use of a complex formed by the mixture of DNA, NPs and microparticles has been 
reported $^{[50]}$. In this case, a complex of plasmid DNA, surface functionalized $36 \mathrm{~nm}$ gold NPs and $1.5 \mu \mathrm{m}$ gold microparticles was formed by electrostatic attachment. Their goal was to deliver large amounts of DNA to mouse NIH 3 T3 fibroblast cells and ear tissue by biolistic. In our case, the particles were not subjected to any surface functionalization, smaller $(0.6$ $\mu \mathrm{m})$ microparticles were used, and only $1 \mu \mathrm{g}$ of DNA was coated using the $\mathrm{CaCl}_{2} / \mathrm{Spe}$ protocol.

\section{Conclusions}

In this study we demonstrated three methods to improve the introduction of nanoparticles and DNA into plant cells through the biolistic system. Firstly, we described, for the first time, the gold plating of MSN as a way to increase the density and performance in biolistic mediated delivery. This improvement allows us to introduce the MSNs into plant cells more efficiently. Even though this gold plating technique can diminish the porosity of MSN and, as a result, the cargo capacity, it will still help to overcome the disadvantages of bombarding plant tissues with MSNs or other types of NP, when applicable, due to their smaller size and density.

Secondly, we have shown that the $\mathrm{CaCl}_{2}$ /Spe DNA coating protocol, routinely used in gold or tungsten microparticles in plant transformation, is suitable for the NPs used in this study. Using the $\mathrm{CaCl}_{2}$ /Spe coating method, instead of DNA-NP incubation protocol, NPmediated DNA delivery efficiency can be improved. This coating method is applicable to different kinds of NP (NR and MSN) regardless of their surface ionic state. Therefore, this method could reduce the burden needed for surface functionalization steps designed to improve DNA binding capacity.

Finally, we have shown that the complex formed by NPs, GPs and DNA after 
performing the $\mathrm{CaCl}_{2} / \mathrm{Spe}$ coating protocol significantly enhances the introduction of NPs to plant cells through bombardment. For each particular case, the NP/GP ratio should be tested to balance the possible mechanical damage to plant cells upon bombardment.

Our group has previously reported the biolistic delivery of $\mathrm{Au}^{\text {capped }}-\mathrm{MSN}$ with 3-nm pore size into plant cells ${ }^{10}$. While the delivery was successful, the procedures and various parameters in the early work were not optimized. We believe that the methodology improvements presented in this work will provide an efficient method to the plant research community, therefore representing a step forward in the transfer of advantages and applications of nanobiotechnology to plant science.

\section{Experimental Section}

Mesoporous silica nanoparticle (MSN) synthesis: All the MSN-10 used were synthesized as described previously ${ }^{[40]}$. Briefly, the non-ionic surfactant Pluronic ${ }^{\circledR}$ P104 (7.0 g) was added to $1.6 \mathrm{M} \mathrm{HCl}(273.0 \mathrm{~g})$. After stirring for $1 \mathrm{~h}$ at $55^{\circ} \mathrm{C}$, tetramethylorthosilicate (TMOS, 10.64 g) was added and stirred for an additional $24 \mathrm{~h}$. The resulting mixture was further hydrothermally treated for $24 \mathrm{~h}$ at $150^{\circ} \mathrm{C}$ in a high-pressure reactor. Upon cooling to room temperature (RT), the white solid was collected by filtration, washed with copious amounts of methanol and dried in air. To remove the surfactant P104, the silica material was heated to $550^{\circ} \mathrm{C}$ at a ramp rate of $1.5^{\circ} \mathrm{C} \min ^{-1}$ and maintained at $550^{\circ} \mathrm{C}$ for $6 \mathrm{~h}$. The fluorescein

isothiocyanate (FITC) labeling of $\mathrm{Au}^{\text {Capped }}$-MSN-10 was done by adding $5 \mathrm{mg}(12.8 \mu \mathrm{mol})$ of FITC to $13 \mu \mathrm{mol}$ of 3-aminopropyltrimethoxysilane (APTMS) in $0.5 \mathrm{~mL}$ dry DMSO and stirred for $30 \mathrm{~min}$, and then added to a toluene suspension $(100 \mathrm{~mL})$ of MSN-10 $(1.0 \mathrm{~g})$. The suspension was refluxed for $20 \mathrm{~h}$ under nitrogen and the resulting material was filtered, washed with toluene and methanol, and dried under vacuum overnight. 
For $\mathrm{Au}^{\text {Capped }}$-MSN-10, 2 mmol of 3-mercaptopropyltrimethoxysilane (MPTMS) was grafted to MSN-10 $(1.0 \mathrm{~g})$ by refluxing in toluene $(100 \mathrm{~mL})$ for $20 \mathrm{~h}$ under nitrogen. The resulting thiol-functional MSN (thiol-MSN-10) was filtered, washed with toluene and methanol, and dried under vacuum overnight. To activate thiol-MSN-10, $3 \mathrm{mmol}$ of 2,2dipyridyldisulfide was added to a methanol suspension of the thiol-MSN-10 and stirred for $24 \mathrm{~h}$ in the absence of light. The resulting material was filtered, washed with methanol, and dried under vacuum overnight. To synthesize amine-linker-MSN-10 (2(propyldisulfanyl)ethylamine-MSN-10), $3 \mathrm{mmol}$ of 2-aminoethanethiol were added to a methanol suspension of the activated thiol-MSN-10 and stirred for $24 \mathrm{~h}$. The resulting material was filtered and washed with methanol, and dried under vacuum overnight. Carboxylic acid-functionalized gold NPs ( $25 \mathrm{mg}$, AuNP-COOH) were suspended in $3 \mathrm{~mL}$ of PBS solution along with $100 \mathrm{mg}$ of $N$-Ethyl- $N^{\prime}$-(3-dimethylaminopropyl)carbodiimide (EDC) and $80 \mathrm{mg}$ of N-hydroxysuccinimide (NHS) and stirred for $15 \mathrm{~min}$. Amine linker-MSN-10 $(50 \mathrm{mg})$ was added to the mixture and stirred for $24 \mathrm{~h}$. The $\mathrm{Au}^{\text {Capped }}$-MSN were collected by centrifugation, washed three times with water and then, resuspended in $5 \mathrm{~mL}$ of water, frozen in liquid nitrogen and dehydrated in a lyophilizer.

For PAMAM-MSN-10 synthesis, $2 \mathrm{mmol}$ of 3-mercaptopropyltrimethoxysilane (MPTMS) was added to a toluene suspension $(100 \mathrm{~mL})$ of MSN-10 $(1.0 \mathrm{~g})$ and refluxed for $20 \mathrm{~h}$ under nitrogen, then filtered, washed with toluene and methanol, and dried under vacuum overnight. The thiol-MSN-10 was activated by the same method as previously described for the amine-linker-MSN-10, instead of 2-aminoethanethiol, an equilimolar amount of 11-mercaptoundecanoic acid was added to a methanol suspension (acid-linkerMSN-10). Acid-linker-MSN-10 (20 mg) were suspended in $3 \mathrm{~mL}$ of PBS solution and 100 
$\mathrm{mg}$ of EDC and $80 \mathrm{mg}$ of N-hydroxysuccinimide (NHS) were added and stirred for $15 \mathrm{~min}$. PAMAM-G4 dendrimer ( $25 \mathrm{mg}$ ) was added to the mixture, stirred for $24 \mathrm{~h}$. The particles were collected by centrifugation, washed three times with water, resuspended in $5 \mathrm{~mL}$ of water, frozen in liquid nitrogen and dehydrated in a lyophilizer. For the gold $1 x \mathrm{Au}^{\text {Plated }}$ MSN-10, $0.45 \mathrm{~mL}$ of ethylenediamine was added to an aqueous solution of $1.0 \mathrm{~g}$ of $\mathrm{HAuCl}_{4} \cdot 3 \mathrm{H}_{2} \mathrm{O}$ in $10 \mathrm{~mL}$ of water, stirred for 30 minutes and followed by the addition of 70 $\mathrm{mL}$ ethanol. The resulting $\mathrm{Au}(\mathrm{en})_{2} \mathrm{Cl}_{3}$ precipitate was filtered, washed with ethanol, dried under vacuum and after that, $0.372 \mathrm{~g}$ was dissolved in $150 \mathrm{~mL}$ of $\mathrm{H}_{2} \mathrm{O}$ and the $\mathrm{pH}$ adjusted to 10.0 using $\mathrm{NaOH}$. MSN-10 (2 g) was added to the solution, the $\mathrm{pH}$ was readjusted to 9.0 with $\mathrm{NaOH}$ and stirred for $2 \mathrm{~h}$. The product was filtered and dried under vacuum for 2 days and then, reduced under $\mathrm{H}_{2}$ flow at $150^{\circ} \mathrm{C}$ for $3 \mathrm{~h}$. For the ionic liquid layer functionalization of IL-1xAu ${ }^{\text {Plated }}$-MSN-10, 2 mmol of 1-propyltriethoxysilane-3-methylimidazolium chloride (PMIm) was added to a N,N-dimethylformamide (DMF) suspension (100 mL) of Au-MSN$10(1.0 \mathrm{~g})$ and then refluxed for $20 \mathrm{~h}$ under nitrogen. The resulting material was filtered, washed with DMF and methanol, and dried under vacuum overnight. To synthesize $2 \mathrm{x}$ and $3 \times \mathrm{Au}^{\text {Plated }}-\mathrm{MSN}-10,1 \times \mathrm{Au}^{\text {Plated }}$-MSN-10 was subjected to the $\mathrm{Au}(\mathrm{en})_{2}$ impregnation and reduction process an additional one and two more cycles, respectively.

Zeta potential measurements: Each sample $(5 \mathrm{mg})$ was sonicated in $10 \mathrm{~mL}$ PBS for $30 \mathrm{~min}$. The samples were then analyzed on a Malvern Instruments Zetasizer.

MSN surface area and porosity measurement: The surface area and average pore diameter were measured using $\mathrm{N}_{2}$ adsorption/desorption measurements in a Micromeritics ASAP 2020 BET surface analyzer system. The data were evaluated using BET and BJH methods to 
calculate surface area and pore distributions, respectively. Samples were prepared by degassing at $100^{\circ} \mathrm{C}$ overnight before analysis.

Nanorods: gold nanorods $(25 \times 73 \mathrm{~nm}$, catalog number 30-25-700-100) were purchased from Nanopartz.

Plant material: Onion epidermis tissue was obtained from white bulk onion bulbs. The tissue was cut in $2 \times 3.5 \mathrm{~cm}$ rectangles and placed with the peeled face upwards in agar media $(0.5$ mM 2-(N-morpholino)ethanesulfonic acid (MES) pH 5.7, and $15 \mathrm{~g} \mathrm{~L}^{-1}$ of BD Bacto ${ }^{\mathrm{TM}}$ agar, pH 5.7) or MS media ${ }^{[51]}$ (MS salts \& vitamins from PhytoTechnology Laboratories, 20\% sucrose, $2.5 \mathrm{mg} \mathrm{L}^{-1}$ Phytagel $^{\mathrm{TM}}$ from Sigma Aldrich, $\mathrm{pH}$ 5.7). Leaf pieces of 3 to 4 week old maize plants of the inbred A188 germinated in soil were cut in approximately $3 \mathrm{~cm}$ long pieces and placed with the adaxial surface up on MS media. Leaves from 6 to 8 week old in vitro-grown tobacco plants (Nicotiana tabacum var. Petite Havana) were placed with the adaxial surface up on MS media.

DNA-MSN complexation experiments: MSN stocks at $10 \mathrm{mg} \mathrm{mL}^{-1}$ in sterile double distilled water $\left(\mathrm{ddH}_{2} \mathrm{O}\right)$ were sonicated in a water bath sonicator (FS6 from Fisher Scientific) for $15 \mathrm{~s}$. One, 10,30 or $50 \mu \mathrm{g}$ of MSN were incubated with $1 \mu \mathrm{g}$ of plasmid DNA in a final volume of $15 \mu \mathrm{L}$ for $1 \mathrm{~h}$ at RT. The total mixture was loaded in a $1 \%$ agarose gel stained with ethidium bromide and electrophoresed at $100 \mathrm{~V}$ for $25 \mathrm{~min}$. The supernatant of the $\mathrm{CaCl}_{2} / \mathrm{Spe} \mathrm{DNA}$ coating protocol was subjected before loading to dialysis for 30 min using a $\mathrm{MF}^{\mathrm{TM}}$ Membrane filter of $0.025 \mu \mathrm{m}$ (Millipore).

Nanoparticle DNA coating and sample bombardment: The plasmids ER-rk ${ }^{[52]}$ and pLMNC95 ${ }^{[53]}$ for mCherry and GFP expression respectively were obtained from the Arabidopsis Biological Resource Center (ABRC stocks CD3-959 and CD3-420 respectively, 
http://www.arabidopsis.org). The DNA coating and bombardment procedures onto NPs were done according to standard protocols ${ }^{[42-43]}$ with the following modifications (protocols described for one shot). One hundred $\mu \mathrm{g}$ of MSN (from a $10 \mu \mathrm{g} \mu \mathrm{L}^{-1}$ stock in sterile $\mathrm{ddH}_{2} \mathrm{O}$ ) or $150 \mu \mathrm{L}$ of the commercial nanorod suspension (previously washed with sterile $\mathrm{ddH}_{2} \mathrm{O}$ after centrifuging at $2000 \mathrm{~g}$ for $6 \mathrm{~min}$ and resuspended in $10 \mu \mathrm{L}$ of sterile $\mathrm{ddH}_{2} \mathrm{O}$ ) were sonicated for $15-30 \mathrm{~s}$ in a water bath sonicator. One $\mu \mathrm{g}$ of plasmid DNA (from a $250 \mathrm{ng} \mu \mathrm{L}^{-1}$ stock in sterile $\left.\mathrm{ddH}_{2} \mathrm{O}\right), 12.5 \mu \mathrm{L}$ of a $2.5 \mathrm{M}$ of $\mathrm{CaCl}_{2}$ and $5 \mu \mathrm{L}$ of a $0.1 \mathrm{M}$ spermidine solution were added to NPs and mixed for $10 \mathrm{~min}$ at RT. The mix was centrifuged at $5000 \mathrm{rpm}$ (Spectrafuge 16M from Labnet) for $15 \mathrm{~s}$ at RT, the supernatant was removed and $60 \mu \mathrm{L}$ of freezer cold $100 \%$ ethanol was added to wash the pellet. After another centrifugation step and removal of the supernatant, the coated NPs were resuspended in $5 \mu \mathrm{L}$ of cold $100 \%$ ethanol and loaded in the center of a macrocarrier.

The DNA coated NPs were bombarded onto plant tissues as described ${ }^{[43]}$. A Bio-Rad PDS-1000/He biolistic gun and Bio-Rad biolistic supplies were used. Five different rupture disks $(650,900,1100,1350$ or $1550 \mathrm{psi})$ and two different target distances $(6$ or $4 \mathrm{~cm})$ were tested. The typical bombardment parameters used in this study for NPs were $1350 \mathrm{psi}, 4 \mathrm{~cm}$ target distance and 2 shots. The $4 \mathrm{~cm}$ target distance was achieved by placing the sample over a Petri dish with the bottom part upwards on the $6 \mathrm{~cm}$ shelf of the gene gun.

For the Treatment \#4, the pellet obtained after $\mathrm{CaCl}_{2} / \mathrm{Spe}$ coating of NP with mCherry expressing plasmid was washed and pelleted (5000 rpm, 15s) 3 times with $60 \mu \mathrm{L}$ of ethanol to remove any non-coated free DNA. The resulting pellet was mixed with $2 \mu \mathrm{L}$ of $0.6 \mu \mathrm{m}$ gold (30 $\mu \mathrm{g} \mu \mathrm{L}^{-1}$ in sterile $\mathrm{ddH}_{2} \mathrm{O}$, Bio-Rad cat\# 165-2262) and $1 \mu \mathrm{g}$ of a $250 \mathrm{ng} / \mu \mathrm{l}$ stock of GFP expressing plasmid DNA and followed by a second round of DNA coating. For 
preparing of DNA coated NP and GP mix, $c(\mathrm{NP}+\mathrm{GP})$, the NPs were mixed by pippeting with the $2 \mu 1$ of the $0.6 \mu \mathrm{m}$ gold suspension. To this mix of particles, $1 \mu \mathrm{g}$ of a $250 \mathrm{ng} / \mu 1$ stock of DNA plasmid was added and followed the described protocol for DNA coating. Bombardments with those two types of NP-GP mixes were made once at $1100 \mathrm{psi}$ and $6 \mathrm{~cm}$ target distance.

Statistical analysis: The graphs presented in Figures 3 and 4 represent the mean of 2 to 4 repeats \pm standard error. The comparisons between treatments were done by ANOVADuncan Test $(\alpha=0.05)$ using the SAS 9.2 statistical program.

Fluorescence microscopy: Fluorescence and bright field images were taken with a 10xAPlan (numerical aperture, N.A. 0.25) objective of a Zeiss Axiostar plus microscope. For GFP images, an Endow GFP BP filter was used $\left(\lambda_{\mathrm{ex}}=470 \mathrm{~nm}\right.$, beam splitter at $495 \mathrm{~nm}$ and $\left.\lambda_{\mathrm{em}}=525 \mathrm{~nm}\right)$; for mCherry images, a Texas Red filter was used $\left(\lambda_{\mathrm{ex}}=560 \mathrm{~nm}\right.$, beam splitter at $595 \mathrm{~nm}$ and $\lambda_{\mathrm{em}}=645 \mathrm{~nm}$ ), both from Chroma Technology Corp. Images were taken with a ProgRes C3 digital camera and the ProgRes Capture Pro 2.6 software from Jenoptik, and were edited for publication using Adobe Photoshop software from Adobe Systems Inc.

Differential Interference Contrast (DIC) Microscopy: DIC and epi-fluorescence images were taken with an upright Nikon Eclipse 80i microscope. A motorized rotary stage (SGSP60 YAM, Sigma Koki) was coupled to the fine-adjustment knob on the microscope to help image sample areas with different depths. For the DIC mode, the samples were illuminated through an oil immersion condenser (N.A. 1.40) and the optical signals were collected with a 100 $\times$ Plan Apo N.A.1.40 oil immersion objective. One bandpass filter with central wavelength in $700 \mathrm{~nm}$ and a full width at half maximum of $13 \mathrm{~nm}$ was inserted into the light path in the microscope. For the fluorescence images, a filter cube containing one $480 \mathrm{~nm}$ 
bandpass filter, one $500 \mathrm{~nm}$ dichroic mirror and one $530 \mathrm{~nm}$ bandpass filter was used. The

optical filters were obtained from Semrock. An Andor iXon ${ }^{\mathrm{EM}}+$ camera $(512 \times 512$ imaging array, $16 \times 16 \mu \mathrm{m}$ pixel size) and the software ImageJ were used to record and analyze the DIC and fluorescence images.

Transmission Electron Microscopy (TEM), Scanning Electron Microscopy (SEM), and Scanning Transmission Electron Microscopy (STEM) imaging: TEM and STEM investigations were done by placing small aliquot of an aqueous suspension on a lacey carbon film coated 400 mesh copper grid and drying it in air. The TEM images were obtained on a Tecnai $\mathrm{F}^{2}$ microscope. Particle morphology was determined by SEM using a Hitachi S4700 FE-SEM system with $10 \mathrm{kV}$ accelerating voltage.

\section{Acknowledgements}

SMO and KW thank Angela Nguyen for technical support and Xing Xu for statistical analysis support. This work is partially supported by Plant Science Institute of Iowa State University and Pioneer Hi-Bred International, Inc. 
References

[1] N. O'Farrell, A. Houlton, B. R. Horrocks, Int. J. Nanomedicine 2006, 1, 451.

[2] I. I. Slowing, J. L. Vivero-Escoto, B. G. Trewyn, V. S. -Y. Lin, J. Mater. Chem. 2010, 20, 7924.

[3] J. Stone, S. Jackson, D. Wright, Wiley Interdisciplinary Reviews: Nanomedicine and Nanobiotechnology 2011, 3, 100.

[4] O. V. Salata, J. Nanobiotechnol. 2004, 2, 3.

[5] C. M. Rico, S. Majumdar, M. Duarte-Gardea, J. R. Peralta-Videa, J. L. Gardea-Torresdey, J. Agric. Food Chem. 2011, online first.

[6] R. Nair, S. H. Varghese, B. G. Nair, T. Maekawa, Y. Yoshida, D. S. Kumar, Plant Sci. 2010, 179, 154.

[7] X. Ma, J. Geiser-Lee, Y. Deng, A. Kolmakov, Sci. Total Environ. 2010, 408, 3053.

[8] K. N. Thakkar, S. S. Mhatre, R. Y. Parikh, Nanomed. Nanotechnol. Biol. Med. 2010, 6, 257.

[9] V. Grichko, V. Grishko, O. Shenderova, NanoBioTechnol. 2006, 2, 37.

[10] F. Torney, B. G. Trewyn, V. S. -Y. Lin, K. Wang, Nat. Nanotechnol. 2007, 2, 295.

[11] P. González-Melendi, R. Fernández-Pacheco, M. J. Coronado, E. Corredor, P. S. Testillano, M. C. Risueño, C. Marquina, M. R. Ibarra, D. Rubiales, A. Pérez-de-Luque, Ann. Bot. 2008, 101, 187.

[12] E. Corredor, P. Testillano, M.-J. Coronado, P. González-Melendi, R. Fernández-Pacheco, C. Marquina, M. R. Ibarra, J. de la Fuente, D. Rubiales, A. Perez-de- 
Luque, M. C. Risueño, BMC Plant Biol. 2009, 9, 45.

[13] Q. Wang, J. Chen, H. Zhang, M. Lu, D. Qiu, Y. Wen, Q. Kong, J. Nanosci. Nanotechnol. 2011, 11, 2208.

[14] J. Liu, F. -H. Wang, L. -L. Wang, S. -Y. Xiao, C. -Y. Tong, D. -Y. Tang, X. M. Liu, J. Cent. S. Univ. Technol. 2008, 15, 768.

[15] K. Birbaum, R. Brogioli, M. Schellenberg, E. Martinoia, W. J. Stark, D. Günther, L. K. Limbach, Environ. Sci. Technol. 2010, 44, 8718.

[16] T. Eichert, A. Kurtz, U. Steiner, H. E. Goldbach, Physiol. Plant. 2008, 134, 151.

[17] M. F. Serag, N. Kaji, C. Gaillard, Y. Okamoto, K. Terasaka, M. Jabasini, M. Tokeshi, H. Mizukami, A. Bianco, Y. Baba, ACS Nano 2010, 5, 493.

[18] Q. Liu, B. Chen, Q. Wang, X. Shi, Z. Xiao, J. Lin, X. Fang, Nano Lett. 2009, 9, 1007.

[19] G. Yu, J. Liang, Z. He, M. Sun, Chem. Biol. 2006, 13, 723.

[20] M. Lucas, B. A. Macdonald, G. L. Wagner, S. A. Joyce, K. D. Rector, ACS Appl. Mater. Interfaces 2010, 2, 2198.

[21] S. Ravindran, S. Kim, R. Martin, E. M. Lord, C. S. Ozkan, Nanotechnol. 2005, 16,1 .

[22] E. Etxeberria, P. Gonzalez, E. Baroja-Fernandez, J. P. Romero, Plant Signal Behav. 2006, 1, 196.

[23] K. Pasupathy, S. Lin, Q. Hu, H. Luo, P. C. Ke, Biotechnol. J. 2008, 3, 1078.

[24] E. Onelli, C. Prescianotto-Baschong, M. Caccianiga, A. Moscatelli, J. Exp. Bot. 2008, 59, 3051. 
[25] E. Wild, K. C. Jones, Environ. Sci. Technol. 2009, 43, 5290.

[26] S. Lin, J. Reppert, Q. Hu, J. S. Hudson, M. L. Reid, T. A. Ratnikova, A. M. Rao, H. Luo, P. C. Ke, Small 2009, 5, 1128.

[27] Q. Wang, B. Chen, P. Liu, M. Zheng, Y. Wang, S. Cui, D. Sun, X. Fang, C. M. Liu, W. J. Lucas, J. Lin, J. Biol. Chem. 2009, 284, 12000.

[28] A. Silva, A. Nguyen, C. Ye, J. Verchot, J. Moon, BMC Plant Biol. 2010, 10, 291.

[29] Z. Cifuentes, L. Custardoy, J. de la Fuente, C. Marquina, M. R. Ibarra, D. Rubiales, A. Perez-de-Luque, J. Nanobiotechnol. 2010, 8, 26.

[30] M. V. Khodakovskaya, K. de Silva, D. A. Nedosekin, E. Dervishi, A. S. Biris, E. V. Shashkov, E. I. Galanzha, V. P. Zharov, Proc. Natl. Acad. Sci. U. S. A. 2011, 108, 1028.

[31] A. G. Perez-Donoso, Q. Sun, M. C. Roper, L. C. Greve, B. Kirkpatrick, J. M. Labavitch, Plant Physiol. 2010, 152, 1748.

[32] R. Chen, T. A. Ratnikova, M. B. Stone, S. Lin, M. Lard, G. Huang, J. S. Hudson, P. C. Ke, Small 2010, 6, 612.

[33] H. Zhu, J. Han, J. Q. Xiao, Y. Jin, J. Environ. Monit. 2008, 10, 713.

[34] H. Warzecha, A. Hennig, in Genetic modification of plants, Vol. 64, Springer Berlin Heidelberg 2010, 23-37.

[35] T. M. Klein, in Plant transformation technologies, Wiley-Blackwell 2011, 5372.

[36] H. A. Clark, M. Hoyer, S. Parus, M. A. Philbert, R. Kopelman, Microchim. Acta 1999, 131, 121. 
[37] P. W. Lee, S. F. Peng, C. J. Su, F. L. Mi, H. L. Chen, M. C. Wei, H. J. Lin, H. W. Sung, Biomater. 2008, 29, 742.

[38] S. A. Svarovsky, M. J. Gonzalez-Moa, M. D. Robida, A. Y. Borovkov, K. Sykes, Mol. Pharm. 2009, 6, 1927.

[39] M. Zhang, W. Tao, P. A. Pianetta, Phys. Med. Biol. 2007, 52, 1485.

[40] T.-W. Kim, I. I. Slowing, P.-W. Chung, V. S.-Y. Lin, ACS Nano 2010, 5, 360.

[41] D. R. Radu, C. Y. Lai, K. Jeftinija, E. W. Rowe, S. Jeftinija, V. S. Y. Lin, J. Am. Chem. Soc. 2004, 126, 13216.

[42] T. M. Klein, E. D. Wolf, R. Wu, J. C. Sanford, Nature 1987, 327, 70.

[43] J. C. Sanford, F. D. Smith, J. A. Russell, Methods Enzymol. 1993, 217, 483.

[44] B. Frame, H. Zhang, S. Cocciolone, L. Sidorenko, C. Dietrich, S. Pegg, S. Zhen, P. Schnable, K. Wang, In Vitro Cell. Dev. Biol. Plant 2000, 36, 21.

[45] S. R. Wilson Methods for genetic plant transformation using water-soluble fullerene derivatives. 20110059529, 03/10/2011.

[46] T. M. Klein, M. Fromm, A. Weissinger, D. Tomes, S. Schaaf, M. Sletten, J. C. Sanford, Proc. Natl. Acad. Sci. U. S. A. 1988, 85, 4305.

[47] B. G. Trewyn, I. I. Slowing, S. Giri, H.-T. Chen, V. S. -Y. Lin, Acc. Chem. Res. 2007, 40, 846.

[48] G. Wang, W. Sun, Y. Luo, N. Fang, J. Am. Chem. Soc. 2010, 132, 16417.

[49] A. S. Stender, G. Wang, W. Sun, N. Fang, ACS Nano 2010, 4, 7667.

[50] S. Svarovsky, A. Borovkov, K. Sykes, BioTechniques 2008, 45, 535.

[51] T. Murashige, F. Skoog, Physiol. Plant. 1962, 15, 473.

[52] B. K. Nelson, X. Cai, A. Nebenführ, Plant J. 2007, 51, 1126. 
[53] S. Luke Mankin, W. F. Thompson, Plant Mol. Biol. Reporter 2001, 19, 13. 


\title{
CHAPTER 5. GOLD FUNCTIONALIZED MESOPOROUS SILICA NANOPARTICLE MEDIATED PROTEIN AND DNA CODELIVERY TO PLANT CELLS VIA BIOLISTIC METHOD
}

\author{
Modified from a paper submitted to Advanced Functional Materials \\ Susana Martin-Ortigosa", Justin S. Valenstein ", Victor S.-Y. Lin, Brian G. Trewyn*, Kan \\ Wang* \\ (In memory of Professor Victor S.-Y. Lin, deceased May 4, 2010) \\ \# These authors contribute equally to the manuscript
}

\begin{abstract}
We report the synthesis and characterization of a gold nanoparticle functionalized mesoporous silica nanoparticle (Au-MSN) platform for codelivery of proteins and plasmid DNA to plant tissues using a biolistic particle delivery system. The in vitro uptake and release profiles of fluorescently labeled bovine serum albumin (BSA) and enhanced green fluorescent protein (eGFP) are investigated. As a proof-of-concept demonstration, Au-MSN with large average pore diameters $(10 \mathrm{~nm})$ are shown to deliver and subsequently release proteins and plasmid DNA to the same cell after passing through the plant cell wall upon bombardment. Release of fluorescent eGFP indicates the delivery of active, non-denatured proteins to plant cells. This advancement represents the first example of biolistic-mediated codelivery of proteins and plasmid DNA to plant cells via gold-functionalized MSN and provides a powerful tool for both fundamental and applied research of plant sciences.
\end{abstract}




\section{Introduction}

Recent advancements in the synthesis of monodispersed, large average pore diameter mesoporous silica nanoparticle (MSN) materials with highly functionalizable surface area $\left(\geq 400 \mathrm{~m}^{2} \mathrm{~g}^{-1}\right)$ and pore volume $\left(1.05 \mathrm{~cm}^{3} \mathrm{~g}^{-1}\right)$ has led to the development of a series of biomolecule delivery vehicles, where various proteins, small DNA and RNA sequences, and other biomolecules are loaded into the mesopores and on the external surface, and released in vitro or in cellular systems. ${ }^{[1-4]}$ The large pore volumes and surface area of these materials allow for the efficient adsorption of biomolecules and subsequent delivery to viable animal and plant cells. Additionally, recent reports on functionalizing the surface of MSN demonstrate that this material can be tuned to optimize various applications. Organic and inorganic functionalization leads to control in MSN uptake by cells, ${ }^{[5]}$ magnetization of MSN, ${ }^{[6]}$ the DNA/RNA affinity for MSN, ${ }^{[7]}$ and increasing the inherent density of MSN. ${ }^{[3]}$ These examples illustrate the potential that MSN materials have on biomolecule entrapment and release applications.

Delivery of biomolecules mediated by MSN materials is particularly interesting because proteins are often unable to cross the membrane barrier of cells without the assistance of protein transport systems. ${ }^{[5]}$ Several proteins have been successfully loaded and released from MSN materials, ${ }^{[9-13]}$ however; only one example demonstrated the in vivo release of active protein from MSN in a mammalian cell system and no protein delivery to plant cells has been reported. ${ }^{[14]}$

There are few methods for protein delivery to plant cells; however, none of them nanoparticle mediated, including microinjection ${ }^{[15,16]}$ and cell-penetrating peptides. ${ }^{[17-19]}$ While these methodologies have been used to introduce model proteins into plant cells, they 
require the skillful handling of cell materials and lack the protection needed for the introduced protein during the process. Recently, using $1 \mu \mathrm{m}$ gold microparticles, $\mathrm{Wu}$ et al. delivered a DNA-enzyme complex into plant cells through the biolistic method. The codelivery of the complex led to enhanced plant transformation efficiency but required covalent modification of the protein so it would remain attached to the gold microparticle during bombardment. ${ }^{[20]}$

Delivery of proteins or codelivery of proteins and DNA to plant cells has great biological significance. In addition to the potential of enhancing genetic transformation and gene targeting in plants, ${ }^{[20]}$ researchers can assess the loss or gain of function of different posttranslationally modified forms of a protein, and protein interactions with other biomolecules. Also, direct delivery and release of proteins in plant cells could facilitate the understanding of cellular machinery or signal pathways more effectively. This would lead to greater understanding of protein functions in host cells where protein production pathways are impaired; or analyzing cellular regulatory functions through delivery of antibodies. ${ }^{[20-23]}$

To date, nanoparticle-mediated delivery of biogenic molecules to plant cells has been limited to nucleic acids, including double or single stranded $\mathrm{DNA}^{[3,24-28]}$ and small interfering RNA. ${ }^{[29]}$ Delivery and release of chemical substances such as phenanthrene and plant growth regulators have also been reported. ${ }^{[30,31]}$ Using the interior pore volume and the exterior surface of MSN along with particle bombardment technology, we previously demonstrated that plasmid DNA carrying a chemically inducible marker gene encoding for green fluorescent protein (GFP) and a chemical inducer ( $\beta$-oestradiol) could be co-delivered to plant tissues. ${ }^{[3]}$ The controlled release of $\beta$-oestradiol led to the expression of GFP in plant cells. ${ }^{[3]}$ Additionally, in our recently published work, we demonstrated that MSN delivery to 
plants through the biolistic method is improved by increasing the density of MSN by gold functionalization; leading to an enhanced cell penetration and subsequent DNA expression. [26]

In this work, we report the modified synthesis and characterization of a previously published gold functionalized, large pore diameter MSN (Au-MSN). ${ }^{[32]}$ The in vitro uptake and release profiles of fluorescently labeled bovine serum albumin (BSA) and enhanced green fluorescent protein (eGFP) by Au-MSN are reported. Protein loaded Au-MSNs were coated with plasmid DNA following our DNA precipitation method. ${ }^{[26]}$ The codelivery of plasmid DNA and proteins into plant cells using the biolistic method are achieved. The expression of the marker genes and the release of fluorescent proteins can be detected in the same plant cells one day after the bombardment. We demonstrated, for the first time, successful protein delivery and DNA/protein codelivery to plant cells mediated by Au-MSN as depicted in Figure 1. 


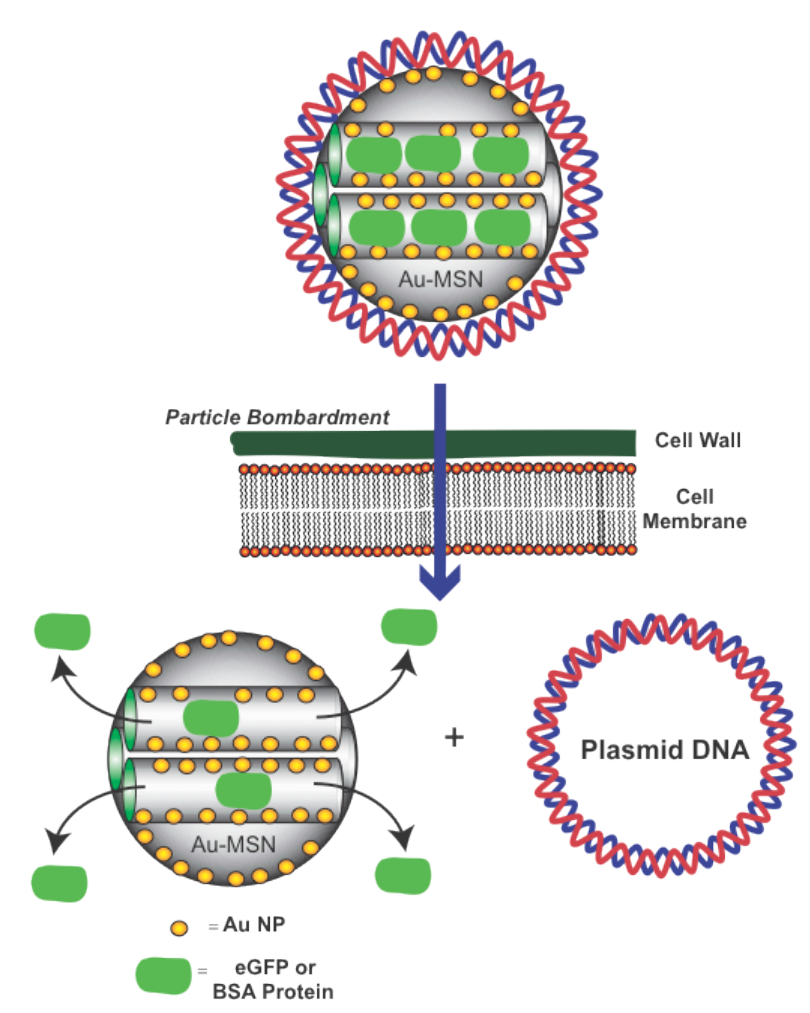

Figure 1. Schematic representation of Au-MSN mediated codelivery of proteins and plasmid DNA to plant cells via particle bombardment.

\section{Results and discussion}

\subsection{MSN material synthesis and characterization}

The synthesis of Au-MSN material was modified from a previous publication by Dai and coworkers $^{[32]}$ and completed according to the protocol described in our previous work. ${ }^{[26]}$ Nitrogen sorption analyses, electron microscopy measurements, and powder X-ray diffraction (XRD) spectroscopy were utilized to fully characterize the Au-MSN materials that were synthesized by repeated gold reduction on the surface of the MSN. The repeated surface gold reduction was necessary to increase the nanoparticle density for successful delivery to plant cells by bombardment. ${ }^{[26]}$ The Au-MSN exhibited a type IV isotherm with a 
BET surface area of $313 \mathrm{~m}^{2} \mathrm{~g}^{-1}$ and a pore volume of $0.89 \mathrm{~cm}^{3} \mathrm{~g}^{-1}$ and the BJH pore size distribution measurement showed a negligible decrease in pore diameter after three cycles of gold reduction (Figure S1). As is observed in the transmission electron micrograph (TEM) (Figure 2a and Figure S2), the pore channels can be seen as parallel stripes running the length of the MSN, confirming the XRD pattern of a well ordered material.

The scanning transmission electron micrograph (STEM) (Figure 2b and Figure S3a) shows the presence of gold nanoparticles on the surface of Au-MSN after the repeated deposition and reduction of gold salt. Scanning electron micrograph (SEM) shows that the structure, shape and size of Au-MSNs are around $600 \mathrm{~nm}$ in diameter and have consistent particle size and morphology (Figure 2c). Energy dispersive X-ray analysis confirms that presence of gold on the surface of the MSN (Figure S3b). The X-ray diffraction pattern of the Au-MSN material indicates a well-ordered pore structure characteristic of two-dimensional (2-D) hexagonal MSN (Figure 2d). High angle XRD patterns of MSN and Au-MSN confirm the presence of crystalline gold on the MSN (Figure S4). 

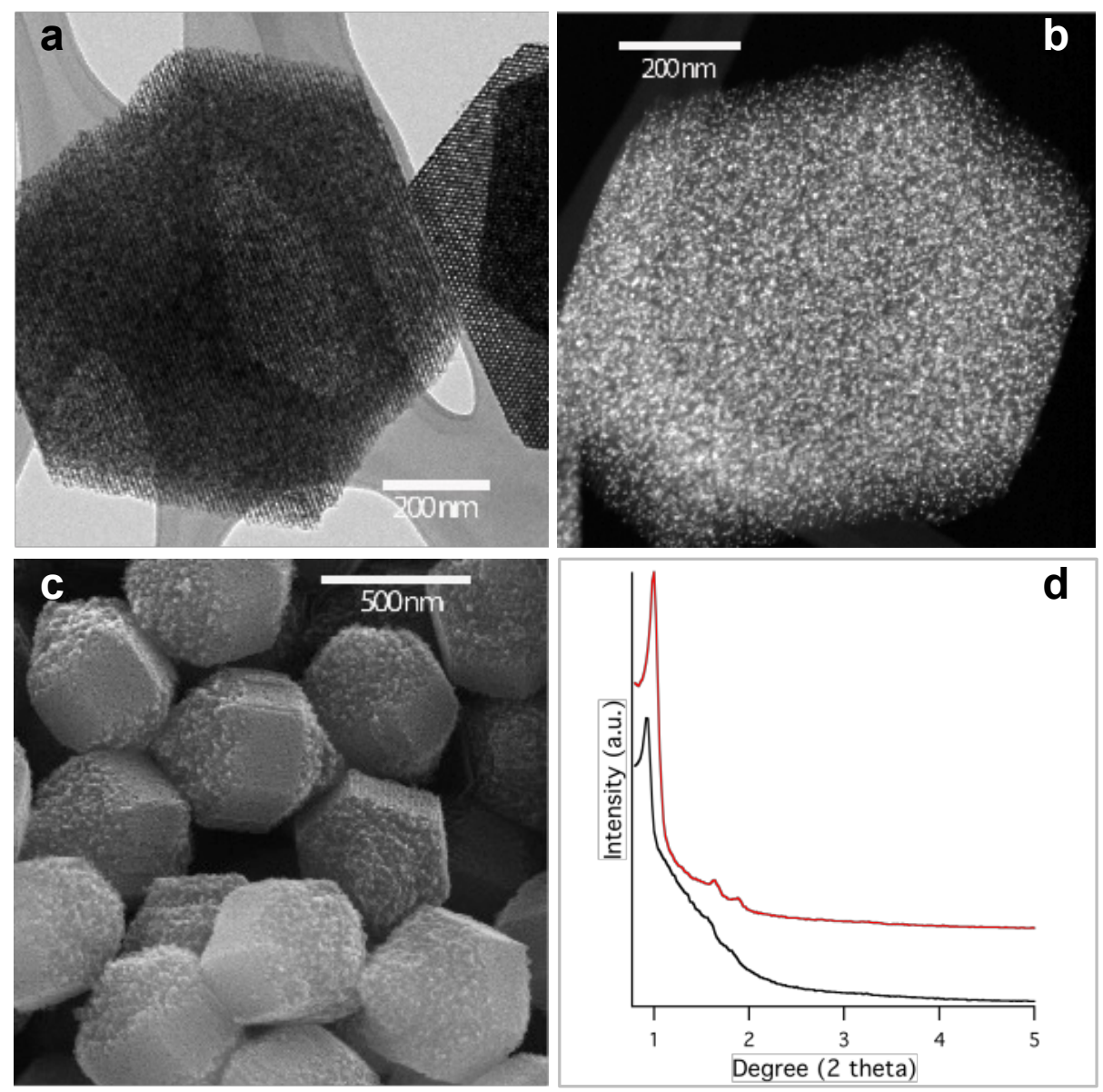

Figure 2. Transmission electron micrograph (a), scanning transmission electron micrograph (b) and scanning electron micrograph (c) images of Au-MSN. X-ray diffraction patterns of MSN (red) and Au-MSN (black) (d). TEM and STEM images were obtained on a Tecnai $\mathrm{F}^{2}$ microscope, and SEM on a Hitachi S4700 FE-SEM system with $10 \mathrm{kV}$ accelerating voltage.

\subsection{Au-MSN protein loading and in vitro release}

As a proof-of-concept, two different proteins were chosen for Au-MSN loading (Table 1): BSA, fluorescein isothiocyanate (FITC-BSA) labeled or tetramethylrhodamine isothiocyanate (TRITC-BSA) labeled and eGFP. The size of these proteins (hydrodynamic radius of 4.5 and $2.3 \mathrm{~nm}$ for BSA and eGFP, respectively) ${ }^{[33,34]}$ was smaller than the $10 \mathrm{~nm}$ 
diameter pore size of the Au-MSN (Table 1). Therefore, high protein loading into the pores was expected. ${ }^{[35]}$ As is described in detail in the experimental section, the amount of each protein that was entrapped in the mesopores was determined by measuring the difference in protein concentration in the supernatant before and after the loading procedure. Our measurements indicated that the maximum protein loading, at the conditions studied, was 625 and $150 \mathrm{mg}$ of protein per $1.0 \mathrm{~g}$ of Au-MSN for FITC-BSA and eGFP, respectively (Table 1).

Table 1. Protein and protein loaded Au-MSN characteristics.

\begin{tabular}{cccccc}
\hline Protein & $\begin{array}{c}\text { Size } \\
{[\mathrm{kDa}]}\end{array}$ & $\begin{array}{c}R_{h} \\
{[\mathrm{~nm}][\mathrm{a}]}\end{array}$ & pl & $\begin{array}{c}\text { Protein/ } \\
\text { Au-MSN } \\
{[\mathrm{mg} / \mathrm{g}]}\end{array}$ & $\begin{array}{c}\text { \% protein } \\
\text { released }\end{array}$ \\
\hline BSA & 66.8 & 4.5 & 4.7 & 625 & 28 \\
GFP & 28 & 2.3 & 6.2 & 150 & 8 \\
\hline [a] $R_{h}$, hydrodynamic radius. ${ }^{[33,34]}$ & &
\end{tabular}

After the proteins were loaded in the Au-MSN, a time course of in vitro release of the loaded proteins was performed at room temperature during which the structure and activity of the proteins were maintained as is evident by continued fluorescence of the released eGFP. ${ }^{[36]}$ The fluorescently-labeled BSAs showed a continuous release pattern during the first 20 hours, while the eGFP achieved maximum release after 10 hours (Figure 3).

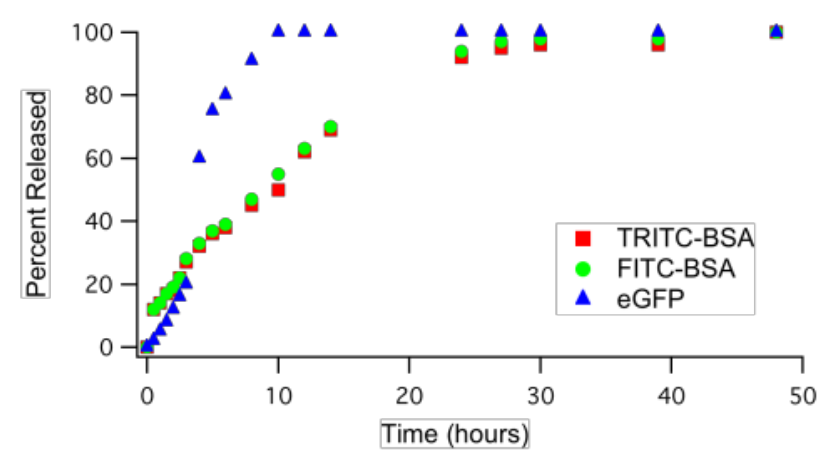

Figure 3. Normalized release profiles of FITC-BSA (green), TRITC-BSA (red), and eGFP (blue) from Au-MSN in pH 7.4 PBS solution. 
The difference in release kinetics could be attributed to the variation in the amount of protein loaded in the Au-MSN, the difference in protein-pore wall interaction, and the difference in the sizes of eGFP and BSA (Table 1). After $48 \mathrm{~h}$ incubating at room temperature $\left(22^{\circ} \mathrm{C}\right)$ in static conditions in phosphate buffered saline (PBS) solution (pH 7.4), the total percent of protein released was $28 \%$ and $8 \%$ for BSA and eGFP, respectively. Improving and controlling the percentage of protein release are research activities currently in progress. Subsequent suspension of the protein loaded Au-MSN pellets for further protein release did not yield more fluorescence in the supernatant, suggesting that no more detectable free proteins were released from the MSN (data not shown).

\subsection{Au-MSN mediated protein delivery to plant cells}

To introduce protein-encapsulated Au-MSN to plant cells, we used the biolistic delivery method as previously reported. ${ }^{[3,26]}$ Release of FITC-BSA was observed in bombarded onion epidermis cells as early as 30 minutes after bombardment (Figure 4a). Nevertheless, protein release was typically observed 1 day after bombardment as in the case of eGFP (Figure 4b). In general, fluorescently-labeled BSA release was more distinguishable and more frequent than eGFP detection. A typical bombardment for fluorescently-labeled BSA release showed hundreds of fluorescent onion epidermis cells, while eGFP release occurred in less than 10 cells per bombarded sample $(2 \times 3.5 \mathrm{~cm}$ in size $)$. This difference could be due to the smaller amount of protein encapsulated into Au-MSN, the lower release percentage (Table 1) and the overall lower fluorescence emission of eGFP comparing to FITC-BSA. ${ }^{[37]}$ Although limited eGFP release could be observed in a small number of cells one day after the bombardment, longer periods of time (up to 6 days) were needed to obtain more fluorescent cells, likely due to continued release of eGFP from Au-MSN in plant cells over time. 


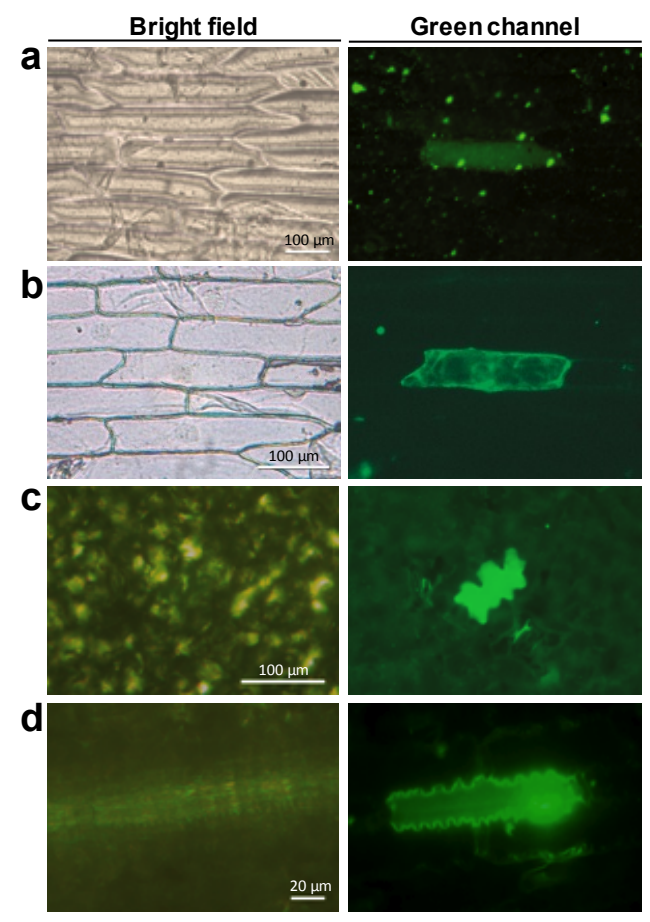

Figure 4. Delivery of proteins into plant tissues. Bright field and green channel images of (a) onion epidermis cells showing FITC-BSA release 30 minutes after bombardment. (b) Intracellular release of eGFP in onion epidermis cells one day after bombardment. Tobacco (c) or teosinte (d) leaf cell showing FITC-BSA release one day after bombardment.

To prove this system is applicable in other plant tissues, leaves of tobacco and teosinte plants were bombarded as described for onion epidermis tissue. In both cases (Figure 4c and 4d, respectively) cells showing FITC-BSA release were found in the plant tissues one day after bombardment. In the plant tissues tested, the fluorescence was observed throughout the cell, not localized in cell compartments, indicating that the fluorescent proteins were released into and diffused throughout the cell cytoplasm (Figure 4a-d).

To confirm that the observed cellular fluorescence is due to MSN introduction and not to isolated protein aggregates formed during MSN-loading, we covalently labeled Au-MSN with FITC prior to TRITC-BSA protein encapsulation. Onion epidermis cells bombarded with this material showed red fluorescent cells (due to TRITC-BSA release) and green 
fluorescent dots (FITC-labeled Au-MSN), confirming that the TRITC-BSA release is associated with the presence of Au-MSN inside the same plant cell (Figure 5).
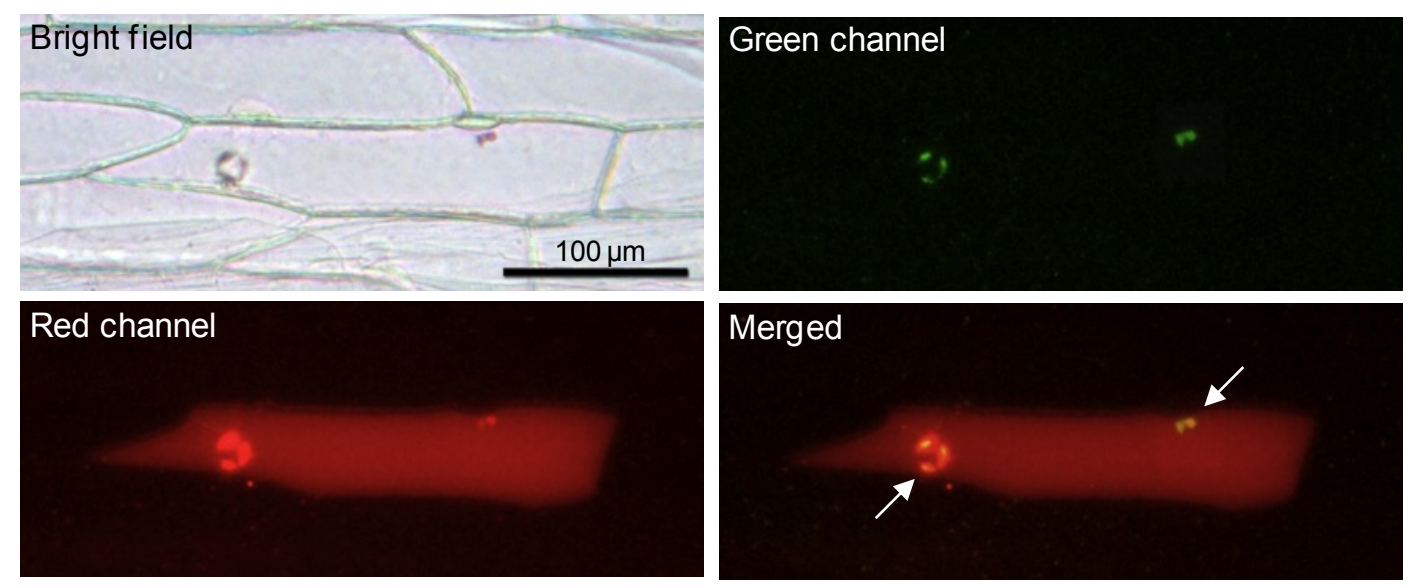

Figure 5. Association of Au-MSN and protein release in plant cells. Bright field, red channel, green channel and merged images of an onion cell 1 day after bombardment with TRITC-BSA loaded, FITC labeled Au-MSN. White arrows point at Au-MSN clusters.

Simultaneous delivery of plasmid DNA and protein in onion epidermis cells is shown in Figure 6. For DNA coating and delivery of protein-encapsulated Au-MSN, we used a recently optimized biolistic procedure for Au-MSN. ${ }^{[26]}$ The plasmids used were ER-rk ${ }^{[38]}$ (red fluorescent protein mCherry gene expression) when FITC-BSA or eGFP loaded AuMSN were used, and pLMNC95 ${ }^{[39]}$ (GFP gene expression) for TRITC-BSA loaded AuMSN. The co-localization of both red and green fluorescent emissions is expected when the codelivery and release of both protein and plasmid DNA is successful. 


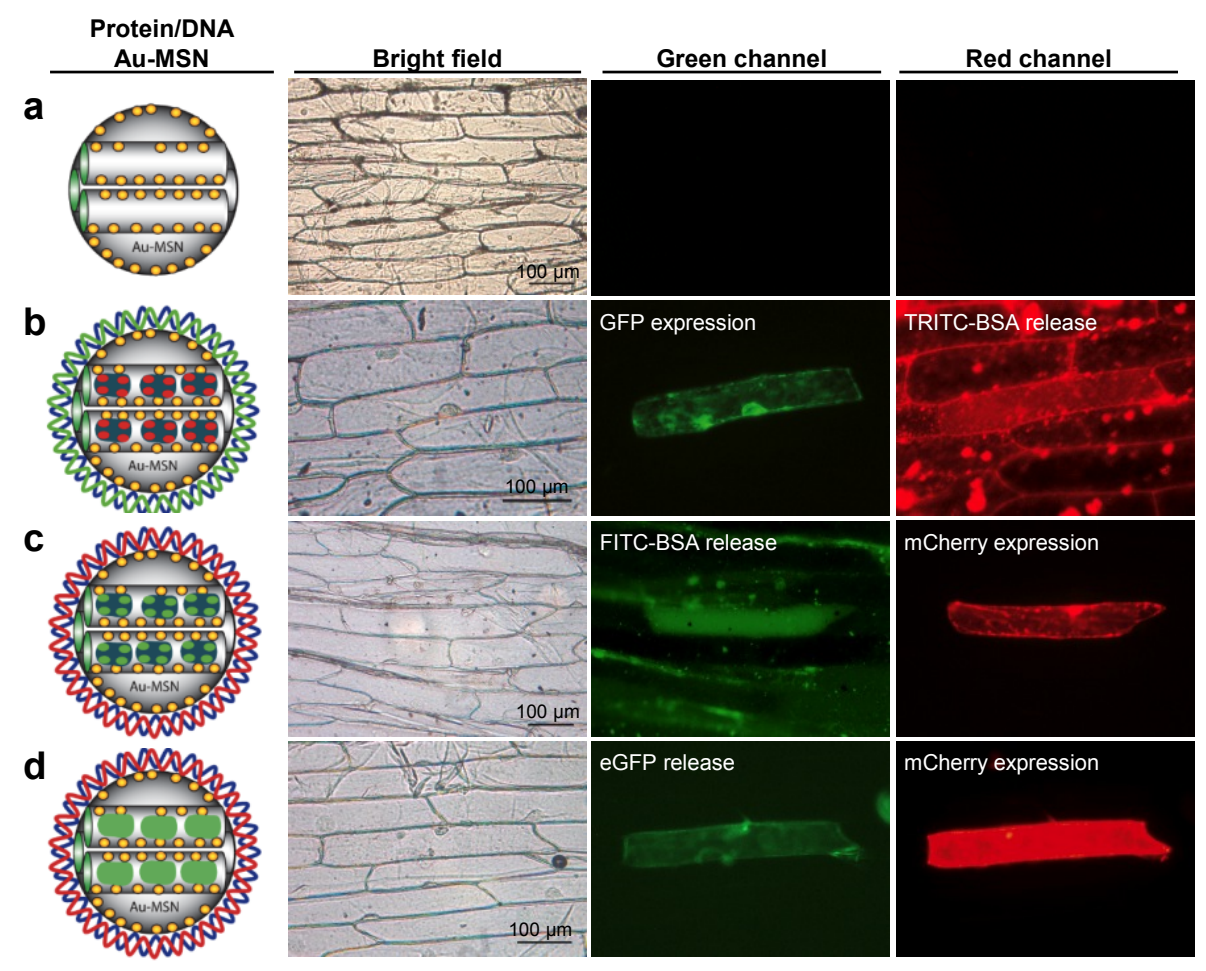

Figure 6. Bright field, green channel, and red channel fluorescent microscopy images of onion epidermis cells bombarded with empty Au-MSN (a), TRITC-BSA protein loaded and plasmid DNA coated Au-MSN (b), FITC-BSA protein loaded and mCherry expressing plasmid DNA coated loaded Au-MSN (c), and eGFP protein loaded and mCherry expressing plasmid DNA coated Au-MSN (d).

The control experiment (Figure 6a) bombarded with empty, non-DNA coated Au-MSN showed no fluorescence on both green and red channels, as expected. Onion tissue bombarded with Au-MSN loaded with TRITC-BSA and coated with the GFP expression plasmid DNA pLMNC95 showed cells simultaneously fluorescent in red (protein release) and in green (DNA expression) (Figure 6b). Cells bombarded with Au-MSN that was loaded with FITC-BSA and coated with mCherry plasmid DNA showed green fluorescence due to the protein release and red fluorescence due to the DNA expression (Figure 6c). Finally, when eGFP-loaded and mCherry plasmid DNA coated Au-MSN was bombarded into onion tissue, co-localization of both green fluorescent (eGFP release) and red fluorescent (mCherry 
gene expression) could be detected (Figure 6d), indicating the consistency of the system for the codelivery of both biomolecules. The presence of green fluorescence diffused throughout the entire cell in Figure 6d indicates that the eGFP delivered and released in plant cells remain in the proper configuration. If eGFP denatured or unfolded, then the protein would no longer be fluorescent. ${ }^{[36]}$

\section{Conclusions}

We have shown that $10 \mathrm{~nm}$ pore-sized, gold functionalized MSN can be used to load proteins with a hydrodynamic diameter as large as $4.5 \mathrm{~nm}$ and release them under physiological conditions. The protein-loaded Au-MSN can be subsequently coated with plasmid DNA and introduced into plant tissues through particle bombardment. The delivery and release of two types of biomolecules, protein and plasmid DNA, can be detected in the same plant cells. Further improvements are currently under way to improve protein encapsulation and release efficiencies of MSN materials as well as frequencies for the biolistic delivery in plant tissues. We anticipate that this novel DNA/protein delivery system will lead to advancements in plant cell and plant genomic manipulation applications and research.

\section{Experimental}

Preparation of MSN-10: To synthesize MSN with 10-nm pore size (MSN-10), $7.0 \mathrm{~g}$ of P104 surfactant was dissolved in $273.0 \mathrm{~g}$ of $1.6 \mathrm{M} \mathrm{HCl}$ and stirred $\left(1 \mathrm{~h}\right.$ at $\left.55^{\circ} \mathrm{C}\right)$, followed by rapid addition of $10.64 \mathrm{~g}$ of tetramethyl orthosilicate (TMOS). The solution was stirred for 24 $\mathrm{h}$, transferred to a high-pressure vessel and placed in an oven at $150{ }^{\circ} \mathrm{C}$ for $24 \mathrm{~h}$. The product 
was filtered and washed with water and methanol. The surfactant was removed by heating the material to $550{ }^{\circ} \mathrm{C}$ for $6 \mathrm{~h}$.

Preparation of $\mathrm{Au}-\mathrm{MSN}$ : To synthesize $\mathrm{Au}(\mathrm{en})_{2} \mathrm{Cl}_{3}$ for gold modification, $0.45 \mathrm{~mL}$ of ethylenediamine was added to an aqueous solution of $1.0 \mathrm{~g}$ of $\mathrm{HAuCl}_{4} \cdot 3 \mathrm{H}_{2} \mathrm{O}$ in $10 \mathrm{~mL}$ of water and stirred for $30 \mathrm{~min}$. Ethanol $(70 \mathrm{~mL})$ was added and the $\mathrm{Au}(\mathrm{en}){ }_{2} \mathrm{Cl}_{3}$ precipitate was filtered, washed with ethanol and dried under vacuum. Three cycles of gold functionalization were performed, and for each cycle, $0.372 \mathrm{~g} \mathrm{Au}(\mathrm{en})_{2} \mathrm{Cl}_{3}$ was dissolved in $150 \mathrm{~mL}$ of water and the $\mathrm{pH}$ adjusted to 10.0 using $\mathrm{NaOH}$. After adding $2.0 \mathrm{~g}$ of $\mathrm{MSN}-10$, $\mathrm{pH}$ was readjusted to 9.0 with $\mathrm{NaOH}$ and stirred for $2 \mathrm{~h}$. The final product (Au-MSN) was filtered and dried under vacuum for 2 days and then, reduced under $\mathrm{H}_{2}$ flow $\left(150^{\circ} \mathrm{C}, 3 \mathrm{~h}\right)$.

Fluorescent Labeling of Au-MSN: For FITC labeling, $5 \mathrm{mg}(12.8 \mu \mathrm{mol})$ of FITC were added to $13 \mu \mathrm{mol}$ of 3-aminopropyltrimethoxysilane (APTMS) in $0.5 \mathrm{~mL}$ dry DMSO, stirred for 30 min and then grafted on to Au-MSN (1.0 g) in toluene. The suspension was refluxed for $20 \mathrm{~h}$ under nitrogen and the resulting material was filtered, washed with toluene and methanol, and dried under vacuum overnight.

MSN Surface Area and Porosity Measurement: The surface area and average pore diameter measurements were recorded using nitrogen sorption analysis in a Micromeritics ASAP 2020 BET surface analyzer system. The Brunauer-Emmitt-Teller (BET) and the Barrett-JoynerHalenda $(\mathrm{BJH})$ equations were used to calculate apparent surface area and pore size distributions, respectively, of MSN samples. Degas of MSN samples were done at $100^{\circ} \mathrm{C}$ overnight before analysis.

Transmission Electron Microscopy (TEM), Scanning Electron Microscopy (SEM), and Scanning Transmission Electron Microscopy (STEM) imaging: TEM and STEM 
investigations were done by placing small aliquot of an aqueous suspension on a lacey carbon film coated 400 mesh copper grid and drying it in air. The TEM images were obtained on a Tecnai $\mathrm{F}^{2}$ microscope. Particle morphology was determined by SEM using a Hitachi S4700 FE-SEM system with $10 \mathrm{kV}$ accelerating voltage.

Protein Loading and in vitro Release: For protein loading, 20 mg of Au-MSN was sonicated in $5 \mathrm{~mL}$ of phosphate buffered saline (PBS) solution ( $\mathrm{pH}$ 7.4) followed by the addition of $15.7 \mathrm{mg}$ of FITC-BSA or TRITC-BSA (Sigma-Aldrich). For eGFP (BioVision) encapsulation, $2 \mathrm{mg}$ of Au-MSN and $0.6 \mathrm{mg}$ of the protein were used. The protein-Au-MSN mixture was stirred at room temperature $\left(22^{\circ} \mathrm{C}\right)$ for $24 \mathrm{~h}$ and then centrifuged. The supernatant was removed and the remaining MSNs were resuspended briefly in PBS solution $(\mathrm{pH}$ 7.4) and lyophilized. To determine protein loading, the fluorescence emission of the FITC-BSA or eGFP in the supernatant was measured using a spectrophotometer. Our measurement indicated that the loaded protein was 0.625 and $0.15 \mathrm{mg}$ of protein per $\mathrm{mg}$ of Au-MSN for FITC-BSA and eGFP, respectively (Table 1). To measure protein release from the Au-MSN, protein-loaded Au-MSN was stirred in $2 \mathrm{~mL}$ of PBS $(\mathrm{pH}$ 7.4) solution for a period of time. An aliquot was removed and centrifuged to separate the released protein in the supernatant from the MSNs in the pellet, and the fluorescence intensity was measured using at a spectrophotometer (FITC-BSA or eGFP: $\lambda_{\mathrm{Ex}}=488, \lambda_{\mathrm{Em}}=518 \mathrm{~nm}$; TRITC-BSA: $\left.\lambda_{\mathrm{Ex}}=557, \lambda_{\mathrm{Em}}=576 \mathrm{~nm}\right)$.

Plant Materials: White onion epidermis tissue rectangles $(2 \times 3.5 \mathrm{~cm})$ were placed in dishes containing agar media (0.5 mM 2-( $N$-morpholino)ethanesulfonic acid (MES), and $15 \mathrm{~g} \mathrm{~L}^{-1}$ of $\mathrm{BD}^{\mathrm{Bacto}}{ }^{\mathrm{TM}}$ agar, $\mathrm{pH}$ 5.7), facing the peeled surface upwards. For tobacco and teosinte leaf bombardment, leaves from 6 to 8 week old in vitro-grown tobacco plants (Nicotiana tabacum 
var. Petite Havana) and leaf pieces of 2-month old teosinte plants (Ames 21785, USDA/ARS/North Central Regional Plant Introduction Station, Iowa State University) were placed with the adaxial surface up on agar media.

Biolistic Method: For the delivery of protein filled Au-MSN, freshly prepared Au-MSN suspensions $\left(5 \mu 1,20 \mu \mathrm{g} \mu \mathrm{l}^{-1}\right)$ in ethanol were loaded onto a macrocarrier. Using a PDS1000/He biolistic gene gun (BioRad Laboratories), plant samples were bombarded twice at 1350 psi rupture disks and $6 \mathrm{~cm}$ target distance. For the delivery of plasmid DNA coated, protein filled Au-MSN, $4 \mu \mathrm{l}$ of DNA $\left(250 \mathrm{ng} \mu \mathrm{l}^{-1}\right)$ was added to $10 \mu \mathrm{l}$ of protein filled AuMSN (10 $\mu \mathrm{g} \mu \mathrm{l}^{-1}$ stock, freshly prepared in $\left.\mathrm{ddH}_{2} \mathrm{O}\right)$ to make a final ratio of $1 \mu \mathrm{g}$ DNA to 100 $\mu \mathrm{g}$ Au-MSN per shot. DNA precipitation onto Au-MSN was achieved by adding $12.5 \mu \mathrm{L}$ of 2.5 $\mathrm{M} \mathrm{CaCl}_{2}$ (1 $\mathrm{M}$ final concentration) and $5 \mu \mathrm{L}$ of $0.1 \mathrm{M}$ spermidine $(16 \mathrm{mM}$ final concentration) to the DNA/Au-MSN mixture. After mixing the contents, the mixture was briefly centrifuged for 15 seconds (5000 rpm, room temperature). The supernatant was discarded, the pellet was washed with $60 \mu \mathrm{L}$ of cold $100 \%$ ethanol and centrifuged again. After removal of the supernatant, DNA-coated protein-loaded Au-MSNs were resuspended in $5 \mu \mathrm{L}$ of cold $100 \%$ ethanol and loaded in a macrocarrier. Each plant sample was bombarded twice at $1350 \mathrm{psi}$ and $6 \mathrm{~cm}$ target distance.

Fluorescence Microscopy Imaging: Bright field and fluorescence images were taken with 10xA-Plan and or 40xA-Plan objectives of a Zeiss Axiostar plus microscope with a green channel (Endow GFP BP: $\lambda_{\mathrm{ex}}=470 \mathrm{~nm}$, beam splitter $=495 \mathrm{~nm}$ and $\lambda_{\mathrm{em}}=525 \mathrm{~nm}$ ) and a red channel (Texas Red: $\lambda_{\mathrm{ex}}=560 \mathrm{~nm}$, beam splitter $=595 \mathrm{~nm}$ and $\left.\lambda_{\mathrm{em}}=645 \mathrm{~nm}\right)$ filters $($ Chroma Technology Corp.) were used. Microscopy images were taken using ProgRes Capture Pro 2.6 
software and a ProgRes C3 digital camera, both from Jenoptik. If necessary, images were edited using Adobe Photoshop software (Adobe Systems Inc).

\section{Acknowledgements}

We dedicate this manuscript to Professor Victor S.-Y. Lin, for his inspiration and friendship. SMO and KW thank Angela Nguyen for technical support. Mark Millard (NCRPIS/USDA/ARS), Patrick Schnable and Lisa M. Coffey (Iowa State University) for providing teosinte seeds. This work is partially supported by Plant Sciences Institute of Iowa State University and Pioneer Hi-Bred International, Inc. 
_[1] Kim, M.-H.; Na, H.-K.; Kim, Y.-K.; Ryoo, S.-R.; Cho, H. S.; Lee, K. E.; Jeon, H.; Ryoo, R.; Min, D.-H, ACS Nano 2011, 5, 3568.

_[2] Li, X.; Xie, Q. R.; Zhang, J.; Xia, W.; Gu, H, Biomaterials 2011, 32, 9546.

_[3] Torney, F.; Trewyn, B. G.; Lin, V. S.-Y.; Wang, K., Nat. Nanotechnol. 2007, 2, 295.

_[4] Xia, T.; Kovochich, M.; Liong, M.; Meng, H.; Kabehie, S.; George, S.; Zink, J. I.; Nel, A. E., ACS Nano 2009, 3, 3273.

[5] Jung, S.; Huh, S.; Cheon, Y.-P.; Park, S., Chem. Commun. 2009, 5003.

_[6] Slowing, I.; Trewyn, B. G.; Lin, V. S.-Y., J. Am. Chem. Soc. 2006, 128, 14792.

_[7] Giri, S.; Trewyn, B. G.; Stellmaker, M. P.; Lin, V. S.-Y., Angew. Chem., Int. Ed. 2005, 44, 5038 .

_[8] Solberg, S. M.; Landry, C. C., J. Phys. Chem. B 2006, 110, 15261.

_[9] Bhattacharyya, M. S.; Hiwale, P.; Piras, M.; Medda, L.; Steri, D.; Piludu, M.; Salis, A.; Monduzzi, M., J. Phys. Chem. C 2010, 114, 19928.

_[10] Ho, J.; Danquah, M. K.; Wang, H.; Forde, G. M., J. Chem. Technol. Biotechnol. 2008, $83,351$.

_[11] Kim, S.-I.; Pham, T. T.; Lee, J.-W.; Roh, S.-H., J. Nanosci. Nanotechnol. 2010, 10, 3467.

_[12] Song, S. W.; Zhong, S. P.; Hidajat, K.; Kawi, S., Stud. Surf. Sci. Catal. 2007, 165, 471.

_[13] Vivero-Escoto, J. L.; Slowing, I. I.; Trewyn, B. G.; Lin, V. S.-Y., Small 2010, 6, 1952.

_[14] Slowing, I. I.; Trewyn, B. G.; Lin, V. S.-Y., J. Am. Chem. Soc. 2007, 129, 8845. 
_[15] Staiger, C. J.; Yuan, M.; Valenta, R.; Shaw, P. J.; Warn, R. M.; Lloyd, C. W., Curr. Biol. 1994, 4, 215.

_[16] Wymer, C. L.; Fernandez-Abalos, J. M.; Doonan, J. H., Planta 2001, 212, 692.

_[17] Chang, M.; Chou, J.-C.; Chen, C.-P.; Liu, B. R.; Lee, H.-J., New Phytologist 2007, $174,46$.

_[18] Chugh, A.; Eudes, F., FEBS J. 2008, 275, 2403.

_[19] Lu, S.-W.; Hu, J.-W.; Liu, B. R.; Lee, C.-Y.; Li, J.-F.; Chou, J.-C.; Lee, H.-J., J. Agric. Food Chem. 2010, 58, 2288.

_[20] Wu, J.; Du, H.; Liao, X.; Zhao, Y.; Li, L.; Yang, L., Plant. Mol. Biol. 2011, 77, 117.

_[21] Lim, Y. T.; Cho, M. Y.; Lee, J. M.; Chung, S. J.; Chung, B. H., Biomaterials 2009, 30, 1197.

_[22] Shah, D. A.; Kwon, S.-J.; Bale, S. S.; Banerjee, A.; Dordick, J. S.; Kane, R. S., Biomaterials 2011, 32, 3210 .

_[23] Trewyn, B. G.; Slowing, I. I.; Giri, S.; Chen, H.-T.; Lin, V. S.-Y., Acc. Chem. Res. $\mathbf{2 0 0 7}, 40,846$.

_[24] Liu, J.; Wang, F. H.; Wang, L. L.; Xiao, S. Y.; Tong, C. Y.; Tang, D. Y.; Liu, X. M., J. Cent. S. Univ. Technol. 2008, 9, 1007.

_[25] Liu, Q.; Chen, B.; Wang, Q.; Shi, X.; Xiao, Z.; Lin, J.; Fang, X., Nano Lett. 2009, 9, 1007.

_[26] Martin-Ortigosa, S. V., J.; Sun, W.; Moeller, L.; Fang, N.; Trewyn, B. G.; Lin, V. S.Y.; Wang, K., Small 2011, 3, 413.

_[27] Pasupathy, K.; Lin, S.; Hu, Q.; Luo, H.; Ke, P. C., Biotechnol. J. 2008, 3, 1078. 
_[28] Wang, Q.; Chen, J.; Zhang, H.; Lu, M.; Qiu, D.; Wen, Y.; Kong, Q., J. Nanosci. Nanotechnol. 2011, 11, 2208.

_[29] Silva, A. T.; Nguyen, A.; Ye, C.; Verchot-Lubicz, J.; Moon, J. H. J., BMC Plant Biol. 2010, 10, 291.

_[30] Grichko, V.; Grishko, V.; Shenderova, O., NanoBioTechnology 2006, 2, 37.

_[31] Wild, E.; Jones, K. C., Environ. Sci. Technol. 2009, 43, 5290.

_[32] Zhu, H.; Liang, C.; Yan, W.; Overbury, S. H.; Dai, S., J. Phys. Chem. B 2006, 110, 10842.

[33] Böhme, U.; Scheler, U., Chem. Phys. Lett. 2007, 435, 342.

_[34] Hink, M. A.; Griep, R. A.; Borst, J. W.; Van Hoek, A.; Eppink, M. H. M.; Schots, A.; Visser, A. J. W. G., J. Biol. Chem. 2000, 275, 17556.

_[35] Katiyar, A.; Ji, L.; Smirniotis, P. G.; Pinto, N. G., Microporous Mesoporous Mater. 2005, $80,311$.

[36] Ward, W. W.; Bokman, S. H., Biochemistry 1982, 21, 4535.

_[37] Bale, S. S.; Kwon, S. J.; Shah, D. A.; Banerjee, A.; Dordick, J. S.; Kane, R. S., ACS Nano 2010, 4, 1493.

_[38] Nelson, B. K.; Cai, X.; Nebenführ, A., Plant J. 2007, 51, 1126.

_[39] Mankin, S. L.; Thompson, W. F., Plant Mol. Biol. Reporter 2001, 19, 13. 


\section{Supporting Information}

a

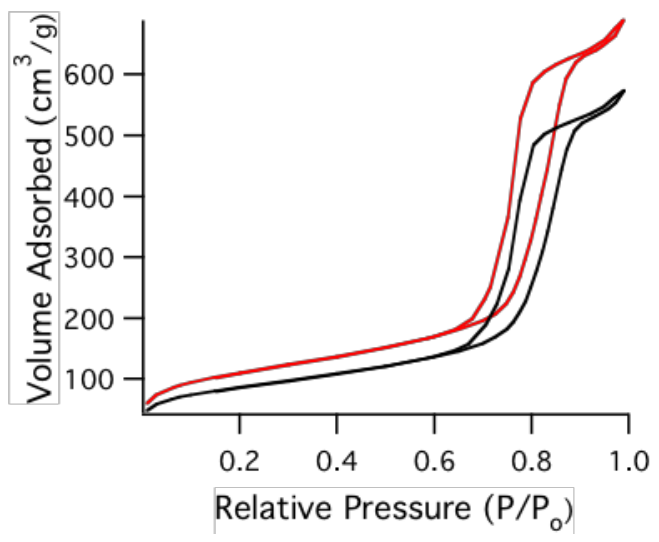

b

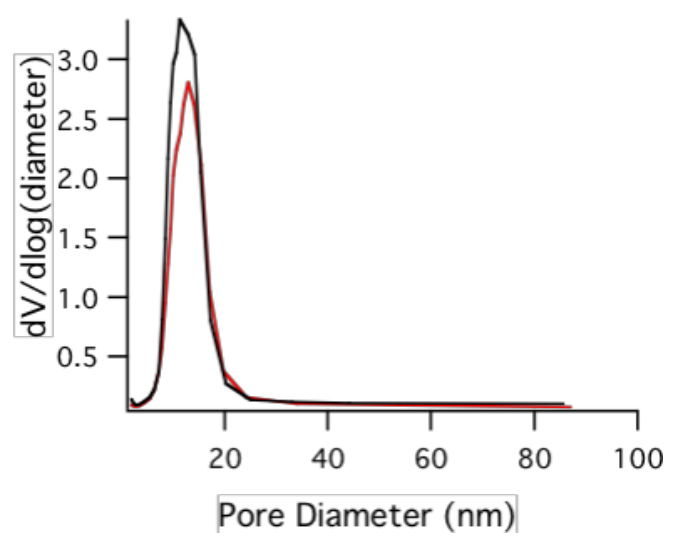

Figure S1. BET nitrogen sorption isotherms (a) and BJH pore size distribution (b) of MSN (red) and Au-MSN (black).

a

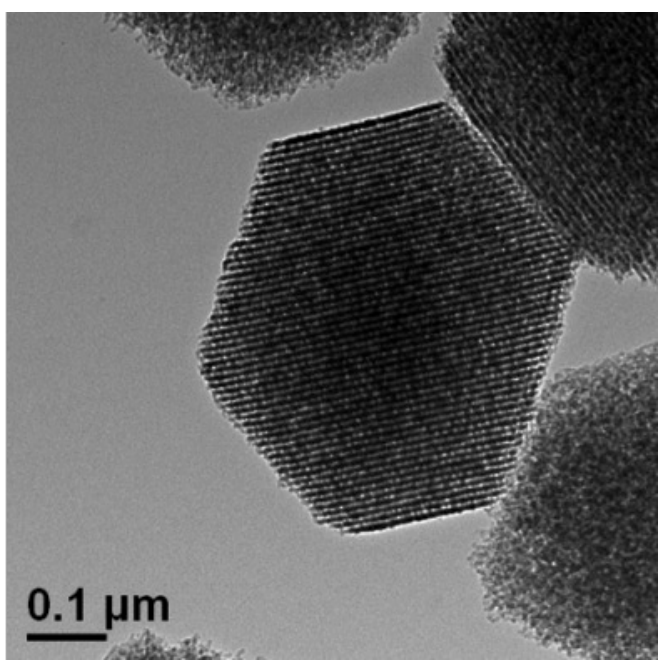

b

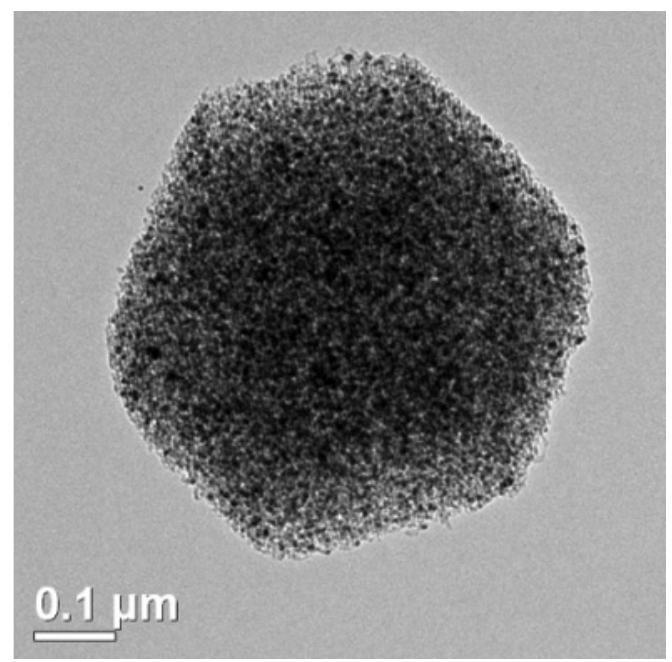

Figure S2. Transmission electron micrographs for direct comparisons of MSN (a) and Au-MSN (b). 

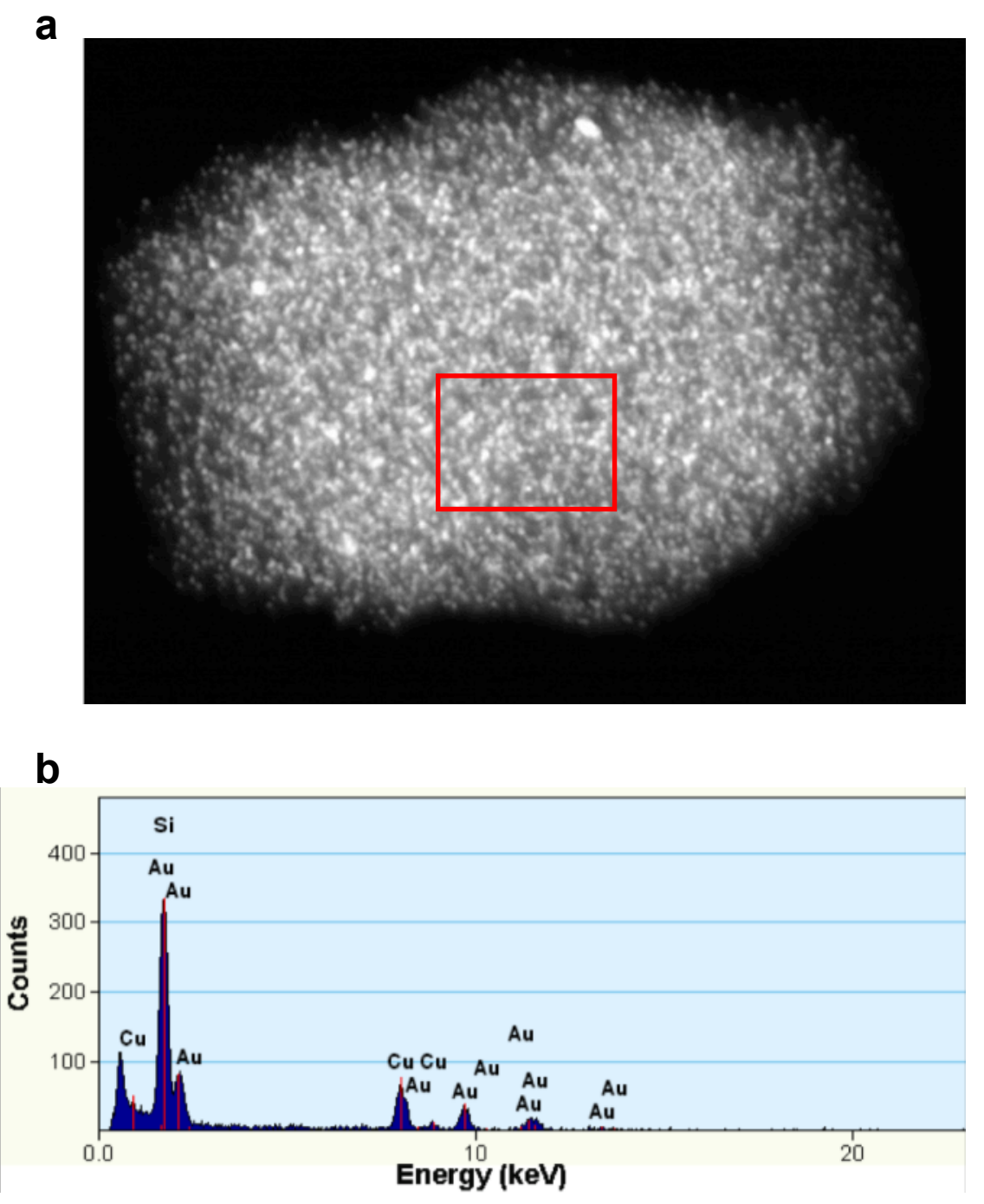

Figure S3. Scanning transmission electron microscopy image (a) and energy dispersive X-ray (EDX) spectrum (b) of Au-MSN. Red box in (a) is the area that was scanned for EDX analysis. The source of the copper detected by the EDX is the TEM grid. 


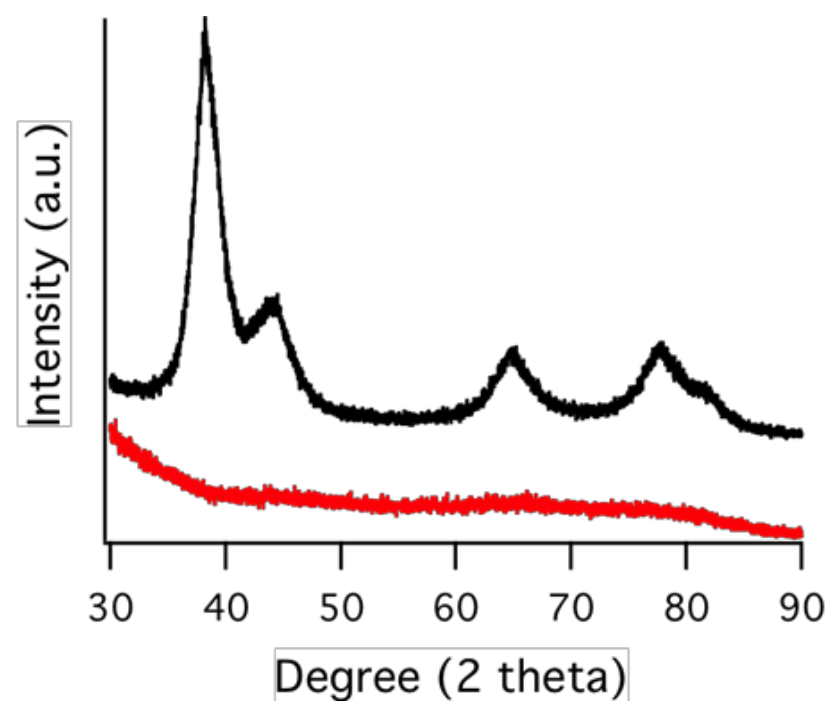

Figure S4. High angle X-ray diffraction pattern for MSN (red) and Au-MSN (black). 


\section{CHAPTER 6. GENERAL CONCLUSIONS}

The research progress presented in this dissertation is a summary of work completed since joining the group at the end of 2007. As previous works have demonstrated, mesoporous silica nanoparticles are a robust material. The silica framework provides a platform that can be tailored for specific applications ranging from molecular delivery, catalysis, sensors, separation and purification. Examples of separation and purification and molecular delivery are described within.

As described in Chapter 2, a series of mesoporous silica nanoparticles with varying functionality were synthesized using the post-synthetic grafting method and a range of organoalkoxysilanes. The resulting materials were then screened for their efficiency of adsorbing free fatty acids. Materials functionalized with a primary amine were found to sequester the highest amount of free fatty acids from a hexane solution. The same material was also shown to selectively sequester the free fatty acid molecules from a simulated microalgal oil solution also containing sterols, terpenes, and triacyl glycerides. Also, a microalgal oil was obtained to verify the adsorption performance of the mesoporous silica nanoparticles and demonstrating a industrial application.

In Chapter 3, the pore size the mesoporous silica nanoparticles was varied from three to ten nanometers and functionalized using the co-condensation method. The particles were mixed with a simulated solution containing free fatty acids with various degrees of unsaturation. The mesoporous silica nanoparticles with an average pore size of three 
nanometers and functionalized with a primary amine showed the best selectivity towards polyunsaturated free fatty acids. The purification of the polyunsaturated free fatty acids is desirable due to their value as a neutraceutical. The separation ability of the previously mentioned material was also shown using microalgal oil, demonstrating a real world application of this technology.

The works of Chapter 4 was focused on omptimizing the delivery of genomic material into plant cell using the biolistic method. The use of gold plating on mesoporous silica nanoparticles can help increase the density of the particles so they are suitable as biolistic delivery vessel. The addition of gold particles was found to decrease the porosity of the silica materials, but still allowed the use of the pores to load a cargo. Also, it was shown that the established $\mathrm{CaCl}_{2} /$ Spermidine DNA coating protocol typically used for gold/tungsten particles is suitable for use with mesoporous silica nanoparticles. This coating method has also been shown to improve the delivery efficiency of DNA compared to the DNAnanoparticle incubation technique.

In Chapter 5, gold-coated mesoporous silica nanoparticles were shown to be able to load proteins with a hydrodynamic radius of approximately five nanometers and release them under physiological conditions. The protein-loaded nanoparticles could then be coated with plasmid DNA and introduced into plant cells using the biolistic method. The delivery and release of both DNA and protein can be detected in the same cell, indicating the co-delivery of the both biomolecules. This novel delivery method can lead to many advancements in genomic transformations for plant cell research. 